Portland State University

PDXScholar

Fall 12-9-2014

\title{
From the Whiteboard to the Web: Equipping Administrators to Recruit, Hire, and Induct Top Quality K-12 Online Teachers
}

Daniel Keith Huld

Portland State University

Follow this and additional works at: https://pdxscholar.library.pdx.edu/open_access_etds

Part of the Educational Leadership Commons, and the Online and Distance Education Commons Let us know how access to this document benefits you.

Recommended Citation

Huld, Daniel Keith, "From the Whiteboard to the Web: Equipping Administrators to Recruit, Hire, and Induct Top Quality K-12 Online Teachers" (2014). Dissertations and Theses. Paper 2106.

https://doi.org/10.15760/etd.2104

This Dissertation is brought to you for free and open access. It has been accepted for inclusion in Dissertations and Theses by an authorized administrator of PDXScholar. Please contact us if we can make this document more accessible: pdxscholar@pdx.edu. 
From the Whiteboard to the Web: Equipping Administrators to Recruit, Hire, and Induct Top Quality K-12 Online Teachers

\section{by}

Daniel Keith Huld

A dissertation submitted in partial fulfillment of the requirements for the degree of

\section{Doctor of Education}

in

Educational Leadership: Administration

Dissertation Committee:

Thomas Chenoweth, Chair

Amy Petti

Pat Burk

Margaret Everett

Laurie Kash

Portland State University

2014 
(C) 2014 Daniel Keith Huld 


\begin{abstract}
Online learning is taking our nation by storm and changing the face of education forever. By 2014 we are projected to have 10 million students taking at least one online class (Nagel, 2009). The online revolution is one of the greatest changes the field of education has seen in the last 25 years (Greenway \& Vanourek, 2006). This major shift in education also represents a major shift in how our teachers are prepared and what great teaching looks like in online settings.
\end{abstract}

The online classroom is distinctly different than the brick-and-mortar classroom, and success in the classroom does not necessarily translate into the online environment (Watson, Murin, Vashaw, Gemin, \& Rapp, 2011). Our students deserve the best online teachers to ensure the potential of online learning is fulfilled (Cavanaugh, Gillan, Kromrey, Hess, \& Blomeyer, 2004). Top quality online teachers are those who have mastered or can demonstrate the ability to quickly learn the specific skills of technology, online instructional design and delivery, communication, and online learning professional development.

This study explored and analyzed the impact of the website $K-12$ Online Staffing Solutions on the recruitment, hiring, and induction practices for K-12 online administrators. Using the R\&D research model, developed by Borg and Gall (1989), the website went through a series of qualitative feedback and product revision cycles with participants. The results of the study showed that the website tool was easy to use and impacted the practice of virtual school administrators in Oregon. The results have implications beyond virtual charter schools in Oregon. Online learning is growing and 
administrators need practical, accessible, and research based tools to successfully meet the need for online K-12 options. 


\section{Dedication}

This study is dedicated to those who ensured this journey was possible. First and foremost, my family who have stood by my side and given me the space, time, and support to complete this journey. I want to give special thanks to my lovely wife for all her sacrifices as we endured this journey together. To my parents who have always been my biggest fans, I will always be indebted. The Educational Administration cohort at Portland State University has been a tireless support and sounding board for my work. I am also thankful for my colleagues in virtual charter school leadership; an amazing group of talented leaders who helped shape my study and give it life. Finally, I want to give my professor, Tom Chenoweth, special gratitude for his helpful advice and high standards. Without him pushing me to excel and supporting me along the way, I would have not have learned so much or been able to make this contribution to a field that is so important to me. 


\section{Acknowledgments}

I want to thank my partners in my work as a virtual charter school administrator in Oregon. Virtual charter school leaders in Oregon are pioneers in a new field; their collaboration, ideas, and teamwork have provided a network of amazing options for students in our state. Without their collaboration on this project I would not have had an environment to test my ideas and research. I also want to thank the staff at my Virtual charter school for their continuous positive attitude, flexibility, and dedication to our school. Their feedback has been invaluable in my journey to provide leadership in a changing environment. 
Table of Contents

Abstract

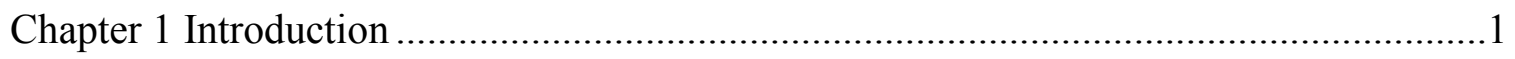

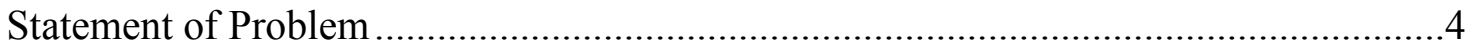

Purpose and Significance of Study ......................................................................... 7

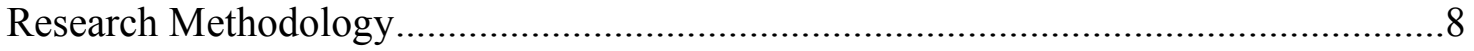

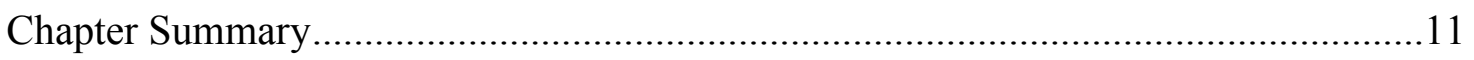

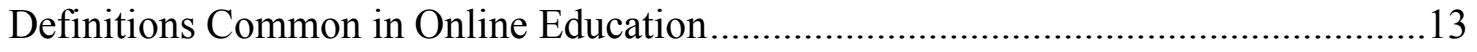

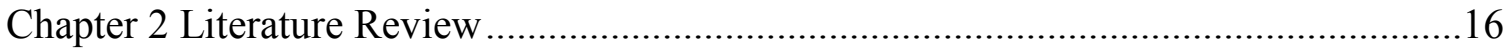

Brief Survey of the K-12 Online Learning Literature .............................................16

Factors That Impact Student Achievement in K-12 Online Schools.........................21

The Importance of Quality Teaching in K-12 Online Schools..................................29

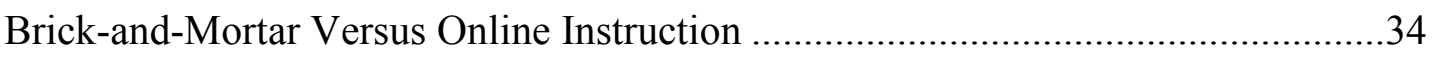

Characteristics of Top Quality K-12 Online Teachers ..............................................36

iNACOL National Quality Standards for K-12 Online Teaching ........................36

Boise State University Survey of Current K-12 Online Teacher..........................43

NEA Guide to Online Courses............................................................................49

Synthesized List of Desired Qualities in New K-12 Online Teachers...................54

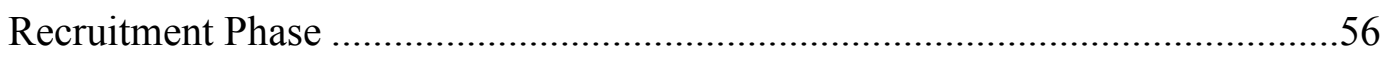

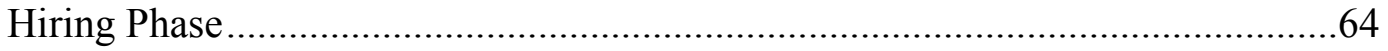

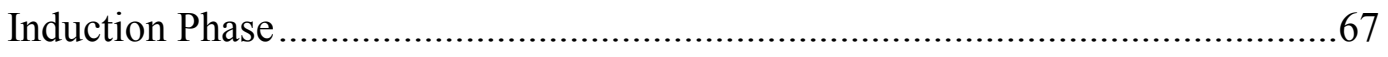

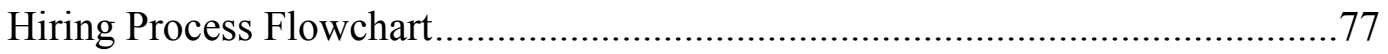

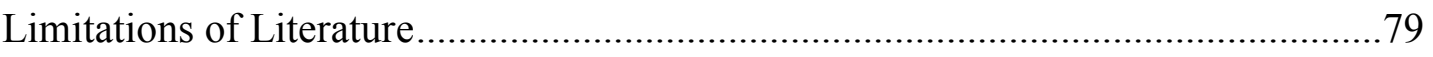

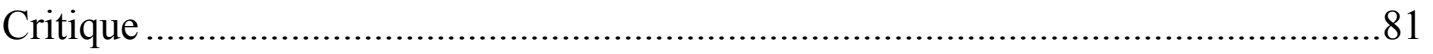

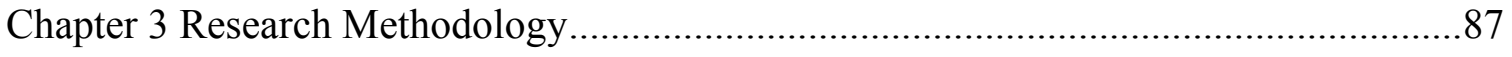

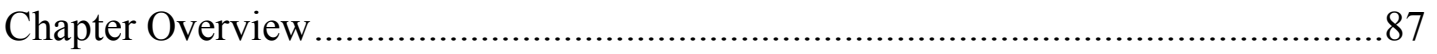

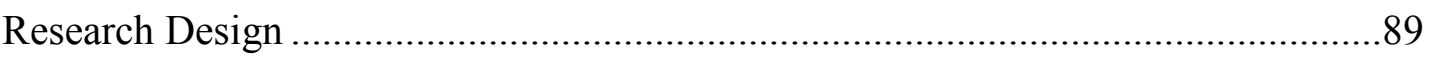

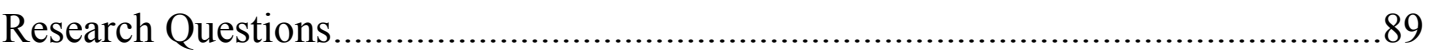




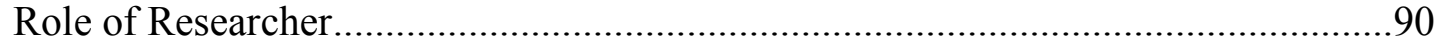

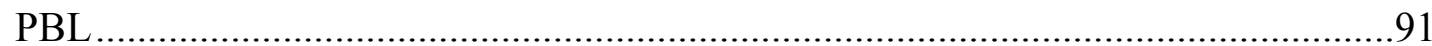

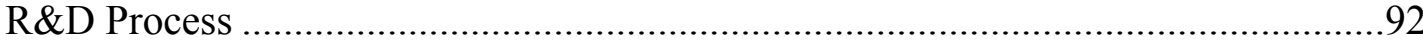

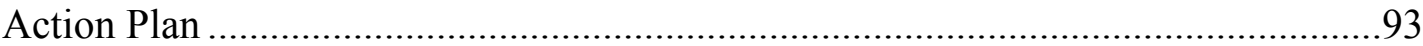

Step 1: Research and Information Gathering..................................................96

Step 2: Planning and Small-Scale Testing .....................................................98

Target Audience and Sample Size .......................................................................99

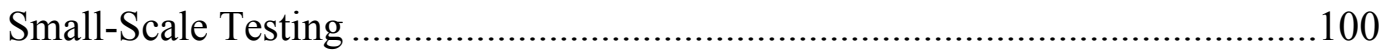

Step 3: Develop Preliminary Form of the Product.............................................101

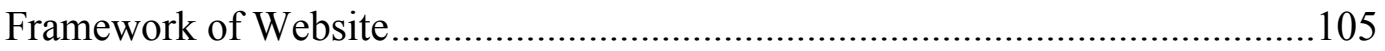

Step 4: Preliminary Field Testing .................................................................... 113

Steps 5 and 6: Main Product Revision and Testing ...........................................116

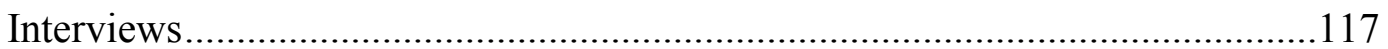

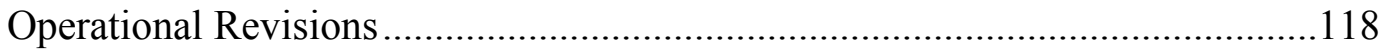

Steps 8-10: Operational Testing and Dissemination..........................................119

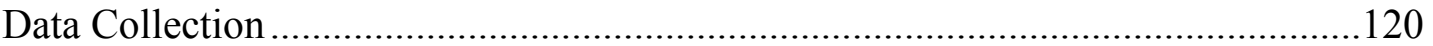

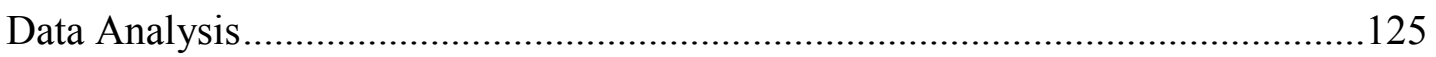

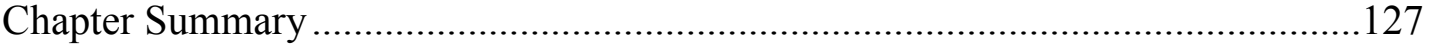

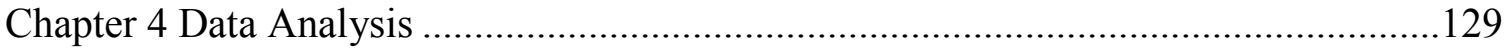

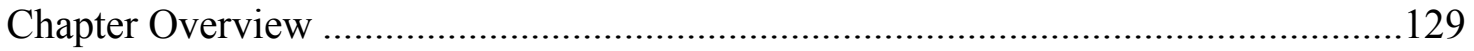

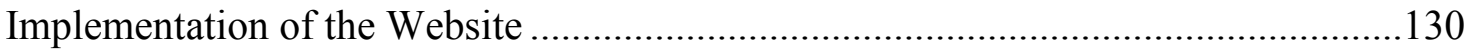

Preliminary Field Testing Results................................................................131

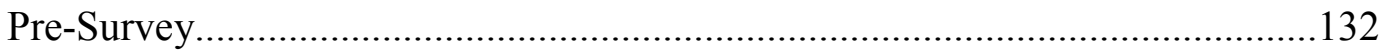

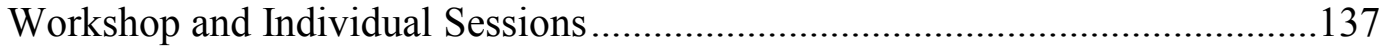

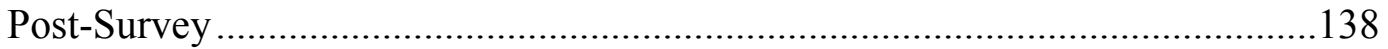

Main Product Revisions ...............................................................................141

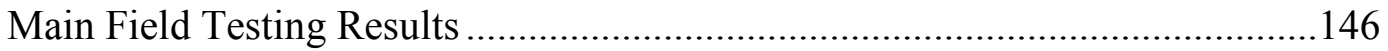

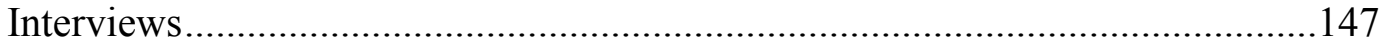

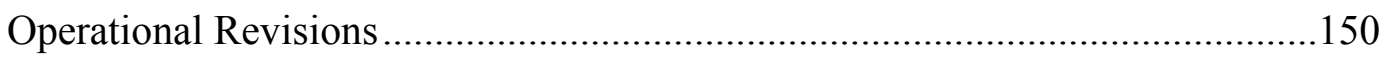

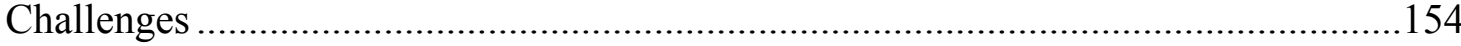

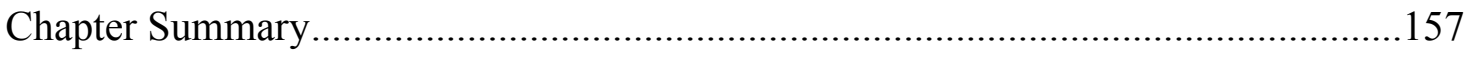

Chapter 5 Conclusions, Speculations, and Recommendations for Leadership...............158

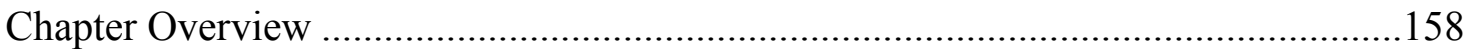

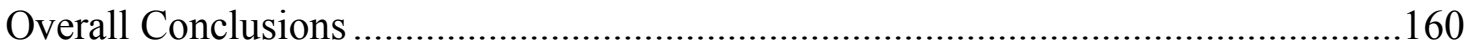

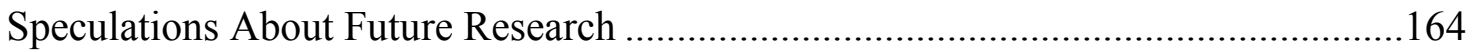

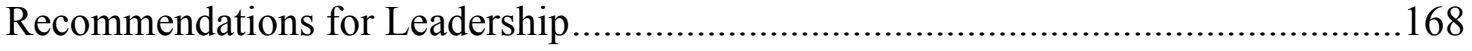

Top 10 List of Leadership Recommendations ...............................................169 
Implications for Higher Education and State Policy ..............................................172

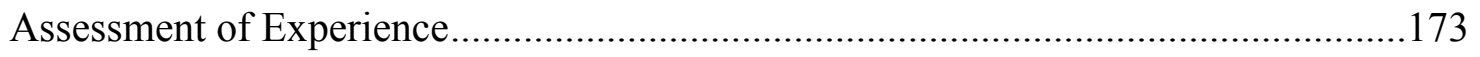

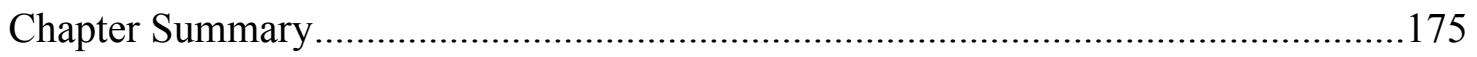

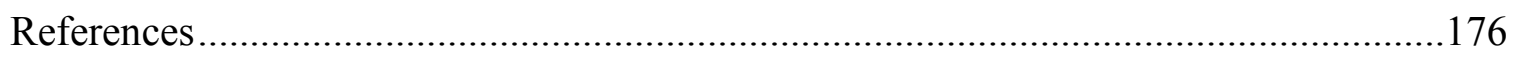

Appendix A- Baker Web Academy Survey ..........................................................181

Appendix B- Consent Form ................................................................................184

Appendix C- Pre-Survey Instrument....................................................................... 189

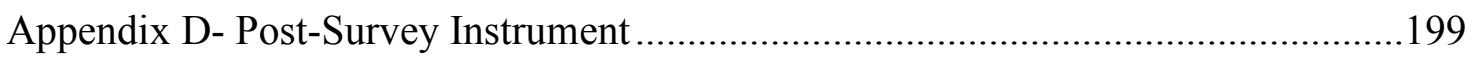

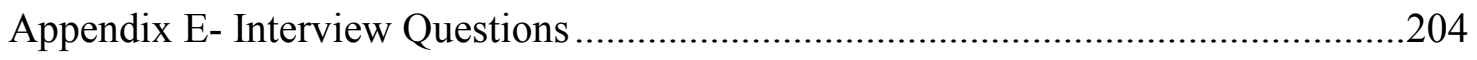

Appendix F- Offline Website Pages..........................................................................206

Appendix G- Workshop Agenda......................................................................214

Appendix H- Committee Formation ........................................................................219

Appendix I- Sample Job Posting and Job Description .............................................221

Appendix J- Sample Candidate Letter ..................................................................225

Appendix K- Online Teacher Interview Bank ........................................................227

Appendix L- Sample Teacher Interview Questions ..............................................231

Appendix M- Demonstration Item Bank...................................................................235

Appendix N- New Online Teacher Orientation Power Point.......................................241

Appendix O- Mentorship Program Sample............................................................246 


\section{List of Tables}

Table Page

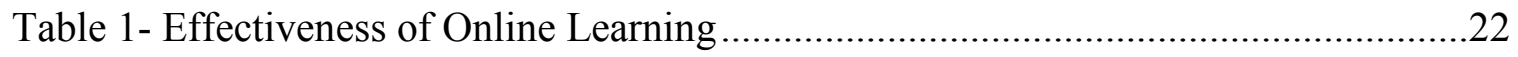

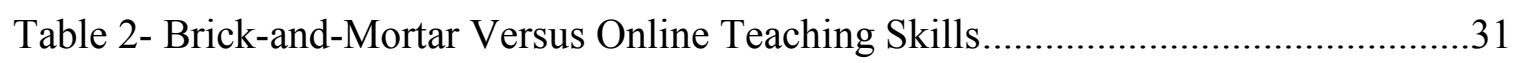

Table 3- Summarized National Standards for Quality Online Teaching Standards ..........37

Table 4- Selections for NEA Guide to Teaching Online Courses .................................49

Table 5- Desired Qualities in K-12 Online Instructors ............................................54

Table 6- Induction Themes From Literature Reviewed..............................................72

Table 7- R\&D Process From Bridges and Hallinger (1995).........................................93

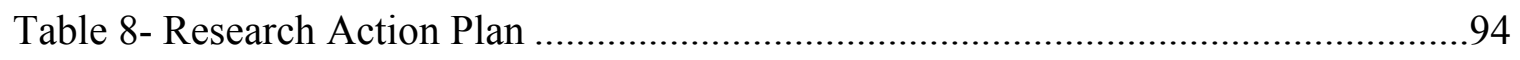

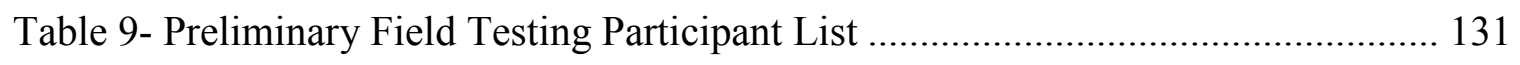

Table 10- Pre-Survey Data Results Before Use of the Website ...................................133

Table 11- Post-Survey Data After Use of the Website ..............................................138

Table 12- Summary of Main Product Revisions From Preliminary Testing Data ..........141

Table 13- List of Participants During the Main Field Test ..........................................148

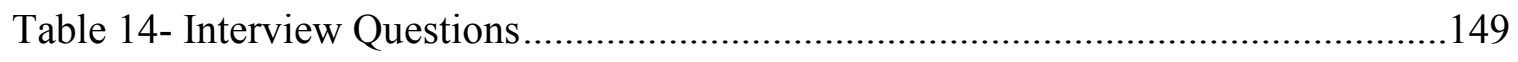

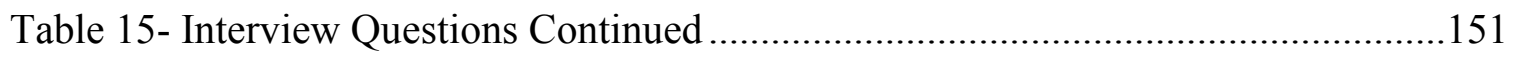




\section{List of Figures}

Figure $\quad$ Page

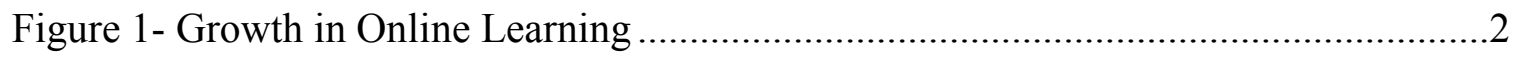

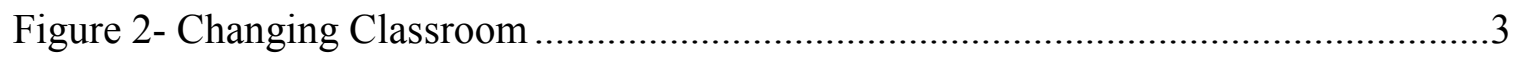

Figure 3- Recruiting and Hiring Process ..............................................................

Figure 4- Recruiting, Hiring, and Induction Flowchart ............................................. 79

Figure 5- Online Teacher Qualities Framework .................................................... 109

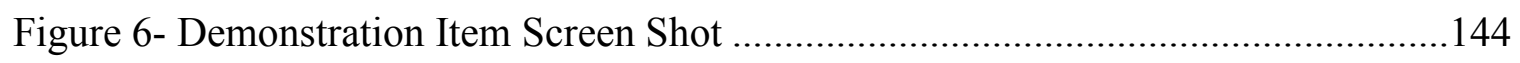




\section{Preface}

The teacher we selected to be a teacher in our online program was an accomplished and award-winning classroom teacher, so my administrative team made the assumption that they would be a good fit for our online school as well. Were we ever wrong! Our team made this mistake once and almost lost the trust of an entire region. What went wrong, what did we miss, and how could we avoid this in the future? The heart of this story captures the entire reason for this dissertation proposal.

This story begins with an amazing interview several summers ago. During the interview, the candidate appeared to our team as one who would be an excellent fit for our school. The answers to the questions showed s/he was genuinely concerned for children and a great educator. The teacher was dedicated to their practice by putting in a lot of overtime and had great letters of reference to back it up. The resume alone was impressive! It was one of the most delightful interviews I have ever been a part of. In his/her current position, s/he had received major awards and was adored by the community. The teacher was an experienced and accomplished teacher in the classroom. Our team made the mistake assuming that was enough. Later I read a great article that warned, "avoid the myth that any regular classroom teacher is qualified to teach online" (Watson, Murin, Vashaw, Gemin, \& Rapp, 2011, p. 56). Our team had to learn this the hard way.

In early fall, the parents' phone calls started coming in. We could hardly believe it; our rock star teacher was the first teacher to receive a complaint during the year, and it was not just one call. As our administrative team evaluated the data, all the signs of a poor fit began to emerge. We had a hard time processing the issue because we had been 
certain this teacher would be a great fit. After processing several situations and losing several students, the admin team began to document our conversations, have multiple conference calls together, email notes after phone calls, conduct special one-on-one training sessions, perform more field observations, and mitigate situations with concerned parents. After a while the issues settled down, but we had already lost many students in the region.

When it came time for contract renewal, we made the choice to non-renew the teacher for a second year. Throughout the process during the year, the teacher let us know s/he was not happy. The teacher struggled with the technology, massive amounts of data entry and analysis, basic functions of the job, isolation, and having reliable internet. It had become clear that while s/he was a fantastic "brick-and-mortar" educator and person, $\mathrm{s} /$ he was not a good fit for an online school. We in online education know that a fully online school is not the appropriate fit for all students. Now we knew that applied to staff as well. Being in an online school is very different than brick-and-mortar classroom instruction and requires a very unique blend of skills, abilities, and ethics.

This story does not end at non-renewal. The teacher actually found her/his way into a better career, and while it was tough losing her/his job, s/he found a better fit for her/his life. This story inspired our team to look deeper into the hiring process, and develop a system to make sure we are recruiting and inducting the teachers who will be a good fit for an online school. What we have learned from this situation will help our students, parents, and school in the future for years to come. This dissertation focused on the research and experience I have gained in formulating effective practices in recruitment and transitioning the best teachers into our online school. 


\section{CHAPTER 1 \\ INTRODUCTION}

Finding quality K-12 online teachers to keep up with the demand for online options has become a complicated dilemma in education. Administrators, policy makers, teachers, and other school staff are struggling to keep up with the shifting demands of the world and technology (Watson, Murin, Vashaw, Gemin, \& Rapp, 2011). Alexander and Boud (2001) from the University of Technology in Australia explained the current crisis in education: "The rise of new technologies has coincided with a crisis of confidence in traditional education and increasing demands for higher and continuing education that have not been able to be adequately met” (pp. 1-2). Changes in technology have altered the face of education forever. Educators and students have instant access to breaking news within minutes of its occurrence. Clark (2007) painted a picture of how quickly information travels by explaining that in 1798 it took 62 days for information of the Battle of the Nile to travel the 2,000 miles to London for a speed of $1.7 \mathrm{mph}$. In contrast it took seven minutes for information about the 2008 Sichuan Earthquake to travel the 5,100 miles to London for a staggering speed of 43,000 mph. Information that travels that quickly is being handled by teachers and administrators who have little to no training in how to operate successful online programs (Holstead, Spradlin, \& Plucker, 2008;

Picciano \& Seaman, 2009; Watson et al., 2011). Teachers and administrators who scarcely have a metaphorical learner's permit are driving a car that goes 43,000 mph, and that's a recipe for disaster. 
The rapid advances in information dispersal and transfer are taking our nation's education system by storm. Entire schools, curricula, and courses are now offered online. This form of learning has many names such as e-learning, virtual schooling, and online learning. In this study I used the term, “online learning," which can come in many formats, yet all forms essentially mean that instruction is delivered to the student through the internet (Greenway \& Vanourek, 2006). The growth of online learning and the significance to K-12 education has been exponential in the last 10 years. A study released by the Sloan Consortium (Picciano \& Seaman, 2009) reported that in 2007-2008 there were $1,030,000 \mathrm{~K}-12$ students active in online courses, that number represented a jump of 47\% from 2004-2005. In 2009 the number leapt to two million and we are currently at approximately 4 million students taking some form of online learning (Watson et al., 2011). Projections for 2014 are that there will be 10.5 million students online (Nagel, 2009) - see Figure 1. This shift represents a change in learning format for more than 10 million students in a short span of 10 years.

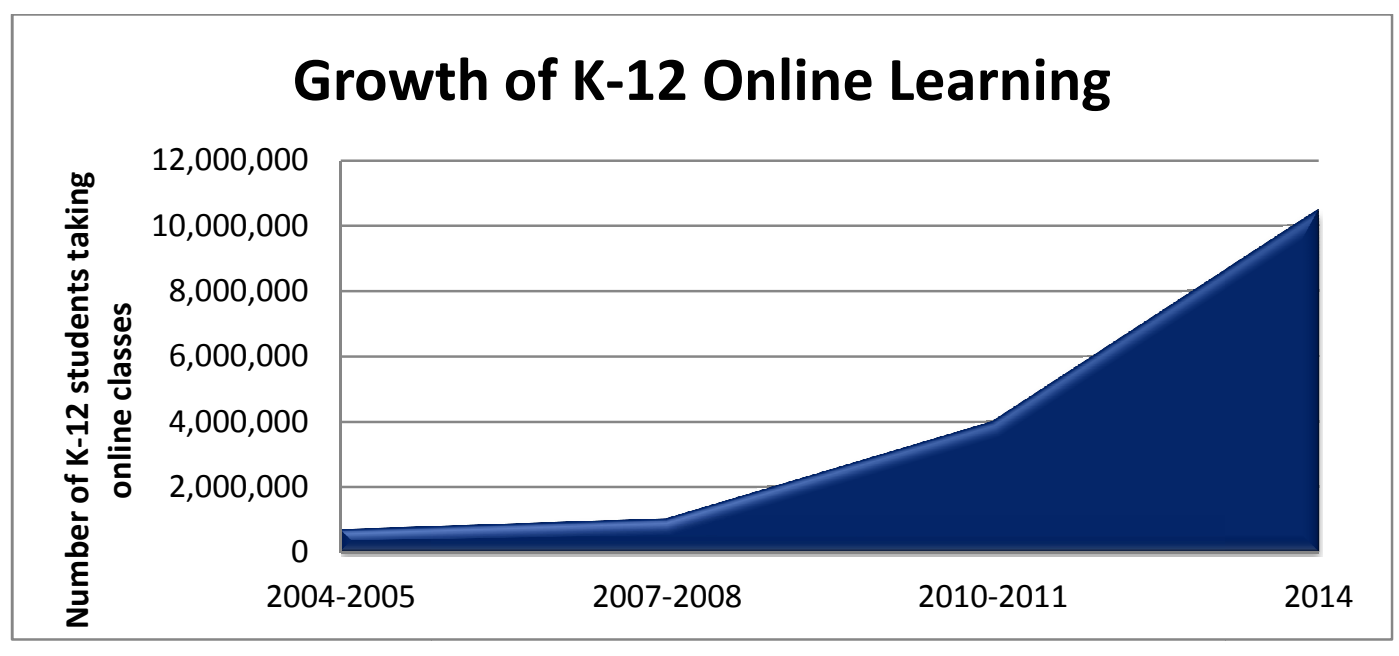

Figure 1. Growth in online learning. K-12 online learning growth model based on data from Nagel (2009) and Picciano and Seaman (2009). 
The Internet is here to stay and is liberating education from the traditional confines of time and space (Greenway \& Vanourek, 2006). Over the next several years, where students are taking their classes will be dramatically shifting. A representation of the data from Nagel (2009) which demonstrates where students are taking classes in 2009 versus the projection of 2014 is shown in Figure 2.

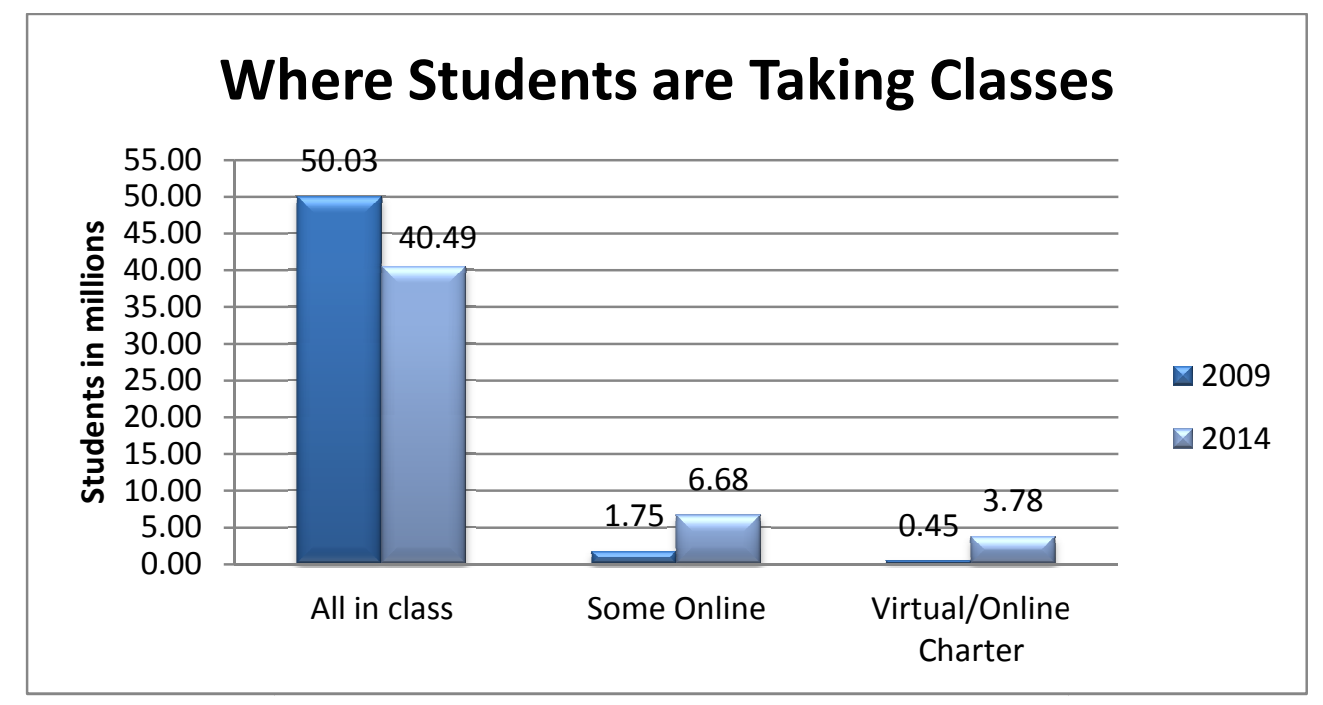

Figure 2. Changing classroom. Data from Nagel (2009) showing where students will be taking classes in 2014 based on a research report from Ambient Insight.

From the growth to the shifting location of education, the virtual revolution has caused educators from kindergarten to postsecondary institutions to completely rethink learning, schools, classrooms, and education (Holstead et al., 2008). School leaders, educators, and policy makers are now faced with several important and critical questions about online learning. For example, will it improve student access to learning? What happens to school boundaries? Will it decrease costs? What happens to the teachers? Does it improve learning (Owston, 1997)? These questions need timely and carefully 
planned responses to ensure online learning is implemented to its greatest potential. Though there are many issues surrounding K-12 online learning, for the purpose of this study I focused on how to recruit and transition top quality K-12 teachers into online schools. Top quality online teachers are those that have already mastered or can demonstrate the ability to quickly learn the specific skills of online instructional design and delivery, have specific professional development to teach online, can communicate in various platforms, and are masters of current and emerging technology.

\section{Statement of Problem}

The focus of this study is about equipping leaders with practical and researchbased methods that aid them in recruiting and transitioning the top quality K-12 teachers into online programs. The primary research question is: how can school leaders recruit and transition top quality K-12 teachers into online settings to increase student learning? Hiring the right teachers is the "single most influential school-based factor" (Stronge \& Hindman, 2003, p. 48). On the other hand, hiring the wrong teacher can cost a school thousands of dollars and result in students needing three years of remediation (Scherer, 2005) for every year of poor instruction. In a recent study it was reported that, "Without 'highly qualified' online teachers, online learning may not have any positive impact on student academic performance" (R. Smith, Clark, \& Blomeyer, 2005, p. 59). Therefore, we can conclude that when building an online program, the most important task becomes finding candidates that exhibit the qualities of great online teachers and supporting their move into online environments.

Administrators need to become experts at closely examining our current field of teachers, and developing effective techniques to help transition the best classroom 
teachers into online programs. A nationwide survey of online teachers revealed that over $80 \%$ of them have previous experience (Dawley, Rice, \& Hinck, 2010). Many online teachers come to online environments with previous classroom and pre-service preparation geared toward face-to-face instruction. Unfortunately, leaders of online schools cannot completely rely on the current teaching force as they must "avoid the myth that any regular classroom teacher is qualified to teach online" (Watson et al., 2011, p. 56). Since not all teachers have the skills to teach online, how should administrators ensure they are finding teachers who will be successful? Teaching online takes a unique blend of experience, skills, and abilities (Barrett, 2010; Holstead et al., 2008). Topquality online teachers should have specific training in online teaching, be able to explain concepts clearly, modify curriculum based on assessment, have previous experience in online settings, display ethics, and be masters of emerging technologies to enhance instruction (Treacy, Baltunis, \& Swiderski, 2011). Administrators should first gain a deeper understanding of the unique skills and characteristics of great online teachers, then move on to developing techniques to recruit these teachers.

In a recent study series out of Boise State University called Going Virtual (Dawley et al., 2010; Rice, Dawley, Gasell, \& Florez, 2008), more than 900 current online teachers across the nation provided a picture of what hiring committees should begin to look for. From this study three important points emerged about current online teachers: (a) nearly $60 \%$ of new online teachers (just hired, no online experience) have more than 6 years of total teaching experience; (b) $95 \%$ of them received training at their programs; and (c) fewer than $30 \%$ received any training or education from a University on how to teach online (Dawley et al., 2010). In fact less than $1 \%$ of online teachers in 
2005 were certified or had advanced training to teach online (R. Smith et al., 2005). As administrators attempt to build quality online teaching programs they can learn a lot from this study. First of all many of the new online teachers come in with prior brick and mortar or other types of teaching experience. Administrators need to build an induction program and professional development plans to help new online teachers transition into online teaching. In addition when looking at resumes they can look for teachers who have successful prior teaching experience. Next from this study, it is rare that online teachers have additional training or certification to teach online, therefore those who do have additional training are rare and worth hiring (Treacy et al., 2011; Watson et al., 2011). Furthermore teachers who have successful online certification and successful online teaching experience should make excellent finalists for positions. Finally, with $95 \%$ of online teachers reporting receiving training at the program level, leaders should fully expect to provide the necessary initial and on-going training to support new teachers. While this research study only focuses on the initial induction of new online teachers, there are a lot of on-going resources offered by iNACOL for helping plug teachers into a thorough and relevant resource. For initial transition/support for new teachers administrators need to carefully construct an induction program that is comprehensive, highly organized, and structured to be suited for adults working through a paradigm shift to teach online (Wong, Britton, \& Ganser, 2005). Mezirow (2000) reminded us that adult learners need to fit their current experience into their old experiences, and require a lot of discussion and collaboration during new learning experiences. While this study presents some important insights about current online teachers, it also highlights an important crossroads for K-12 schools. 
Right now we are at a critical junction in K-12 online teaching. Not all teachers can teach online, but we will have another five to six million students starting to take at least one online class in the next two to three years (Nagel, 2009; Watson et al., 2011). The student demand for online classes and programs will rapidly outpace the preparation and availability of quality online teachers across our nation. The dilemma of student demand versus availability of qualified staff has created a difficult dilemma in education that requires a thoughtful, purposeful, and timely response from school leaders. Right now our leaders need the skills to hand pick the best teachers from our current teaching force and help transition them into online teaching. My goal is to provide simple, effective, and research-based tools to help administrators become experts in identifying staff members who are masters of technology, online instructional design and delivery, communication and have experience/certification to teach online and help them make the transition to online positions.

\section{Purpose and Significance of Study}

This study explored the best recruitment, hiring, and induction practices as they apply to K-12 online learning. My goal was to create a research-based website to assist online school administrators through the recruiting, hiring, and induction process of online teachers. The website was designed to help administrators regardless of their program type or structure. To create this website, I used a combination of analysis of current research, performing new research on recruitment, hiring and induction practices, and my experience as an online charter school administrator. For the last five years I have fulfilled various administrative roles in virtual charter schools in Oregon. In this time period I have seen tremendous demand for online schooling, as well as an economic 
downturn and an increase in excellent traditional teachers looking for teaching positions in the field of online learning. In my setting, the demand for online schools combined with an increased availability of candidates, provides a unique opportunity to refine current recruitment and transitioning techniques. During my recent leadership experience, I have worked diligently to adapt research-based concepts learned in my university preparation programs to become an emerging leader in this new arena of K-12 online learning. This unique combination of research-based knowledge coupled with significant practical experience to help create meaningful solutions to recruitment and transitioning challenges of K-12 online teachers.

\section{Research Methodology}

Research in the field of education should be connected to practice and make a difference to the field. Based on an analysis of research techniques the best framework to guide this study is a Problem-Based Learning (PBL) approach developed by Bridges and Hallinger (1995). The PBL model grew out of a desire to challenge Doctor of Education (EdD) students to apply their knowledge to a real-world setting within the field of education. Bridges and Hallinger developed the framework to guide the research of EdD students to address problems of policy or practice. Generally, research relating to educational leadership comes to a difficult crossroads in trying to "meet the expectations of two different organizational cultures: the professional workplace of schools and the academic environment of the university" (Bridges \& Hallinger, 1995, p. 115). In the PBL model, Bridges and Hallinger shifted the focus to analyzing the effectiveness of an educational product by using the Research and Development (R\&D) process developed by Borg and Gall (1989). The R\&D process is "one way to bridge the gap between 
research and practice in education" (Bridges \& Hallinger, 1995, p. 118). Through the R\&D process, the researcher builds a product to address an educational problem. The product is then field tested and assessed to determine its impact. The product has greater potential to impact educational settings than traditional $\mathrm{PhD}$ dissertations, which are typically more abstract and theoretically based. The product I developed, field tested, and assessed was a teacher recruiting, hiring, and induction website for online school administrators. My goal was to inform the field about the effectiveness of using researchbased recruitment, hiring, and induction website to improve the hiring of top quality teachers in online schools.

The design of the website would be to create a product that administrators could use in their own efforts to plan and implement research-based recruiting and induction practices in their online schools. The website would be built on a three-step comprehensive staffing model with a chapter about each phase in the hiring process as shown in Figure 3.

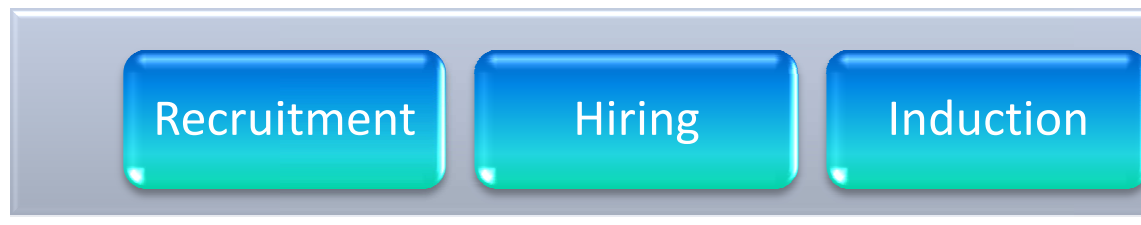

Figure 3. Recruiting and hiring process. Comprehensive staffing model for online Sshools. (c) All rights reserved. 
To analyze the effectiveness of the toolkit, I designed a study based on Borg and Gall's (1989) R\&D process that Bridges and Hallinger (1995) recommended for use in EdD dissertations. The $R \& D$ process consists of 10 steps starting with research and information gathering, planning and small-scale testing, development of a draft product, preliminary field testing, main product field testing, operational product revision, operational field testing, final product revision, dissemination and implementation (Bridges \& Hallinger, 1995). In this study I went through the seventh step of further revisions after the main field testing as steps 8-10 require mass production and dissemination. Candidates can pursue using their tool as a consultant after defense of the dissertation; however, steps 1-7 are sufficient for EdD research. To develop an effective study, Maxwell (2005) added that much of the design of a research study stems from the research questions. Following the first seven steps of the R\&D process in this study, my primary questions were: (a) What happened as the website was developed and field tested, (b) What were the perceived benefits and challenges of the website, and (c) How can the website be further refined and improved? These questions took me down the path of a qualitative study as my target population was small, and the data collected were mostly qualitative in nature. The first question guided me as I proceed through the process of researching my problem in the field. Through the initial development and primary field testing, I sought to refine my product through feedback and analysis before implementing a final product for main field testing. The next question focuses on perceived benefits and would be best studied using qualitative research methods as I am trying to discover perceived benefits of the product for administrators. Qualitative methods as described by Krathwohl (2009) are best used to "make people, problems, and 
situations 'come alive;' portray phenomena in context”' (p. 237). The final question's goal is used to continue the refinement and development of the product, which can also be studied through qualitative research strategies such as interviews. If all 10 steps of the study are completed, the product may be deployed on a large scale after continuous refinement once the EdD dissertation has been defended.

After completing the steps of the R\&D process final analysis of my data resulted in recommendations and further applications that have great potential to make a lasting impact on K-12 online learning. Establishing effective recruiting, hiring, and induction programs for K-12 online teachers helped increase the quality of online learning. Much of the burden is on practitioners rather than postsecondary or research institutions to make the staffing programs line up with best practices (Dawley et al., 2010). Using an interactive dynamic approach to research and analysis, I hope to ensure a lasting impact on the field of K-12 education.

\section{Chapter Summary}

Online technologies offer powerful teaching tools that are capable of truly creating amazing learning environments. From the teacher who shows YouTube science videos to the Virtual charter schoolteacher who travels to student's homes for one-on-one tutoring, online learning is and will continue to be an integral part of education for the next century (Greenway \& Vanourek, 2006; Watson et al., 2011). Now that it's here to stay and growing quickly, educators need to be thoughtful about what they do with this new method of instructional delivery. Literature has challenged the field to develop quality online programs and schools (Cavanaugh, Gillan, Kromrey, Hess, \& Blomeyer, 2004; Picciano \& Seaman, 2009; R. Smith et al., 2005; Watson et al., 2011). Quality 
online instruction is what our children who want to pursue online learning deserve.

Students who try online learning need to be exposed to the best teachers possible in order to ensure their success (Cavanaugh et al., 2004; Watson et al., 2011). Online learning may not work for all students but the students who try online learning deserve a quality experience. While online learning may not work for all students, the pressure and demand for online learning shows no signs of slowing. With higher demand for online learning and more demands for resources elsewhere, the field of education will be challenged to do more with less. The scene in education is very exciting, albeit demanding. The tools are before us to change education forever.

All of these changes have brought education to a fork in the road, and the path we choose will transform the face of education. Online learning has truly changed education and stretched the system beyond its typical change cycles. Historically, change in education is cyclical and slow. Educational institutions are resistant to change (Mintzberg, 1979). The emergence and refinement of digital technologies catapulted education through a major shift in how and where students learn (Greenway \& Vanourek, 2006). With demand that is ahead of our policies, teacher preparation programs and research, the heavy lifting is left to current administrators and teachers to be resourceful in meeting the demand. Many of the best online teachers will come from the brick-andmortar classrooms (Dawley et al., 2010). Teachers making the transition will need the right support to ensure they will be successful in online settings. Administrators need effective and practical research to guide their decisions. Finding and supporting quality online teachers is the most important goal in online education. Without quality instruction the true potential of online learning will not be met. My research will give administrators 
the recipe for recruiting, hiring, and inducting the right teachers into K-12 online learning environments. With proper staffing models in place, administrators can safely guide students, teachers, and parents through the use of one of the most powerful tools man has ever invented, the World Wide Web.

\section{Definitions Common in Online Education}

Asynchronous: Online or computer courses without direct interaction between instructor and student (Owston, 1997)

Bricks and mortar: A traditional school or building compared to that of an online school (Watson, 2008)

Blended learning: "combines online delivery of education content with the best features of classroom interaction and live instruction to personalize learning" (Watson, 2008, p. 4)

Distance education (DE): Learning environment "where students and instructors are separated by time, location, or both" (Blomeyer, 2002, p. 4)

Distance learning: "The desired outcome of distance education” (Blomeyer, 2002, p. 4)

e-Mentorship: "a relationship that is established between a more senior and/or experienced individual (mentor) and a lesser skilled or experienced individual (mentee or protégé), primarily using electronic communications, and is intended to develop and grow the skills, knowledge, confidence, and cultural understanding of the protégé to help him or her succeed" (Thompson, Jeffries, \& Topping, 2010, p. 305)

Flipped Classroom: Teachers are now "creating flipped or inverted classrooms in which they record lectures and post them online" (Goodwin \& Miller, 2013, p. 78). 
Classroom time is then reserved for discussion, application, and synthesis of content presented online.

Full-time programs: Programs or schools that offer the majority of their curriculum through online methods (Holstead et al., 2008)

Hiring: The process of recruitment of teachers that begins with the interview and continues through the job offer (Peterson, 2002)

Hybrid programs: Schools that provide access to online classes in addition to their traditional coursework (Holstead et al., 2008)

iNACOL: "The International Association for K-12 Online Learning is a nonprofit organization that facilitates collaboration, advocacy, and research to enhance quality K-12 online teaching and learning” (Patrick, 2012, para. 1).

Induction: Induction is the initial processes educational programs have in place to help teachers transition into work in the classroom. These may include "support, guidance, and orientation programs" (T. Smith \& Ingersoll, 2004, p. 681).

Learner Management System (LMS): A tool in online schools that allows administrators, teachers, support staff, and parents to view student grades and progress in their online classes (Watson et al., 2011)

Online/e-learning: Electronically delivered learning (Blomeyer, 2002)

Progress Monitoring: When a teacher evaluates student progress toward academic goals and adjusts learning to ensure progress (Treacy et al., 2011)

Quality Online Instruction: Online instruction in alignment with the National Quality Standards for Online Teaching (Treacy et al., 2011) 
Recruitment: Recruitment is the process by which hiring committees can attract the best or most qualified candidates for the particular position (Hirsch, 2001)

Student Information System(SIS): A tool in schools that allows staff and parents to view student grades, credit history, academic records, and pertinent student information (Watson et al., 2011)

Synchronous- Online or computer courses with direct two-way communication between the instructor and student (Owston, 1997)

Transformation Learning: The learning process by which learners "become critically aware of one's own tacit assumptions and expectations and those of others and assessing their relevance for making an interpretation" (Mezirow, 2000, p. 5). In other words where new learning is critically analyzed and merged with previous learning.

Virtual schools: "An educational organization that offers K-12 courses through the Internet- or Web-based methods" (Blomeyer, 2002, p. 4)

Virtual charter school: Public charter schools that use online curriculum for the majority or entirety of their coursework (Holstead et al., 2008) 


\section{CHAPTER 2}

\section{LITERATURE REVIEW}

The review begins by surveying the literature about the field of K-12 online teaching to provide a context for the study. Next the discussion focuses on the effectiveness and importance of online teaching in K-12 settings. A synthesized set of criteria and indicators of effective online teaching are developed from the literature. The discussion analyzes the literature looking for effective recruitment, hiring and induction practices, and tools for finding and selecting the best candidates for online K-12 teaching

positions (Barrett, 2010; Ingersoll \& Strong, 2011; T. Smith \& Ingersoll, 2004; Watson et al., 2011). In conclusion, the review discusses limitations of the literature available on this topic and how these limitations may present gaps in need of future research. From recruitment to selection and induction, the process of transitioning teachers into online work is a process that needs to be carefully thought out to ensure teacher and student success in the virtual learning environment.

\section{Brief Survey of the K-12 Online Learning Literature}

As stated in the introduction of this study, because $\mathrm{K}-12$ online is a rapidly growing and relatively new area of K-12 education, the topic needs careful research, analysis, and development to provide a meaningful context for future research studies (R. Smith et al., 2005; Watson et al., 2011). A review of literature about K-12 online learning begins with a definition of what online learning is. Online learning has its roots in DE which is an "Educational situation in which the instructor and students are separated by 
time, location, or both" (Blomeyer, 2002, p. 4). Traditional DE includes media such as, "written correspondence, text, graphics, audio- and videotape, CR-ROM, online learning, audio- and videoconferencing, interactive TV, and facsimile" (Blomeyer, 2002, p. 4). Online learning falls under the broad umbrella of DE. Online learning, more specifically defined, is "Education in which instruction and content are delivered primarily over the internet" (iNACOL, 2011, p. 6). Online learning does not include other forms of distance education such as correspondence courses, Interactive TV courses, or CD-ROM based instruction. Within the field of online learning, there are many delivery and participation methods that provide several options for districts and programs. The two primary participation models of K-12 online learning are full-time and supplemental. Full-time online learning is where the student takes all their online classes from the online school while supplemental students take one or two online classes in combination with regular brick-and-mortar classes (Watson, 2008). Within both models there are two main delivery methods: full-time online, and blended. Fully online instruction is where all of the instruction takes place through a computer and the internet. Blended learning is "anytime the student learns at least in part at a supervised brick-and-mortar location away from home, and at least in part through online delivery with some element of student control over time, place, path, and/or pace" (iNACOL, 2011, p. 2). Communication and instruction in these online environments can be asynchronous with no direct contact with instructor or synchronous with live real time contact between student and teacher (Owston, 1997). K-12 online learning is an emerging field that has many layers of implementation; however, the literature reviewed in this study is focused on instruction that takes place over the Internet. 
It is also important to carefully consider sources that do not fit within the narrow field of K-12 online learning. Resources that include forms of DE that do not involve technology or the use of the internet explained, or in some cases, excluded. First and second generation DE methods are correspondence courses and later print materials integrated with broadcast TV, radio, and videocassettes that were available as early as the 1960s (Bernard et al., 2004). Early forms of DE are fundamentally different than later generations because over time the amount of communication, interaction, technology, and flexibility has significantly altered DE. Therefore earlier forms of DE does not bear as much significance on the dynamic online learning environments of today (Bernard et al., 2004; Cavanaugh et al., 2004). In additional to limiting resources about earlier forms of $\mathrm{DE}$, resources focusing on postsecondary online learning was considered with caution as well. Cavanaugh et al. (2004) provided this warning about postsecondary online learning literature, "The temptation may be to attempt to apply or adapt findings from studies of K-12 classroom learning or adult distance learning, but K-12 distance education is fundamentally unique" (p. 6). The literature also points out that, "Younger online learners may have a lower degree of autonomy needed to learn independently and less integral locus of control and intrinsic motivation to persist in their studies" (R. Smith et al., 2005, p. 13). Additionally "younger students will need more supervision, fewer and simpler instructions, and a more extensive reinforcement system than older children" (Cavanaugh et al., 2004, p. 7). Therefore postsecondary online learning research had fundamental differences from K-12 focused articles and resources should be considered with these limits in mind to ensure they are the most applicable to the specific focus of K-12 online learning. Now that we have a greater focus on the foundations of K-12 
online learning, it is important to take a closer look at what online learning looks like on a daily basis.

Online learning's day to day operations are quite different than brick-and-mortar programs for students and teachers. A day in an online school can look different depending on whether the school is a blended, supplemental, or a fully online program (Watson et al., 2011). Selected examples from an article called The virtual revolution; Understanding online schools by Greenway and Vanourek (2006) discussed a day in the life of a sixth grade, fully online student. The article reported that his day starts around 8:00 am with a review of his topics through a personalized webpage and curriculum portal. During the course of the school day, he works for several hours on history, spends several minutes going over a recent science lab, works for about one hour in pre-algebra, and spends about one hour developing his reading skills. There are breaks throughout the day for meals and activities such as soccer, and a break for dinner with his family. After dinner, the online student finishes the day at 9:00 pm after reading literature and having a discussion with his parents about what he learned that day. In this example the student spent about six hours working on his online classes with breaks and meals mixed in through the day. For perspective from the teacher's point of view, an article published by Faucett (2011), who teaches for Florida Virtual School, details the daily life of a virtualschool teacher. In her article, Faucet mentioned that her day starts early at 6:00 a.m. with grading time, progress review, providing feedback to students on assignments that will turn mistakes into opportunities to learn, and then organization for the day. As the day continues, she makes phone calls to students based on their unique needs; at times she uses a virtual whiteboard for online tutoring; during lunch she eats a sandwich with her 
son; in the afternoon she travels to visit students while organizing for the next day and making more calls to students; and finally, she finishes the day by planning for the next day. In another school across the nation, Kristin Kipp, National Virtual School Teacher of the year in 2011, had her day cataloged in an interesting video that followed her through a typical day at Jeffco Virtual Academy in Colorado (Jeffco Virtual Academy, 2011). Ms. Kipp works from home in a fully online modality and only reports to a physical location for occasional training, spending her days working from her home office. In a conversation with Ms. Kipp at the 2012 fall iNACOL conference in New Orleans, she related to me that she loves what she does and feels like she is making a difference for her students (K. Kipp, personal communication, October 23, 2012). The video shows Ms. Kipp has a mix of activities, including synchronous online instruction in a literature class, phone calls to students, grading, building relationships with students, providing one-onone tutoring with students, and guiding students through the use of an online blog discussion, as well as interacting with her own family at home. In this video we also hear students from Jeffco Virtual Academy telling stories about how they are able to share more openly in an online school, ask questions, how they appreciate the personalization, with some even sharing that Ms. Kipp was the first person to care about them. Day-today activities in virtual schools can vary greatly depending on the structure of the schools, curriculum chosen, and dynamics of the teacher. However, they all are delivered through the power of the internet with students and staff interacting through the use of the technology. With a deeper understanding of what online learning looks like in the field, it is appropriate to consider the characteristics of effective online schools. 
Since the field of K-12 online learning is new and diverse in its approach to teaching, it is important to establish a context before further review and research. Ensuing review of the literature can be better understood through using the definitions and background information in the section above. Building a context has allowed the review of literature to focus on the most important resources. Resources relating to early versions of DE not involving technology or the internet should be considered with caution. Additionally resources focusing on higher education DE may not have the same implications for K-12 online learning. Furthermore, it is important to note that even though virtual schools may appear different on the surface, there are common factors that may lead to student success. Now that the literature has provided a general context for the study, it is important to look at how student achievement is impacted in online schools.

\section{Factors That Impact Student Achievement in K-12 Online Schools}

Within the literature reviewed there were several studies that focused specifically on factors that lead to student success in online schools. For this study there were main research studies that were selected to establish factors that influence student success in online schools. These particular studies were selected for several reasons: first, each study includes seminal authors in the field of K-12 online learning that are quoted often in other articles; secondly, each study is a meta-analysis, which explores larger quantities of literature while offering helpful synthesizing recommendations; and finally, they are written by authors with multiple publications within the field of K-12 online learning. These articles discuss a variety of topics critical to research in K-12 online learning such as how online learning impacts student achievement, professional development for online teachers, learning theory online, success factors for online schools, teacher preparation, 
costs, and methods of online programs. Table 1 outlines the four main research studies in the literature that were reviewed as well as provides a summary of their key findings. The goal of using these articles is to discover the factors that lead to student success in online schools.

Table 1

Effectiveness of Online Learning

\begin{tabular}{|c|c|c|c|}
\hline Author & Date & Study Title & Findings \\
\hline $\begin{array}{l}\text { Means, Toyama, } \\
\text { Murphy, and Baki }\end{array}$ & 2013 & $\begin{array}{l}\text { The effectiveness of online } \\
\text { and blended learning a } \\
\text { meta-analysis of the } \\
\text { empirical literature }\end{array}$ & $\begin{array}{l}\text { - "On average, student in online } \\
\text { learning conditions performed } \\
\text { modestly better than those } \\
\text { receiving face-to-face instruction" }\end{array}$ \\
\hline $\begin{array}{l}\text { Cavanaugh, Gillan, } \\
\text { Kromrey, Hess, and } \\
\text { Blomeyer }\end{array}$ & 2004 & $\begin{array}{l}\text { The effects of DE on } \mathrm{K}-12 \\
\text { student outcomes: A meta- } \\
\text { analysis }\end{array}$ & $\begin{array}{l}\text { - "Students can experience similar } \\
\text { levels of academic success" (p. 21) } \\
\text { - Some environments yielded results } \\
\text { that were not as good as others } \\
\text { - Quality of environment is critical in } \\
\text { success }\end{array}$ \\
\hline $\begin{array}{l}\text { Bernard, Abrami } \\
\text { Lou, Borokhovski, } \\
\text { Wade, Wozney, } \\
\text { Wallet, Fiset, and } \\
\text { Huang }\end{array}$ & 2004 & $\begin{array}{l}\text { How does DE compare with } \\
\text { classroom instruction? A } \\
\text { meta-analysis of the } \\
\text { Empirical Literature }\end{array}$ & $\begin{array}{l}\text { - "no significant difference" (p. 383) } \\
\text { - "works extremely well sometimes } \\
\text { and extremely poorly other times" } \\
\text { (p. 405) } \\
\text { - "attention to quality course design } \\
\text { should take precedence over } \\
\text { attention to the characteristics of } \\
\text { media" (p. 411) }\end{array}$ \\
\hline $\begin{array}{l}\text { R. Smith, Clark, and } \\
\text { Blomeyer }\end{array}$ & 2005 & $\begin{array}{l}\text { A synthesis of new research } \\
\text { on } K-12 \text { online learning }\end{array}$ & $\begin{array}{l}\text { - "equal or better" to classroom } \\
\text { instruction" (p. 71) } \\
\text { - Instruction designed to foster } \\
\text { communication between student- } \\
\text { student and teacher-student has a } \\
\text { positive impact on performance } \\
\text { - Instruction that provides immediate } \\
\text { feedback enhances student } \\
\text { achievement }\end{array}$ \\
\hline
\end{tabular}


For a study in K-12 distance learning it is important to explore factors that impact student achievement. All four studies had their own unique themes as well as several factors in common. The first and most recent study, The effectiveness of online and blended learning: A meta-analysis of the empirical literature, is a meta-analysis including more than 45 studies with participants ranging in age from 13-44 (Means et al., 2013). The study includes other studies in Table 1 as well additional articles. When exploring student success in online settings it is important to acknowledge that online learning may not be the right choice for all learners. Students who are a good fit for online learning in K-12 settings are those learners who desire more flexibility, personalization, have good study skills, are independent learners, and are motivated learners (Cavanaugh et al., 2004). Although students who exhibit these skills tend to be more successful in online environments, expelled students and students who struggle academically can also be successful online (Watson et al., 2011). For students who do make the choice to pursue online learning, Means et al. (2013) found that "on average, students in online learning conditions performed modestly better than those receiving face-to-face instruction" (p. 2). For this dissertation the main claim is not to ascertain that one model is better than the other model, rather to use these findings to make the point that online learning is a form of education that is working and worth investing in. Further this paper makes claims about finding ways to make online learning more effective for students who chose this option. Discovering factors that help students be successful online is one of the most important elements of this dissertation. To further understand which factors lead to success in online schools, the next section explores several other articles and seeks to understand the success factors in online schools. 
The next study, The Effects of Distance Education on K-12 Student Outcomes: A Meta-Analysis (Cavanaugh et al., 2004), included data from a combined student grouping of 7,561 students who took DE options to a control group that did not take any DE classes. In this study it was revealed that, "distance education is as effective as classroom instruction" (p. 16). Therefore online delivery method of learning does not negatively impact student achievement. As seen in the Means et al. (2013) article online learning may actually benefit students if it is implemented using best practices. Cavanaugh et al., (2004) highlights several factors for successful K-12 online programs; student autonomy, student responsibility, system design, abilities of student, demands of the content, and quality of the teacher.

It is important to understand each of the factors mentioned by Cavanaugh et al. (2004) to achieve a deeper understanding of the literature. First of all they mention student autonomy. For students to be successful online they need to be at a place where they can be more independent in their learning. Next the researchers mention that younger online learners will have special needs in working with online schools. They may not be ready for online environments unless they have additional support or can demonstrate a higher level of independence as a learner. Also the authors mention that if the technology and infrastructure to support online learning is not present, students struggle. Students need equal access to technology and generally fast, reliable internet to be successful in online settings (Blomeyer, 2002; Cavanaugh et al., 2004). Rigorous content is also a factor that can influence student success online. Content should be age appropriate, standards based, and personalized (Watson et al., 2011). Younger students may be more successful with more parental involvement, paper and pencil materials, and 
plenty of reading and language development. Students who are struggling readers need reading interventions and more audio/visual based programs until their reading level can be increased (Cavanaugh et al., 2004). While each of the factors listed above can influence student's success; the following quote places specific emphasis on the quality of the teacher.

In classrooms, teacher effectiveness is a strong determiner of difference in student learning, far outweighing differences in class size and heterogeneity. Based on the similarities in student outcomes between distance and classroom setting, there is every reason to expect that teacher preparation is critical in distance education. However, there has been very little formal preparation available addressing the unique nature of online instruction and very little time for teachers to develop their expertise as online instructors. As professional development becomes more common and expertise grows, student success is likely to grow as well.

(Cavanaugh et al., 2004, pp. 20-21)

In this statement, it becomes clear that out of the many factors that impact student success online Cavanaugh et al. (2004) believe that teacher effectiveness may be one of the most important factors. The literature makes a strong connection between the importance of quality teachers in both classroom and online environments. However, the researchers do comment that online learning is quite new, and there has not been a lot of time to develop online teacher experts. Over time with professional development, further training, and postsecondary options the field will improve, and we will be able to measure the impact of teacher effectiveness more effectively. This article notes a strong correlation between teacher quality and student success in an online environment.

Adding to the previous research by Cavanaugh et al. (2004) another study, How Does Distance Education Compare With Classroom Instruction? A Meta-Analysis of the Empirical Literature, from Bernard et al. (2004) concluded that, overall, classroom and DE are comparable. This study was designed to be a "quantitative synthesis of empirical 
studies conducted since 1985 that compared the effects of DE and traditional classroombased instruction on student achievement” (Bernard et al., 2004, p. 388). This article focused on DE studies that included a "high degree of learner control and two-way communication, as well as group-orientated processes and greater flexibility in learning" (p. __ . More specifically, the types of DE included in the analysis are fourth generation DE- computer and internet-based courses and fifth generation DE, fully online courses. The meta-analysis included 232 studies that were selected from 862 total studies on the topic. Criteria that were used to select the final studies for the meta-analysis included the following: the study had to involve distance between instructor and student; the study had to be published in a journal article or dissertation; occur within the date range of 19852002; it had to be public; and had to include outcome and several other measures. Given this selection criteria, the study was a perfect fit for a literature review on K-12 online learning for several reasons. First of all, the study emphasized later generations of DE that are more closely aligned with online learning. Secondly, it included outcome measures that are important to studying student success in online learning. Finally, the studies had to be published in a journal or dissertation so they would be fairly reliable sources.

There were several findings from the Bernard et al. (2004) study that support the argument for teacher effectiveness leading to student success. In this study, Bernard et al. (2004) placed a strong emphasis on instructional design. The study points out that attention to course quality, creating active learning experiences, increasing opportunities to communicate, and using high-quality asynchronous videos/media are success factors in online classes. Of particular interest to the topic of instructional design is the statement, 
"Attention to quality course design should take precedence over attention to the characteristics of media" (Bernard et al., 2004, p. 411), meaning that online learning as a medium itself does not change or significantly alter student achievement. No significant difference between learning mediums were found in both Cavanaugh et al. (2004) and Bernard et al. (2004). One interpretation of these results would be that the medium (or type of learning) is not as important as the delivery of quality instruction. Cavanaugh et al. (2004) emphasized teacher quality, while Bernard et al. (2004) took the position that course design is more important than the medium. In addition to course design, Bernard et al. (2004) found that "Active learning (e.g., problem-based learning [PBL]), which includes (or induces) some degree of collaboration among students appears to foster better achievement and attitude outcomes in asynchronous DE” (p. 411). Furthermore, the study found that one-way multimedia videos and audio from the instructor increase student success. It can be concluded that course design, opportunities to collaborate, and instructional multimedia are effective means for increasing student achievement in DE settings.

R. Smith et al. (2005) identified additional qualities leading to success in online learning. The study, A synthesis of new research on $\mathrm{K}-12$ online learning, had many recommendations for future research and emerging best practices. This meta-analysis of research articles also reported no significant difference in academic achievement for online schools versus brick-and-mortar programs. This study was developed by the North Central Regional Educational Laboratory with funds from the Institute of Education Sciences under the U.S. Department of Education. The research synthesized of eight of 33 new studies completed during 2004-2005. North Central Regional Educational 
Laboratory placed priority on studies that were fully experimental in nature, followed by those that had high validity, included surveys, and used mixed methods. The eight studies selected covered topics such as instructor/student attitudes, brick-and-mortar comparisons in Algebra, teacher mentor programs, tests of the "no significant difference" hypothesis, and abilities of online teachers (R. Smith et al., 2005, p. 21). From these research studies in K-12 online learning, a pattern of success emerges that is explained in the following section:

Many complex factors influence student academic performance in online courses: (1) program effectiveness (e.g. pedagogical approaches, including studentcentered teaching, constructivist learning models, collaboration, problem-based learning, authentic performance-based assessment, principles of differentiation); (2) socio-economic status of participants; (3) school climate; (4) parental involvement; and (5) learner characteristics. (p. 54)

As discovered in the above-mentioned articles, there are many factors that can impact student success in online settings. Of the factors mentioned by Cavanaugh et al. (2004) and Bernard et al. (2004), it is important to focus on factors that schools can control. Many factors such as demographic characteristics, socioeconomic levels, and characteristics of students are generally not factors public schools have much influence on. Most public schools have open-enrollment policies dictated by state and federal policy. However, schools can begin to develop environments that have strong pedagogy, student-centered teaching, a positive school climate, parent involvement, collaboration, and other factors mentioned above. These are important areas of emphasis for emerging online schools to emphasize to ensure success of their students. While each of these components reveal important areas of emphasis for online schools there is one area that can influence most of the above categories, a top quality teacher. R. Smith et al. (2005) 
and Cavanaugh et al. (2004) both agreed that one of the most important factors that influence student success online is the quality of their teachers. R. Smith et al. (2005) reported "Without 'highly qualified' online teachers, online learning may not have any positive impact on students' academic performance" (p. 59). Of the five factors listed above, a top quality teacher has the potential to directly impact program effectiveness, school climate, and parental involvement.

An emerging trend within these research studies indicates student success is determined by elements controlled by the teacher of an online program. In the Cavanaugh et al. (2004) study, the researchers specifically highlight the teacher as a "strong determiner of difference in student learning” (p. 20). Bernard et al. (2004) emphasized the elements of course design and communication, which are all controlled by the online teacher. Finally, in the R. Smith et al. (2005) study it was apparent that without a high quality teacher, all other factors may not be as important. From the literature reviewed so far, it is clear that online learning students perform at roughly the same level or slightly above their classroom counterparts, and that much of a student's success depends on high quality online teachers. In the next section I continue to review the literature supporting the need for top-quality online teachers.

\section{The Importance of Quality Teaching in K-12 Online Schools}

In online learning settings teaching is so important that Smith et al. (2005) reported that without high quality online teachers other factors influencing student achievement may not even matter. Cavanaugh et al. (2004) made the early connection between teacher quality and student success in online programs. Bernard et al. (2004) emphasized instructional design and communication, which both depend on top quality 
online instructors. Based on this foundation the importance of top quality instruction has been established. As administrators begin to build programs, it is critical for them to find highly qualified teachers that are able to master the online environment. In the following section, literature was reviewed to build a case for top quality teachers in K-12 online classrooms.

The majority of literature reviewed in this analysis has emphasized the need of quality teachers to ensure student and staff success in online programs (Barrett, 2010; Bernard et al., 2004; Cavanaugh et al., 2004; Picciano \& Seaman, 2009; R. Smith et al., 2005; Watson et al., 2011). Cavanaugh et al. (2004) reported on five variables that had an impact on student achievement in online schools, "grade level, school type, content area, the qualifications of the teacher in the teaching field, and the setting of the students" (p. 19). The study concluded that "teacher effectiveness is a strong determiner of differences in student learning" (p. 20) compared to other factors listed above that may impact student success. It is becoming clear that teacher effectiveness has a significant impact on student success according to the literature reviewed. What became significant about continuing the study is searching the literature for ways in which teachers can be the most effective in online settings.

Additional articles provide further evidence of the importance of top quality teachers in K-12 online schools. In a nationwide survey of administrators by Sloan Consortium led by Picciano and Seaman (2009), it was reported that a key to the future success of online learning was "well trained online instructors" (p. 15). Well trained would mean that the online teacher had previous online experience or specialized college coursework in how to teach online. In their meta-analysis, R. Smith et al. (2005) pointed 
out that highly qualified online teachers are a critical element in the implementation of effective online programs. Based on their report it would be easy to make the case that without top quality online teachers nothing else matters. Watson et al. (2011) continued to say that "successful student outcomes derive from a successful classroom experienceregardless of whether that classroom is in a brick-and-mortar or online environment" (p. 36). They added that, "online and blended teaching also requires additional skills that should be identified and developed" (p. 36). Barrett (2010) further emphasized that “Online instructors must have a different type of skills sets in order to compete in today's online learning environment" (Barrett, 2010, p. 18). These skills are listed in Table 2 after further synthesizing of the literature. At this point the literature is clear that for online programs to be successful they must have highly trained and qualified instructors at the core of the program. Therefore the most important step in building a quality online program should be to hire effective teachers who are able to demonstrate they have mastered the desired skills for online teachers.

\section{Table 2}

\section{Brick-and-Mortar Versus Online Teaching Skills}

Brick and Mortar Teaching Skills Online Classroom Teaching Skills

Classroom Management

Procedures

Behavior Management

Safety

Respect/Rapport
Online Classroom Management

Technology Support

Ability to use technology to facilitate learning Monitor online participation

Troubleshoot Access to online classroom 
Table 2 (continued)

\begin{tabular}{|c|c|}
\hline Brick and Mortar Teaching Skills & Online Classroom Teaching Skills \\
\hline Delivery of Content & Delivery of Content \\
\hline Understanding Students & Rich use of media to meet individual student needs \\
\hline Teaching Pedagogy & Personality in delivery \\
\hline Instructional Design & Discussion and Feedback \\
\hline Engagement & Collaboration \\
\hline Curriculum Design & Curriculum Design \\
\hline CCSS/Alignment & iNACOL Best Practices \\
\hline Breadth/Depth & Use of technology \\
\hline Scope and Sequence & Applications/Extensions \\
\hline Mastery of Technology & Mastery of Technology \\
\hline Elmo/Doc Cam & Website/HTML \\
\hline Power Point & $\mathrm{B} \log \mathrm{s}$ \\
\hline Blogs & SIS/LMS Proficiency \\
\hline Websites & Online Meeting/Classroom \\
\hline Smart Board & Multiple Communication Platforms \\
\hline PBL & Project Based Learning \\
\hline Applications of Learning & Online Collaboration \\
\hline Hands-On Activities & Posting/Blogging/Discussion \\
\hline Labs/Projects & Building Online Portfolios \\
\hline Connection to real world & Create and post projects \\
\hline Professional Responsibilities & Professional Responsibilities \\
\hline Records & iNACOL/Organizational involvement \\
\hline Communication & Mass data management \\
\hline Conferences & Communication via Multiple Platforms \\
\hline Education & Online Learning Training \\
\hline Training & Online Learning Certificates \\
\hline
\end{tabular}

Top quality teachers working in a program that is well designed increases opportunities for improvement in student achievement. Carefully designed online 
environments may have the ability to increase student access to courses, increase the flexibility of teaching and learning opportunities, and open the doors to new learning methods (Owston, 1997). According to the National Education Association (2003) and Watson et al. (2011) before online programs are built, administrators or program developers should ensure they have a shared vision, available technology infrastructure and support, carefully designed and built curriculum, a system for accountability and evaluation, a plan for solid support systems such as special education and admissions, and a commitment to student centered learning. Each of these suggested factors can be built or maintained by top quality staff. For example, the curriculum in top quality programs will be heavily influenced by teachers as they implement the program. In addition to influencing curriculum design, top quality teachers will assist in developing a program that has direct feedback, student centered learning, and opportunities to collaborate (Cavanaugh et al., 2004; R. Smith et al., 2005). Effective online environments have elements that are significantly influenced by teachers, such as communication between students and teachers - both asynchronous and synchronous. Online teachers also play a key role in building an online presence that is maintained throughout a course by one or more teachers. Effective teachers regularly assess online students both through summative and formative feedback that is timely and personalized to each student. Courses and instructors must be evaluated by principals and observed by peers to promote best practices. Finally online courses should leverage available technologies and technology support to build courses that are student centered and emphasize collaborative learning. Every one of these factors is influenced by top quality teachers. Based on the literature available, one could easily make the case that without top quality online staff 
further program development may not be as successful. Success in online schools starts with finding the best teachers possible.

While top quality teachers are important in online schools, there is a disconnect between teacher preparation and placement. "Many of the teachers currently teaching in online environments lack both the theoretical and practical understanding and are 'learning on the job,' and they are 'often overwhelmed by the enormity of the enterprise"” (R. Smith et al., 2005, p. 59). While teacher quality is clearly an important issue in the implementation of K-12 online settings, there appear to be issues in training and availability of experienced K-12 online teachers. Quality online teaching is clearly important for online schools to be successful, yet many teachers are under trained and overwhelmed. Consequently administrators of online programs need to become experts at finding and supporting top quality candidates to avoid excessive remediation and training upon hire (R. Smith et al., 2005). Before administrators can begin to locate and hire the best online teachers, there is a need to establish criteria and indicators of quality online teaching. In the next section, the literature began to separate out the qualities of brickand-mortar teaching skills versus online teaching skills.

\section{Brick-and-Mortar Versus Online Instruction}

In review of the literature and development of this research study, it became important to clearly define the differences between brick-and-mortar and online instruction carefully focusing on what makes a great online teacher. In a recent article by Burns (2013) an excellent point is made in saying that:

As anyone who has been a teacher knows, teaching well in a facto-to-face environment is hard, but I would argue that teaching well online is even harder. A good online teacher must enact all of the above skills-but she must do it through 
technology-and she faces challenges that elude face-to-face teachers because everything is different online. Communication is different, instruction is different, assessment is different, the social dynamic is different, and learning is different. (p. 2)

Great instruction is critical in both brick-and-mortar and online schools but part of this study was to clearly defining what skill sets are unique to online learning. Burns (2013) has provided a great analogy in her article that states classroom teachers are like Fred Astaire and online teachers are like Ginger Rogers, "they have to do everything Astaire does-but backwards and in high heels" (p. 2). Online teachers generally have to have already mastered great classroom teaching to be able to take great teaching schools into the online world. While some skills transfer over, others do not. Table 2 was helpful in developing the difference between the two environments. On the left are skills that classroom teachers need to manage, the column on the right assumes the teacher has already mastered the column to the left and must also master the skills on the right. The classroom teaching skills were taken from Danielson and McGreal's (2000) highly used continuum of teacher effectiveness while the online skills were taken from the literature reviewed in this study.

Now that it is clear that online teachers need to master additional skills beyond classroom instruction it is important to take more time exploring those important skills. The relevance to this study is to ensure online school administrators will be able to identify these top quality teaching skills during the recruitment and hiring phases to ensure they have the most effective teachers in their schools. 


\section{Characteristics of Top Quality K-12 Online Teachers}

When hiring top quality online teachers, the hiring team needs to begin with a thorough understanding of what characteristics they are looking for. Instruction is different in an online environment and high quality teaching is essential for student success. Organizations such as iNACOL (International Association for K-12 Online Learning), Boise State University and the National Education Association (NEA) have been working for the last 10 years to define quality online teaching. To provide a background regarding the skills needed for online teachers, literature first be reviewed from the iNACOL national quality standards. Next, a survey series from Boise State University was considered because they conducted a survey series that is often cited by online learning authors and is quite popular in the field. Finally, the NEA Guide for Online Teaching was analyzed as the NEA is often seen as a guiding force in K-12 education standards and practices. In conclusion, the literature from these three sources was analyzed and synthesized to create a list of desired qualities hiring teams can easily identify in the hiring process.

\section{iNACOL National Quality Standards for K-12 Online Teaching}

In 2011 iNACOL (Treacy et al., 2011) released a fully redesigned set of national quality standards for K-12 online teaching that has provided a foundation for defining teacher quality for online schools around the nation. These standards have been a driving force in the development of courses and programs nationwide since their original release in 2008 (Watson et al., 2011). Having a thorough understanding of the standards would provide a solid foundation for hiring teams looking top quality candidates. Table 3 
presents selections from the standards to demonstrate what online teachers should know

and be able to do.

Table 3

Summarized National Standards for Quality Online Teaching

\begin{tabular}{|c|c|c|c|}
\hline Standard & Knowledge & The online teacher is able to... & In my experience \\
\hline $\begin{array}{l}\text { A: Understands } \\
\text { Effective } \\
\text { Online } \\
\text { Instruction }\end{array}$ & $\begin{array}{l}\text { "The teacher understands } \\
\text { current best practices in } \\
\text { online teaching." (p. 4) }\end{array}$ & $\begin{array}{l}\text { "apply the current best } \\
\text { practices and strategies in } \\
\text { online teaching to create rich } \\
\text { and meaningful experiences } \\
\text { for students" (p. 4) }\end{array}$ & $\begin{array}{l}\text { I challenge each of our } \\
\text { teachers to keep up with } \\
\text { current trends through } \\
\text { conferences and } \\
\text { continuing education. }\end{array}$ \\
\hline $\begin{array}{l}\text { B: Able to Use } \\
\text { a Range of } \\
\text { Technologies }\end{array}$ & $\begin{array}{l}\text { "The online teacher is able } \\
\text { to select and use a variety } \\
\text { of online tools." (p. 5) }\end{array}$ & $\begin{array}{l}\text { "effectively use and } \\
\text { incorporate subject specific } \\
\text { and developmentally } \\
\text { appropriate technologies, } \\
\text { tools, and resources" (p. 5) }\end{array}$ & $\begin{array}{l}\text { Teachers in our } \\
\text { program use a variety of } \\
\text { technology every day } \\
\text { that is always changing. }\end{array}$ \\
\hline $\begin{array}{l}\text { C: Teachers } \\
\text { Uses Strategies } \\
\text { to Encourage } \\
\text { Active } \\
\text { Learning }\end{array}$ & $\begin{array}{l}\text { "The online teacher is able } \\
\text { to use student centered } \\
\text { instructional strategies." } \\
\text { (p. 6) }\end{array}$ & $\begin{array}{l}\text { "use student centered } \\
\text { instructional strategies that are } \\
\text { connected to real-world } \\
\text { applications to engage students } \\
\text { in learning (e.g. peer based } \\
\text { learning, inquiry based } \\
\text { activities, collaborative } \\
\text { learning, discussion groups, } \\
\text { self-directed learning, case } \\
\text { studies, small group work, and } \\
\text { guided design" (p. 5) }\end{array}$ & $\begin{array}{l}\text { Our entire program is } \\
\text { based around students } \\
\text { each having a } \\
\text { personalized learning } \\
\text { plan. Each student is } \\
\text { given diagnostic tests } \\
\text { and assigned classes } \\
\text { that help them at their } \\
\text { own unique } \\
\text { developmental level. }\end{array}$ \\
\hline $\begin{array}{l}\text { D: Student } \\
\text { Feedback and } \\
\text { Instructions }\end{array}$ & $\begin{array}{l}\text { "The online teacher is able } \\
\text { to use effective } \\
\text { communication skills with } \\
\text { students." (p. 7) }\end{array}$ & $\begin{array}{l}\text { "provide prompt feedback, } \\
\text { communicate high } \\
\text { expectations, and respect } \\
\text { diverse talents and learning } \\
\text { styles" (p. 7) }\end{array}$ & $\begin{array}{l}\text { Student feedback is } \\
\text { critical through video } \\
\text { conferencing, written } \\
\text { feedback or rubric } \\
\text { based systems so that } \\
\text { students know what } \\
\text { they did wrong and } \\
\text { what they need to } \\
\text { adjust. }\end{array}$ \\
\hline
\end{tabular}


Table 3 (continued)

\begin{tabular}{|c|c|c|c|}
\hline Standard & Knowledge & $\begin{array}{l}\text { The online teacher is able } \\
\text { to... }\end{array}$ & In my experience \\
\hline $\begin{array}{l}\text { E: Ethical Use } \\
\text { of Technology }\end{array}$ & $\begin{array}{l}\text { "The online teacher is able } \\
\text { to establish standards for } \\
\text { student behavior that are } \\
\text { designed to ensure } \\
\text { academic integrity." (p. 9) }\end{array}$ & $\begin{array}{l}\text { "identify the risks and } \\
\text { intervene in incidents of } \\
\text { academic dishonesty for } \\
\text { students" } \\
\text { "provide resources for } \\
\text { students related to } \\
\text { intellectual property and } \\
\text { plagiarism" (p.9) }\end{array}$ & $\begin{array}{l}\text { Teachers are given a lot of } \\
\text { latitude with technology } \\
\text { outside of a school } \\
\text { building. Ethical use of } \\
\text { technology is critical for } \\
\text { students to be successful. }\end{array}$ \\
\hline $\begin{array}{l}\text { F: Teacher } \\
\text { Cognizant of } \\
\text { Diversity }\end{array}$ & $\begin{array}{l}\text { "The online teacher is able } \\
\text { to monitor student progress } \\
\text { and apply activities and } \\
\text { tools that are relevant to } \\
\text { the needs of all students." } \\
\text { (p. 10) }\end{array}$ & $\begin{array}{l}\text { "demonstrate awareness } \\
\text { of different learning } \\
\text { preferences, diversity, and } \\
\text { universal design } \\
\text { principles" } \\
\text { "identify students who are } \\
\text { struggling with various } \\
\text { learning obstacles" (p. 10) }\end{array}$ & $\begin{array}{l}\text { Monitoring student } \\
\text { progress takes about } 30- \\
40 \% \text { of our instructional } \\
\text { staff's week to ensure } \\
\text { students are being } \\
\text { successful in their } \\
\text { learning pathway. }\end{array}$ \\
\hline $\begin{array}{l}\text { G: Student } \\
\text { Assessment }\end{array}$ & $\begin{array}{l}\text { "The online teacher is able } \\
\text { to create and implement } \\
\text { assessments in online } \\
\text { learning environments in } \\
\text { ways that ensure validity } \\
\text { and reliability of the } \\
\text { instruments and } \\
\text { procedures." (p. 11) }\end{array}$ & $\begin{array}{l}\text { "create and implement } \\
\text { assessments in online } \\
\text { learning environments in } \\
\text { ways that ensure validity } \\
\text { and reliability of the } \\
\text { instruments and } \\
\text { procedures" (p. 11) }\end{array}$ & $\begin{array}{l}\text { Our teachers all use a } \\
\text { variety of assessment } \\
\text { techniques to ensure } \\
\text { authenticity of student } \\
\text { work. }\end{array}$ \\
\hline $\begin{array}{l}\text { H: Standards } \\
\text { and Goals }\end{array}$ & $\begin{array}{l}\text { "The online teacher is able } \\
\text { to create, select, and } \\
\text { organize the appropriate } \\
\text { assignments and } \\
\text { assessments, and align } \\
\text { curricular content with } \\
\text { associated and standards- } \\
\text { based learning goals." (p. } \\
\text { 12) }\end{array}$ & $\begin{array}{l}\text { "create, select, and } \\
\text { organize the appropriate } \\
\text { assignments and } \\
\text { assessments, and align } \\
\text { curricular content with } \\
\text { associated and standards- } \\
\text { based learning goals" (p. } \\
\text { 12) }\end{array}$ & $\begin{array}{l}\text { When building curriculum } \\
\text { or student learning plans, } \\
\text { it is important that } \\
\text { teachers understand goal } \\
\text { setting and how they can } \\
\text { be used to help students } \\
\text { be successful. We set two } \\
\text { week goals with every } \\
\text { student and revisit them } \\
\text { regularly. }\end{array}$ \\
\hline $\begin{array}{l}\text { I: Data to } \\
\text { Modify } \\
\text { Instruction }\end{array}$ & $\begin{array}{l}\text { "The online teacher is able } \\
\text { to use student data to plan } \\
\text { instruction." (p. 13) }\end{array}$ & $\begin{array}{l}\text { "use observational data } \\
\text { (e.g. tracking data in } \\
\text { electronic courses, Web } \\
\text { logs, e-mail) to monitor } \\
\text { course progress and } \\
\text { effectiveness" (p. 13) }\end{array}$ & \\
\hline
\end{tabular}


Table 3 (continued)

\begin{tabular}{|c|c|c|c|}
\hline Standard & Knowledge & $\begin{array}{l}\text { The online teacher is able } \\
\text { to... }\end{array}$ & In my experience \\
\hline $\begin{array}{l}\mathrm{J}: \\
\text { Professionalism }\end{array}$ & $\begin{array}{l}\text { "The online teacher } \\
\text { knows and understands } \\
\text { the need for professional } \\
\text { activity and collaboration } \\
\text { beyond school." "The } \\
\text { online teacher knows and } \\
\text { understands the need to } \\
\text { coordinate learning } \\
\text { experiences with other } \\
\text { adults involved in } \\
\text { providing support to } \\
\text { student (e.g. parents, local } \\
\text { school contacts, mentors) } \\
\text { to support student } \\
\text { learning." (p. 15) }\end{array}$ & $\begin{array}{l}\text { "The online teacher is } \\
\text { able to engage in } \\
\text { professional development } \\
\text { activities and } \\
\text { collaboration beyond } \\
\text { school. The online teacher } \\
\text { is able to provide ongoing } \\
\text { communication with } \\
\text { parents or guardians } \\
\text { concerning student } \\
\text { learning." (p. 15) }\end{array}$ & $\begin{array}{l}\text { Online teachers are } \\
\text { representing our school in } \\
\text { families' homes, at } \\
\text { libraries, and other public } \\
\text { forums. It is critical that } \\
\text { they represent the school } \\
\text { in a professional fashion. } \\
\text { You can often see our } \\
\text { staff in public places and } \\
\text { doing a great job. This has } \\
\text { resulted in students } \\
\text { signing up for our school } \\
\text { on the spot. } \\
\text { Professionalism is critical. }\end{array}$ \\
\hline
\end{tabular}

Source: Treacy et al. (2011)

The iNACOL standards provide hiring committees a foundational look at what online teachers need to know and be able to do. It is important for a hiring committee to know how these skills are unique to online settings. Candidates may have great classroom skills, but they may not be transferable or have similar applications in an online environment (Watson et al., 2011). Therefore, it is critical for hiring teams to be uniquely aware of the unique skills online teachers should have. In the next section the skills in Table 3 was analyzed on a deeper level to continue to develop an understanding of the skills of top quality online teachers.

Online teachers, more so than classroom teachers, need to be masters of communication over many of the other skills important for online teachers (Barrett, 2010; Watson et al., 2011). In many of the standards in Table 3, communication is a key component to the factors emphasized, such as progress monitoring (reviewing student progress toward goals), delivery of instruction, working on student goals, and feedback. There are many reasons why communication is important for online teachers, but perhaps 
the most important reason is that younger K-12 students need a strong relationship with their teacher to be successful in an online school. Cavanaugh et al. (2004) pointed out that younger K-12 online learner's need clear and personalized instructions and support to be successful in online schools. Therefore, online teachers need to master effective communication to effectively meet the needs of younger K-12 online students. Without mastering online communication skills students will feel isolated and lack the self-control or direction to be successful in their studies. By using a variety of communication tools effectively, a top quality online teacher can use technologies such as Skype, texting, video messages, phone calls, online blogs, online presentations, digital tutoring, classroom discussion boards, emails, and classroom messaging tools to provide their students with robust and thorough communication (Watson et al., 2011). Effective communication from an online teacher can help build relationships, support instruction, offer tutoring, identify struggling students, provide interventions, connect to additional support, and help students be more successful. In communication with students, online teachers should build an ongoing relationship that fosters higher order thinking skills, independence in learning, creativity, and authenticity (Treacy et al., 2011). Since students in online schools will often be working in asynchronous environments (no direct contact with a teacher during instruction), students need focused communication at the right time to guide the learning and offer the support they need to be successful (Bernard et al., 2004; Cavanaugh et al., 2004). Finally, a critical communication skill in online schools is providing students with rich, meaningful, and timely feedback. Quality feedback from online teachers is critical to student success. Without timely quality feedback students may be stuck on a topic for days until they know what is needed to modify or relearn lesson objective (Bernard et al., 2004). 
In addition to communication, online teachers need to master current technology and also demonstrate the ability to quickly learn new technology. Table 3, standard B says., "The online teacher is able to select and use a variety of online tools" (Treacy et al., 2011, p. 5). Technology changes so fast top quality online teachers have to be quick to learn new concepts and incorporate them in their practice. Top quality online teachers should constantly update their technology tools and never settle into any one technique or tool as they will most likely change or improve (Cavanaugh et al., 2004). Proper use of technology by master teachers when combined with other factors such a good course design will enhance instruction (Cavanaugh et al., 2004). Poor quality online instruction will not fully utilize all of the media and instructional technology possible today and student learning may be impacted. "Just putting the word 'virtual' in front of the word 'school' doesn't make it good, bad, or even innovative anymore. What matters is the school's ability to educate children" (Greenway \& Vanourek, 2006, p. 41). In the same way putting a textbook online and having student's click through is not using technology properly. The best online teachers use a variety of methods, blending in multi-media technology such as pre-recorded labs and lectures, podcasts of researchers or important figures, links to supplements and interventions, and use technology to constantly monitor student learning (Watson et al., 2011). Technology is a tool that online teachers can use to effectively deliver and support both asynchronous and synchronous instruction. When used in a thoughtful combination, communication and technology skills will enhance and support student success in online schools.

Instructional design and curriculum delivery come second only to communication and technology with regard to the skills of online teachers. In table 3 instructional design 
is described as the online teacher's ability to use student data in instruction, e.g., the ability to create and implement ongoing formative and summative assessments using student centered strategies, and their ability to apply the best practices in online instruction (Treacy et al., 2011). R. Smith et al. (2005) and Bernard et al. (2004) both reported that courses that are designed to include multiple methods of interaction and communication will help students be more successful. By giving students more of a chance to interact with their teachers and other students they are able to synthesize, discuss, and analyze their learning on a deeper level leading to long-term retention of material (R. Smith et al., 2005). In an online setting versus a brick-and-mortar classroom instructional design becomes more important especially in asynchronous settings. In asynchronous courses, the student is interacting solely with the curriculum with no support from the teacher (Bernard et al., 2004). For this reason, especially in K-12 settings where students have a lower threshold for self-control than adult learners, quality instructional design will have an impact on student success (Cavanaugh et al., 2004). The learning delivered by a master online teacher should be appropriate to the student's learning level and tied to regularly communicated goals (Barrett, 2010; Cavanaugh et al., 2004). Online teachers must provide multiple assessment techniques to encourage authenticity of student work, and they must use data to shape future instructional experiences for students (Holstead et al., 2008). Constant progress monitoring and assessment is critical for online teachers in instructional design because it allows the teachers to truly personalize the learning and make sure the student is being successful in their courses. An online teacher has the ability to offer each student their own unique curriculum pathway using a variety of core and supplemental online programs. Fully 
utilizing the nature of self-paced personalized learning in K-12 online classrooms takes a master online teacher (Greenway \& Vanourek, 2006). The true potential of K-12 online learning can only be met with the best possible candidates for online teaching jobs.

From the iNACOL standards it is clear that online teachers must be masters of communication, technology, as well as instructional design and delivery. The literature reviewed thus far shows the overwhelming importance of quality teachers in online schools and has begun to provide details about what quality online instruction looks like. Further clarification of quality online instruction will be achieved by adding in literature from Boise State University and the NEA. Both of these sources add to the foundation of iNACOL's quality standards. I believe that for online programs to be successful they must properly identify and recruit teachers that demonstrate the unique skills sets being identified in this review (Barr \& Parrett, 2007; Watson et al., 2011). Hiring teams need to carefully understand findings from the extant literature to make informed personnel

decisions. The following section describes and analyzes research studies from Boise State University to add depth to the growing description of quality online instruction.

\section{Boise State University Survey of Current K-12 Online Teachers}

Boise State University studies focus specifically on the current demographics, professional development needs, and levels of preparation of online teachers across the nation. This survey studies provide greater depth about defining quality online teachers by capturing important data from the current K-12 online teaching force. The series, called Going Virtual, was conducted in 2008 and 2010. Drs. Dawley and Rice from Boise State University led a nationwide survey of over 900 K-12 online teachers (Dawley et al., 2010; Rice et al., 2008). Both surveys examined K-12 online teachers and their unique 
needs and challenges. The 900 surveyed teachers provided a cross section of instructors who are currently in the online education field and shared characteristics hiring teams might want to look for. These characteristics are important for hiring committees to identify in candidates applying for online teaching positions. Hiring committees can combine the standards in Table 3 with characteristics that emerge from the Boise State University series to continue to further understand the skills needed for quality online teaching. Below, the survey series was carefully analyzed to discover trends and patterns within the current field of online teaching.

First, the surveys revealed that current online teachers are mostly experienced in both online and brick-and-mortar settings. $56 \%$ of current online teachers surveyed as of 2010 have six to 15 years of experience with an additional 24\% reporting more than 16 years (Dawley et al., 2010). Most of the teachers surveyed with experience had a mix of classroom and online experience. "The majority of respondents have been online teachers from one to five years (69\%)" in addition to previous experience (p. 17). Fifty-three percent of the online teachers with 10 or more years of experience online had 20 or more years in the education profession while $20 \%$ had $16-20$ and $25 \%$ had $10-15$ (p. 17). For hiring purposes it is incredibly significant that more than $80 \%$ of online teachers have more than six years of experience, and a good portion of that experience was completed online. Based on this information, hiring teams should look for teachers with experience in online settings or applicable classroom experiences. Applicable classroom experience would be operating a flipped classroom (where the lecture occurs online through cloud technology and discussion/application occurs in the classroom), or the utilization of blogs, websites, sharing resources, social media, or other heavy use of technology in the 
classroom (Goodwin \& Miller, 2013). Teachers with previous experience in online settings will require less training and already have a foundation of online learning pedagogy (Watson et al., 2011). Experienced online teachers will be able to build on their foundation of theoretical and practical knowledge to learn the specifics of the program rather than burning valuable professional development time learning both theory and practice (R. Smith et al., 2005).

Second, the survey series revealed important information about levels of professional development and training within the field of K-12 online teachers. Ninetyfour percent of the respondents reported receiving professional development and ongoing training at their local site, program or school (Dawley et al., 2010). Since most of the current online teachers are receiving training at their program, this means that local administrators will be largely responsible for building the next generation of online teachers. As reported in R. Smith et al. (2005) many current online teachers are learning on the job. Administrators need to take careful note and not only build time for training into their schools but also find candidates who need less foundational training. If a candidate comes into the school with two to three years of successful experience in another online program, they need less basic training and will be able to pick up the program specifics and begin teaching immediately. To avoid unnecessary training, administrators should search for candidates with experience, training, and the ability to quickly learn. Online teachers should not be resistant to change since future professional development and training will continuously evolve with advancements in technology (Bernard et al., 2004). 
Since much of current online training is happening at the school program level, university teacher-training programs have been playing catch-up with K-12 online learning. Very few new online teachers $(12 \%)$ reported receiving any training at a college or university focusing online pedagogy (Dawley et al., 2010). On the other hand $43 \%$ of online teachers with more than six years of experience online reported completion of additional training through universities. It can be observed that the longer a teacher remains in online settings, the more their professional development and formal training increases, thereby making them a valuable asset to their school. Online teachers appear to be seeking college training and certification programs as they become available during their time in online schools. Cavanaugh et al. (2004) would argue that, overtime professional development opportunities, university training, and certification programs will increase over time. Currently, teachers with specific training in online learning theory are rare (12\% of new teachers and $43 \%$ of experienced teachers) and unique, making them attractive candidates for online positions. Some universities that are leading the way in providing continuing education courses in online teaching pedagogy accessible in the Pacific Northwest Region are: Portland State University, Concordia University, and Grand Canyon University. Nationally other programs offer full certification programs such as the University of Wisconsin Stout and Madison that offer a graduate certificate in E-Learning (University of Wisconsin-Madison, 2011; University of Wisconsin-Stout, 2013). Online learning is such a specific teaching skill that teachers need specific training in how to be most effective online. Universities are currently meeting this need through specific programs that focus entirely on how to teach online through a certificate or continuing education process (Burns, 2013). Graduates of these 
programs who are able to demonstrate their skills in the interview process would be a great addition to a K-12 online school.

Finally, it is important to note that most teachers (53\%) preferred fully online trainings and blended face-to-face/online workshops (49\%) for their ongoing training opportunities (p. 8) (Dawley et al., 2010). An online workshop would most likely be synchronous with instructional leaders and teachers in an online classroom going over professional development topics. A blended meeting might include some online videos and instructional materials with some amount of face to face time spent as well. Online administrators need to leverage the benefits of face-to-face time for discussions, collaborations, team building and other events best done face-to-face. On the other hand, they should use online technology to record training sessions for viewing online or meet in an online classroom to host meetings. Based on this survey the manner in which teachers prefer their professional development is important for administrators to consider in order to be able to best support their teachers. When online administrators are developing induction programs, this information can be used to generate opportunities that align with the desires of online teachers. Administrators in the hiring and induction processes should consider using online tools to interact with candidates and support their transition into online schools. Orientation programs, pre-screening events, and other processes in the online staffing program should use online technologies (Watson et al., 2011). Some examples from my experience would be an online support cohort where I load important links, demonstration videos, and links to other training programs. These are best handled using an online platform. When I meet in person with my staff, I have to be very intentional about our time together as it takes significant resources to gather my 
team from all over Oregon. Face-to-face times are used for building consensus around our mission and vision, team building, professional development/training, reflection on progress, and celebrations of success. Using that knowledge base, a hiring team should consider using technologies teachers use in their daily jobs in the hiring process. Having to use the technology in the hiring process will give the team a chance to see how the candidates will handle the technology. For example if a school uses "Blackboard Collaborate" or "Go-To-Meeting," they should host a part of the interview in those settings. This hands-on approach will test the candidate's comfort level with the technology and also display their online personality for the hiring committee. Teachers may be asked to record course sessions or host live classes in an online school. The team will want to see the teacher in action in a synchronous environment in order to gauge how they would connect with students online. Face-to-face time in the hiring and induction process should be leveraged for the most important activities like interviews, collaboration with peers, or synchronous instruction (Dawley et al., 2010).

In summary, the Boise State University survey series presents several key findings that can inform administrators during the recruitment, hiring, and induction process. Experienced online teachers are trained at the program level, new teachers receive little training from their universities, and the more experienced teachers take advantage of the university system over time and prefer online training (Dawley et al., 2010; Rice et al., 2008). This information is important for the recruitment, hiring, and induction of new online teachers. 


\section{NEA Guide to Online Courses}

Building on the foundation of the iNACOL standards and the Boise State

University survey series, the NEA has developed a guide for assessing online teaching. Similar to iNACOL the NEA has developed a rubric-based continuum for K-12 online teachers. This guide, when combined with the previous two sources, continues to build the hiring team's understanding of what quality teaching looks like online. The NEA guide emphasis is on the instructional components of the online teacher, so selections from this rubric only include elements not discussed in the first two sources. Table 4 offers selections from the NEA rubric on quality online instruction.

Table 4

Selections From NEA Guide to Teaching Online Courses

\begin{tabular}{ll}
\hline Criteria & Description \\
\hline Revise/write course & "Online teachers should be able to \\
documents in CMS & make appropriate use of the CMS \\
& (Content Management Systems) \\
& platforms features, producing \\
& documents that are well organized \\
& for use by students and that are kept \\
& up-to-date during course delivery." \\
& (p. 15)
\end{tabular}

Use CMS elements effectively to facilitate course design

Design, evaluate and deliver online course to appropriate online design and content standards
Online teachers need to be fully aware of the CMS elements and how they can be used to enhance instruction.

Teachers should keep their online courses up to date and accurate. Curriculum should be continuously reviewed and updated as needed to stay current.
In My Experience

We currently use Canvas, a CMS program that teachers can use to build content, host discussions, post finals, and have announcements for the classes they teach. My best teachers are those that quickly learned the system and were able to produce teacher created content over the summer or during their busy lives as teachers in a virtual charter school.

Within our CMS, teachers need to effectively leverage how students learn to break content into comprehensible sections.

Since all of our content is web based, it is continuously updated and I provide stipends to teachers each summer to develop content. 
Table 4 (continued)

\begin{tabular}{|c|c|}
\hline Criteria & Description \\
\hline $\begin{array}{l}\text { Communicate an } \\
\text { appropriate online } \\
\text { tone during course } \\
\text { delivery }\end{array}$ & $\begin{array}{l}\text { "Because online communication } \\
\text { may lack the full array of visual and } \\
\text { oral clues that help the listener } \\
\text { interpret the speaker's messages, it } \\
\text { is important online teachers be } \\
\text { sensitive to problems of } \\
\text { misinterpretation, and that they are } \\
\text { careful to use an appropriate online } \\
\text { tone in course design and course } \\
\text { delivery." (p. 16) }\end{array}$ \\
\hline $\begin{array}{l}\text { Foster student to } \\
\text { student discussion }\end{array}$ & $\begin{array}{l}\text { "Online teachers should foster } \\
\text { student-student discussion during } \\
\text { course design and delivery." } \\
\text { "During course delivery, online } \\
\text { teachers should facilitate course } \\
\text { discussion by intervening } \\
\text { appropriately when discussions are } \\
\text { either not occurring or are } \\
\text { inappropriate." (p. 17) }\end{array}$ \\
\hline
\end{tabular}

Provide appropriate and timely feedback to students

Be present online
"Online teachers should monitor student learning and provide students with feedback on their performance." "They should review submitted work in a timely fashion (usually within one week of submission) and should provide students with feedback." (p. 17)

"It is vitally important that online teachers be active and regular participants in their classes. They should take part in class discussion, review submitted work promptly, respond to student questions on a regular and consistent basis, and schedule online meeting times as needed." (p. 17)

Communicate with students, parents, school administrators, and other teachers via a variety of online and traditional means
Online teachers should be able to communicate with all necessary stakeholders using a variety of appropriate technology. They should be aware of the appropriate communication tools for one-on-one instruction versus. whole group instruction.

\author{
In My Experience \\ Teaching in my schools is not just \\ about teaching. It is about the \\ communication, organization, and \\ follow-up that comes after instruction. \\ Online teachers need to be masters of \\ communication through text, Skype, \\ curriculum messages, phone, email, \\ and blogging tools.
}

Student to student discussions are something we have been developing now that we have a CMS in place. Rich content-driven discussion can really unlock the potential of online education for K-12 students.

One of the biggest jobs for our teachers is to manage a caseload of 25-35 students that they visit with regularly to discuss progress and performance in each class the student is taking. Written reports are sent to the student and parent every two weeks at minimum.

Most of our teachers are signed up as students in their own classes so they can see the course from the student's angle and understanding, in order to determine how programs are tracking students through the course. Our best teachers respond rapidly and are consistent in their involvement with students.

All of our teachers use a plethora of communication devices and techniques to reach students, such as cell phone, iPads, discussion boards, phone calls, Skype, Blackboard Collaborate, email, announcements in classes, and curriculum messaging boards. 
Table 4 (continued)

\begin{tabular}{|c|c|c|}
\hline Criteria & Description & In My Experience \\
\hline $\begin{array}{l}\text { Provide students with } \\
\text { basic tech support } \\
\text { recognizing which } \\
\text { issues for forwarded to } \\
\text { technical support } \\
\text { teams }\end{array}$ & $\begin{array}{l}\text { Online teachers should be able to } \\
\text { provide basic tech support to ensure } \\
\text { student and parent success in online } \\
\text { schools such as posting discussions, } \\
\text { uploading assignments, using the } \\
\text { internet for research, and viewing } \\
\text { online grades. }\end{array}$ & $\begin{array}{l}\text { Each of our teachers is able to help a } \\
\text { student load a printer or driver device, } \\
\text { how to connect to wireless, and how } \\
\text { to operate web browsers for } \\
\text { optimization. In addition each teacher } \\
\text { continuously supports students' } \\
\text { understanding of the resources } \\
\text { available to them, and how to use } \\
\text { those resources for learning. }\end{array}$ \\
\hline
\end{tabular}

Additional details emerged from the NEA Guide to Teaching Online Courses about characteristics top quality teachers should demonstrate in the design and implementation of their online courses. These design and implementation elements will be critical for student success. The research-based literature analyzed showed that K-12 students will be more successful in courses that include elements in Table 4, such as: communication, feedback, support, personalization, and design (Cavanaugh et al., 2004; R. Smith et al., 2005). Skills that were selected from the NEA Guide to Online Courses add value and depth to previous literature. The skills listed in Table 4 can by categorized into two general categories: communication and implementation of online programs. These categories were analyzed in the next section and finally combined with the iNACOL standards and Boise State University survey series.

With regard to communication, the NEA Guide to Online Courses adds additional depth to what online teachers should focus on in their work. First of all, the NEA guide places special emphasis on the importance of timely, appropriate, and multi-media feedback to online students (NEA, 2003). The importance of feedback was also seen in 
the iNACOL standards (Treacy et al., 2011). However, the NEA guide provides specific timelines for feedback (approximately one week or less), and recommendations for participation in group discussions and being present online. By being constantly active in their feedback and involvement in the online course, teachers begin to build a collaborative and supportive environment that will help K-12 students be more successful (Cavanaugh et al., 2004). Communication should also be appropriate to the online setting and should foster connections between students. Each of these unique clarifications adds further depth to understanding how online teachers should communicate. From the literature analyzed, timely feedback is one of the top communication skills interview teams should look for in new candidates (Cavanaugh et al., 2004; NEA, 2003; Treacy et al., 2011). An interview team can easily discover the candidate's ability to provide feedback as the team communicates with the teacher during the interview process. How quickly do they return communication? Do they communicate with positivity and demonstrate flexibility? According to the NEA (2003) guide, the communication should be appropriate to the online setting. This means that teachers should carefully select words, images, and phrases to capture their true meaning "so that students are not confused when teachers make a joking reference and should quickly intervene if online dialogue turns disrespectful” (p. 16). The importance of making connections between students was also mentioned in previous literature. Dialogue between students in online settings provides opportunities for higher order thinking skills, critical thinking, social interactions, peer review, analysis of information, and synthesizing content (Bernard et al., 2004; Cavanaugh et al., 2004; R. Smith et al., 2005). Throughout the literature communication was heavily emphasized as a key component to student success in online 
schools in both the iNACOL standards and NEA guide (NEA, 2003; Treacy et al., 2011). Hiring teams need to able to assess effective online communication skills throughout the recruitment and hiring process in order to be absolutely confident their new teacher candidates can communicate effectively with students in an online environment. In addition to communication, the NEA guide also placed emphasis on specific skills teachers need to implement an online class. The rubric demands that online teachers have basic technology support skills with the ability to be able to pass on more difficult problems to the technology department. For example, not all teachers have the ability to know how to connect a computer to the internet or how to sign a student into an online class. Consequently, not all classroom teachers would be good candidates for online positions (Watson, Murin, Vashaw, Gemin, \& Rapp, 2011). Besides communication skills and technology savvy, the use of technology in instruction was noted as important in multiple sources. Interview teams should challenge candidates to demonstrate mastery of technology in the interview process by using the tools they will use as teachers such as Skype, Blackboard Collaborate or Go-To-Meeting (Barrett, 2010). In addition to technology support, teachers will need to carefully design and deliver their online content using all of the technology and resources available (NEA, 2003). In this aspect of the implementation of an online course, teachers need to leverage the technology available to keep the course active, engaging, and up to date. For example, links built into online courses will most likely need to be updated every semester or at the very least every year as information changes quickly in the online world. In the implementation of an online course, there is a vast array of skills teachers need to demonstrate, therefore when hiring for online positions, hiring teams need to find teachers who specialize in online 
instruction. Online instruction is so unique that not all skills will transfer. The following section synthesizes skills online teachers will need to demonstrate during the recruitment and induction phases.

\section{Synthesized List of Desired Qualities in New K-12 Online Teachers}

After analyzing the National Standards for Quality Online Teaching (iNACOL, 2011), the Boise State University (Dawley et al., 2010) survey series, and the NEA (2003) Guide to Online Courses, hiring teams can develop criteria and indicators to look for in their selection of teacher candidates. This type of information is synthesized in

Table 5, which combines the iNACOL (2011) standards, survey data from the Going Virtual series (Dawley et al., 2010; Rice et al., 2008), and the NEA Guide to Online Courses, to build a list of desired criteria and indicators for hiring online teachers.

Table 5

Desired Qualities in K-12 Online Instructors

\begin{tabular}{lll}
\hline Criteria & Indicators of Online Teaching Effectiveness & In my Experience \\
\hline Experience & - Previous successful online school experience & $\bullet$ My most successful teachers \\
& $\begin{array}{l}\text { - Classroom experience with relevant use of } \\
\text { technology, such as maintenance of a blog, } \\
\text { website, using online curriculum, or having a } \\
\text { flipped classroom }\end{array}$ & $\begin{array}{l}\text { before coming to our virtual } \\
\text { charter school. }\end{array}$ \\
& - Certification program completed at & \\
Training & University or School District Program Level & $\begin{array}{l}\text { Very few of my instructors } \\
\text { have had online training } \\
\text { courses. Those who have are } \\
\text { leaders and innovators in our } \\
\text { in online learning theory }\end{array}$ \\
& - College coursework in online pedagogy \\
& - Professional development opportunities in \\
& online learning &
\end{tabular}


Table 5 (continued)

\begin{tabular}{|c|c|c|}
\hline Criteria & Indicators of Online Teaching Effectiveness & In my Experience \\
\hline Communication & $\begin{array}{l}\text { - Ability to communicate in multiple platforms } \\
\text { to build relationships and monitor progress } \\
\text { such as Skype, text, blogs, discussion groups, } \\
\text { websites, or appropriate social media forums } \\
\text { such as Edmodo } \\
\text { - Organization with multiple lines of timely } \\
\text { communication and feedback. Candidates } \\
\text { should be able to have a Skype session going } \\
\text { with students while emailing their parents a } \\
\text { log of the communication, checking the } \\
\text { student's classes, and text with their } \\
\text { teammates all at the same time }\end{array}$ & $\begin{array}{l}\text { - Our teachers who excel are all } \\
\text { master communicators. Often } \\
\text { this was absolutely apparent } \\
\text { in the interview process. } \\
\text { Great candidates will call, } \\
\text { email, text, and easily Skype. }\end{array}$ \\
\hline $\begin{array}{l}\text { Use of } \\
\text { Technology }\end{array}$ & $\begin{array}{l}\text { Leverage existing technology such as Skype, } \\
\text { face time, Google Hangouts, Blackboard } \\
\text { Collaborate, Go To Meeting, texting, } \\
\text { messaging, blogging or building websites for } \\
\text { communication and instructional design } \\
\text { Ability to learn and adapt to new technology } \\
\text { quickly; not resistant to change }\end{array}$ & $\begin{array}{l}\text { Teachers are constantly } \\
\text { evaluating new technology } \\
\text { and bringing it to our team for } \\
\text { evaluation. } \\
\text { - We never sit still and never } \\
\text { stop learning. }\end{array}$ \\
\hline $\begin{array}{l}\text { Instructional } \\
\text { Design and } \\
\text { Delivery }\end{array}$ & $\begin{array}{l}\text { - Knowledge of pacing and student learning } \\
\text { patterns to build or manage appropriate } \\
\text { content to build custom online learning } \\
\text { pathways for students } \\
\text { - Knowledge of adjusting online curriculum to } \\
\text { unique student needs such as keeping in mind } \\
\text { the unique needs of K-12 students who need } \\
\text { more support and might demonstrate less } \\
\text { independence than postsecondary online } \\
\text { learners } \\
\text { - Effect use of multimedia components in } \\
\text { courses posted in CMS programs using } \\
\text { YouTube videos, live video feedback to } \\
\text { students, having the students build websites, } \\
\text { building and maintaining their own website } \\
\text { and home page, and using uploaded files or } \\
\text { smartphone photos for assessments and } \\
\text { projects } \\
\text { Using assessments to build personalized }\end{array}$ & $\begin{array}{l}\text { - Our teachers need to fully } \\
\text { understand all } 13 \text { curriculum } \\
\text { providers from whom we buy } \\
\text { content, as well as have the } \\
\text { ability to build their own } \\
\text { courses in our CMS. Teachers } \\
\text { need to be experts in using all } \\
\text { of the tools we have available } \\
\text { to build unique and individual } \\
\text { plans for students. My best } \\
\text { teachers have built amazing } \\
\text { courses on their own that are } \\
\text { supplemented by Khan } \\
\text { Academy online content, } \\
\text { include dynamic content } \\
\text { based discussions, and } \\
\text { challenge the student to } \\
\text { demonstrate mastery, not just } \\
\text { pass the quiz. }\end{array}$ \\
\hline
\end{tabular}
online course pathways according to the students unique needs as an online learner

The literature from Boise State University has shown there is a need for quality online teachers and has provided some useful information about the current field of 
online teaching. It is critical for hiring teams to thoroughly understand the importance of the above mentioned criteria, indicators, and practices to build a recruitment plan that will give candidates plenty of opportunities to demonstrate their effectiveness. As a hiring team moves into selecting candidates, they should rely on their previous experience with the hiring of traditional teachers combined with a knowledge and awareness of how online teaching qualifications are unique and distinctive. What differs from the traditional teacher selection process is a focus on online teaching criteria, indicators and practices. The following section reviews the literature focused on the recruitment of K-12 online teachers. There is very limited literature around this topic, but enough was identified to provide an initial basis of understanding.

\section{Recruitment Phase}

While there is limited literature specifically focused on the recruitment of online teachers, the traditional teacher-selection literature can be helpful in the recruitment process. Traditional resources such as the recruitment phase includes all the planning, preparation, and searching processes up to the actual interview (Peterson, 2002). For online teachers, the recruitment process should give candidates opportunities through the application, pre-interview, interview, and simulations to demonstrate they clearly have the specific skills online hiring teams are looking for. Online teachers must have different skills than classroom teachers. Table 5 above highlights these desired qualities: previous online teaching experience, college or program level online teaching training, communication skills, mastery of the use of multiple forms of technology, and mastery of online instruction design and delivery. Recruitment of online teachers should focus on identifying these unique skills, "interviewers and HR personnel must create and 
implement different practices and procedures in order to determine the best possible candidate for an online teaching position" (Barrett, 2010). Different procedures for online candidates should begin with a thorough understanding of the criteria, indicators and practices in Table 5, using the technology such as online job posting sites available in most states to find and sort through candidates who have skill indicators present on the online application. Recruitment and interview programs should challenge candidates to demonstrate their skills, rather than just responding to interview questions.

Identification of specific pre-service skills is critical to hiring new online teachers. Strong and Hindman (2003) indicated that hiring teams should look for candidates who have "coursework in pedagogy, knowledge about working with students of special needs, teacher certification, and content knowledge" (p. 49). Literature in previous sections has established that it is critical for hiring teams to seek online teaching candidates with as much theoretical and practical experience as possible. Teachers who have previous experience, training, or certificates in online learning theory are highly valuable to hiring teams (Dawley et al., 2010; R. Smith et al., 2005). Hiring teams can leverage technology to identify these skills through online applications, observing teacher webpages or online portfolios, college transcripts, and other items collected during the recruitment phase.

Stronge and Hindman (2003) suggested looking for candidates who have the caring attitude of a teacher, and this is equally important in hiring online teachers. In both the iNACOL standards and the Going Virtual series as well as the research reports from R. Smith et al. (2005) and Cavanaugh et al. (2004) it was apparent that online teachers need to be master relationship builders. Students in an online environment can feel isolated and lack the motivation to be successful if they do not have a positive 
relationship with their instructor (Cavanaugh et al., 2004). Therefore, it is important in the pre-screening process to identify online candidates who have built successful relationships with students during their pre-service or in-service experience. In the recruitment phase, online hiring teams should look at letters of reference from parents or students as indicators of a teacher's ability to build relationships with students. Secondly, reference letters from supervisors may demonstrate these skills as well. Additionally as mentioned above, often a teacher's personality and ability to build relationships comes across in the dialogue leading up to an interview. By the time the hiring team sits down and interviews a teacher they have often emailed, called, texted, and reviewed their online application. In written, verbal and non-verbal communications in the recruitment process the team has had an opportunity to get a strong feeling for the candidate's ability to communicate and build relationships.

Stronge and Hindman (2003) also recommended looking for candidates with strong classroom management skills. While these recommendations may not directly apply to online teachers, they do offer important information for consideration. For teachers who may work in a blended learning environment where face -to-face instruction is required, teachers need strong classroom management skills (Watson, 2008). Blended learning is growing in popularity around the nation and offers a combination of online learning and face- to-face instruction in a teacher facilitated computer lab (Holstead et al., 2008). Blended learning environments combine the best of face-to-face instruction with the best in online instruction, leveraging face-to-face time for discussion, tutoring, activities, and support while individual online learning may be completed at home away from the school building (Watson, 2008). Activities done at home are normally anything 
the program has designed to be asynchronous, meaning no live teacher to student connection. Asynchronous activities in online schools can be watching videos, reading content, doing virtual assignments, performing activities, researching projects, writing papers, or anything else the program has designed to be done independently. Classroom management skills would also remain important for teachers hosting synchronous courses where multiple students may be in an online classroom together. Teachers need to master communication and technology in this fast paced and interactive environment (Treacy et al., 2011). Therefore, hiring committees should work with candidates to observe them in action during the recruitment process. If the hiring team has the ability to receive recorded online classroom sessions, links from the teacher's webpage or other media sources, they should leverage those sources to assess the management skills of the candidate.

Furthermore, online teachers also need to understand the diverse needs of online students and how to meet those needs through modifications in curriculum (Treacy et al., 2011). Stronge and Hindman (2003) added that "effective teachers monitor learning and use their findings to adjust instruction" (p. 49). One of the most important tasks in online teaching is monitoring students' progress and adjusting curriculum as appropriate (Treacy et al., 2011; Watson et al., 2011). Therefore, new online teacher candidates should be able to demonstrate they have experience in modifying curriculum. By modifying the curriculum an online teacher will, "use student data to inform instruction, guide and monitor the student's management of their time, monitor learner progress with available tools, and develop and intervention plan for unsuccessful learners" (Treacy et al., 2011, p. 8). Teachers can explain times they have modified curriculum to meet individual 
needs, or perhaps bring in a sample lesson plan they have delivered. Hiring teams may search for the skills and practices listed in Table 5 when assessing resumes, online applications, letters of reference, or other evidence during the pre-interview process. The Stronge and Hindman (2003) article is helpful and could be modified to search for online candidates. The article provides a foundation of how all good teachers will modify curriculum to meet individual student needs.

Another helpful traditional teacher hiring resource that can be used for the selection of online teachers is Peterson's (2002) book, Effective Teacher Hiring: A Guide to Getting the Best. Peterson reported that no other task an administrator can do will make as lasting an impression as the, "quality of the staff he or she hires" (p. vi). Furthermore, Stronge and Hindman (2003) reported that nothing impacts student learning more than the overall quality of their teachers. Cavanaugh et al. (2004) and R. Smith et al. (2005) reminded us that high quality teachers are needed in online settings as well. The principle is the same online, the literature is clear; hiring quality staff is the most important task administrators can do. Peterson's book is one of the few books containing hiring strategies that would be incredibly helpful in recruitment of online teachers. Peterson suggested creating a teacher selection system that is comprehensive and multilayered. The system should:

Secure the best possible educators and meet district needs... involve all interested parties ... meet professional standards . . . be based on teacher role expectations derived from national professional standards . . . conform to legal requirements ... employ multiple and variable data sources and be subject to evaluation. (p. 8) Peterson's (2002) system mentioned above is thoughtful and could easily transfer to online environments. Peterson's system outlined above involves including all parties, 
meets hiring standards, is based on role descriptions, and collects multiple data sources, would be easy to follow, and online hiring teams could easily implement this plan as a basis for their hiring process. The literature concerning online teachers supports Peterson's system by reinforcing the importance of quality standards, ethics, using data to make decisions, quality instruction, and continuous improvement (Cavanaugh et al., 2004; Treacy et al., 2011; Watson et al., 2011). Hiring teams for online teachers could borrow from the traditional literature as a foundation and look to the online learning literature for specifics. For example Peterson suggested looking for the best possible educators. Hiring teams from online schools should use the list in Table 5 to identify candidates who represent these characteristics in the recruitment phase. Additionally, it was suggested that teams involve all parties. Online hiring teams should implement a staffing methodology that utilizes student/parent feedback, teacher involvement, support staff feedback, and other relevant sources to ensure that all parties are involved in the hiring process. An online school may involve a technology director or computer specialist to assess the mastery of technology for an online teacher candidate. Additionally, online hiring teams should look for teachers who demonstrate mastery of the iNACOL standards. Peterson suggested building a process that is based on teacher expectations and role descriptions. iNACOL and the NEA have taken the time to clearly define quality online teaching. Therefore, online hiring teams should leverage this work to quickly identify teachers who have the skills described earlier in Tables 2, 3, 4, and 5 . Finally, using multiple sources of data on a candidate is one of the strongest recommendations that Peterson made. For online hiring teams this means utilizing an array of technology in the interview process. The online application should be posted to 
statewide recruitment sources, school webpages, and potentially, local newspapers, with the goal of asking appropriate questions so that candidates with unique online teacher skills will apply for openings. Then hiring teams can begin to sort candidates based on their alignment to the iNACOL standards, modified standards in Table 5, and any local priorities (such as blended learning versus full-time online). Finally, in the interview process teams should require candidates to teach in online classrooms, participate in virtual meetings, and demonstrate applications of other technologies. Candidates who come in with a website built, a blog they have used, or evidence of technology used have a heads up on candidates without these skills. For each candidate applying to our school, either in support or instructional roles, I have them take a problem from our online curriculum and role play as though I were a student that is stuck, and give them an opportunity to demonstrate how they would help that student. It is a quick and easy way to observe their instructional paradigm, see them think on their feet, and how they would support online students.

Stronge and Hindman (2003) and Peterson (2002) provided a conceptual foundation hiring teams can rely on in the recruitment process beginning with prescreening candidates. Before the candidate interviews with the local hiring team, they should be one of the top 3-5 recruits out of a wide pool of candidates (Peterson, 2002; Stronge \& Hindman, 2003). Barrett (2010) suggested that online teacher hiring teams need to dig deep into online profiles and look for the specific online skills highlighted in Table 5. In many districts the central office or human resources personnel screen candidates (Stronge \& Hindman, 2003). However, in new virtual schools local administrators often fulfill many roles and are more involved in the hiring process 
(Campbell, Gross, \& Lake, 2008; Watson et al., 2011). Whoever is doing the screening needs to be familiar with the skills to look for in online candidates, and to consider widening the pool of candidates through leveraging technology (Barrett, 2010).

Pre-screening begins with the application process. By posting jobs in online statewide search databases, search teams can easily screen candidates for the skills they are looking for. Search teams also need to get a chance to view the candidate's mastery of digital technology through online interviews, and review content created by the teacher, such as online portfolios, blogs, websites, online curriculum that the teacher built, or other media produced by the candidate. As the team reviews applications they need to "gather and assess additional information in order to best determine which candidate best "fits" the need of the organization and position" (Barrett, 2010, p. 19). On the resume they should be looking for pre-service and experience indicators that would give the team a clue about their preparation for the position (Stronge \& Hindman, 2003). For online teachers the team would want to look for specific training in online education, successful prior experience in online settings, mastery of technology, examples of using data to modify instruction, examples of meeting diverse needs of students, and demonstration of online teacher ethics as outlined in Table 5 (Dawley et al., 2010; Rice et al., 2008; Treacy et al., 2011). By mining the resume and looking for the uniquely desired characteristics of online teachers, hiring teams begin to identify quality online candidates. During the screening process there is great opportunity for hiring teams to ensure that the candidates can demonstrate or perform with clarity that they have the qualities described in Table 5 (Barrett, 2010; Treacy et al., 2011). For example, if the application is not filled out completely, the candidate may not pay enough attention to detail or have the capacity and 
clarity that is needed in online teaching. Additionally, teams can determine if the candidate has any relevant training or experience in online education. Finding candidates with online training or experience is highly valuable as they are rare in the K-12 online teaching field (Dawley et al., 2010). Furthermore, if the teacher has a website, online portfolio, records of classroom sessions, or other media available, it can further demonstrate alignment to desired online teacher qualities.

An important step in the recruitment process is to perform an online preinterview. Hosting an online pre-interview is critical for several reasons: (a) it gives the candidate an opportunity to demonstrate mastery of appropriate technology, (b) it assesses the candidates online presence, (c) it provides an opportunity for asking follow up questions about experience or details within the application, and (d) it allows the hiring team to go deeper in assessing the candidates knowledge of online learning. These are critical steps in hiring teachers and combines wisdom from Stronge and Hindman (2003) and Peterson (2002) in combination with online technology to perform an online interview prior to face-to-face interviews. Before utilizing district resources, time, travel budgets, staff energy, etc., hiring teams need to host online pre-interviews. After the preinterview process in which potential candidates have been identified, it is time for the hiring team to move into the hiring phase.

\section{Hiring Phase}

The literature reviewed concerning hiring online teachers establishes that online program administrators need to upgrade the interview process. For example, online program administrators need to keep pace with the advancements of technology and the changing nature of the online learning environment in their interview process (Barrett, 
2010). Barrett reports that hiring committees need to change their selection processes for online teachers to ensure that the team finds candidates who are top quality online teachers, not just good classroom teachers. During the interview process candidates should be challenged to demonstrate they have the skills and tools necessary to be successful in an online environment.

Online hiring teams need to utilize multiple means of technology in the hiring process. Hiring teams should use technology such as web-conferencing in their interview process, not only because it is convenient to survey distant candidates, but also because it gives the candidates a chance to demonstrate their mastery of various technologies in the actual hiring process (Barrett, 2010; Watson et al., 2011). Mastery of technology is one of the skills a hiring team needs to have clearly demonstrated in the hiring process (Treacy et al., 2011). Watson (2011) reported that hiring teams should, "challenge candidates by using online instructional tools in the hiring process" (p. 57). Candidates should demonstrate their past knowledge of online pedagogy and how they it will be used in the new K-12 online setting. Additionally, they should be able to express through responses to questions or demonstrations of proficiency how they have modified, created, or supported top quality digital curriculum.

To increase the rigor of the hiring process online hiring teams should consider using demonstrations to identify master online teachers. MacGregor (2011) stated that a demonstration can be used to “judge a job applicant's knowledge, skills, and dispositions required for the position" (p. 1). Demonstrations in online environments should be focused on the specific skills the hiring team is looking for, such as those listed in Table 5, or perhaps follow up on questions gathered during the recruitment phase. For example, 
if the team wanted to see how a teacher would clearly explain a concept, the team may want to have the teacher take a problem from their online curriculum and explain the problem as they would to a student. Another example could be reviewing an online course, website, or blog that the teacher built in a previous assignment. An additional useful demonstration would be to have the teacher host an online synchronous class with teachers or parents' role playing students. In these real world examples the team is able to see the candidate in action and gain a deeper understanding than from the traditional interview process. Demonstration of proficiency helps to reveal the true talents of prospective online teachers (MacGregor, 2011). Because online teaching is distinctly different than classroom teaching, online candidates need an opportunity to show the hiring team they are capable and comfortable working in online environments (Watson et al., 2011)..

Not all classroom teachers will be effective online teachers, yet there is high probability top candidates will have prior and successful brick-and-mortar experience (Dawley et al., 2010). Recruitment and hiring processes that follow a combination of Stronge and Hindman's (2003) and Peterson's (2002) hiring recommendations with modifications to emphasize online teaching skills will result in top candidates being selected for online jobs. Online teachers require a unique set of skills, and hiring teams must be experts at identifying these skills. Once teams have hired their desired candidate, they will need to start thinking about how to successfully transition their candidate into the online environment. Peterson stated that new teachers need to be placed immediately into a new teacher induction program. Effective induction programs have a huge impact 
on teacher success during the initial years of teaching. The next section explores effective induction programs and how they help new teachers become successful.

\section{Induction Phase}

The induction phase is important for all teachers, but especially critical for new online teachers. New online teachers can be overwhelmed by the transition into a new medium of instruction, and the initial support they receive is absolutely necessary to ensure a smooth transition (R. Smith et al., 2005). This phase of the selection process is important because many online teachers learn on the job (Dawley et al., 2010). If they can master the bulk of needed online skills before they actually begin teaching, they will be much more effective (R. Smith et al., 2005, p. 59). The following discussion explores how induction programs make a difference for new teachers. The review then shifts to examine the unique needs of online teachers in professional development settings. Next, the review evaluates the literature to determine the characteristics of effective online induction programs. Finally, the review identifies specific training elements for online induction programs. At the conclusion of a successful induction program, the new teacher will be equipped with all of the skills and resources they need to start their first job in an online school.

Induction programs are invaluable and indispensable to the success of online schools. Over the years induction programs have proven to reduce teacher turnover and increase beginning teacher success within their first years in the classroom (T. Smith \& Ingersoll, 2004). Induction programs should include "support, guidance, and orientation for beginning teachers during their transition into their first teaching job” (T. Smith \& Ingersoll, 2004, p. 681). Teachers who complete a well-designed induction program are 
less likely to leave the school or the profession after their first two years (Ingersoll \& Strong, 2011; T. Smith \& Ingersoll, 2004). A large scale critical review of the literature on induction programs completed by Ingersoll and Strong (2011) found that, "beginning teachers who received some kind of induction had higher job satisfaction, commitment, or retention" (p. 211). The literature also shows that induction programs positively impacted student achievement in that, "almost all of the studies reviewed showed that students of beginning teachers who participated in some kind of induction had higher scores, or gains, on academic achievement tests” (Ingersoll \& Strong, 2011, p. 225). Quality induction programs make a lasting difference on the success of a K-12 online learning program. Principals and program developers of K-12 online schools need to make professional development and training a priority in their programs and take the time to invest in quality induction programs (Zimmerman, 2003). Based on the results of the Going Virtual series, it has been established that principals and local administrators of online schools need to be heavily involved in the professional development and induction programs of new online teachers. Many online teachers need specific training in how to teach online or extend their classroom knowledge into the online setting (Cavanaugh et al., 2004; Holstead et al., 2008; Watson et al., 2011). Therefore, online principals need to carefully create a system that utilizes best practices in induction programs to ensure the proper use of the vast array of technologies available. A significant part of building a quality induction program is for leaders to know their teachers. Experienced adult learners transitioning into a new teaching environment have very specific and unique learning needs. 
The research literature pertaining to the needs of adult learners has strong implications for creating effective induction programs for online teachers. Since more than $80 \%$ of the online teachers have prior teaching experience (with a mix of online/classroom experience), they will be going through a difficult paradigm shift (Dawley et al., 2010). Watson et al. (2011) reminded leaders to "support those who are making a big shift in instructional style. Help them master new communication tools and requirements" (p. 57). Adult learners going through the transition to full-time online teaching need time to learn and practice the requisite knowledge and skills. New online teachers go through what Mezirow (2000) has called a transformative experience. In transformative adult learning situations, it is important to "emphasize contextual understanding, promote critical reflection of basic assumptions and validate new meanings by assessing reasons for proposed changes" (Mezirow, 2000, p. 4). In other words, adults need to fit their new learning into the context of what they already understand and have critical conversations about what fits and what does not fit. Online teachers, in particular, want and need this type of support as they transition from classroom based experiences to online environments (Barrett, 2010; Dawley et al., 2010; Rice et al., 2008; R. Smith et al., 2005; Watson et al., 2011). Mezirow reminded us that "adults are never neutral ... they do not want to be indoctrinated ... what counts is what the individual learner wants to learn" (p. 31). Therefore, collaboration, discussion, and reflection are foundational components of new online teacher training. New online teachers need time to discuss what they are experiencing with a team of teachers. Sometimes new online teachers are so overwhelmed and struggling for a frame of reference, they create situations that reflect traditional classroom instruction. At one point 
I asked a new online teacher if she had synchronous face-to-face study groups at the local library for the students or for herself, and she said, "Both." New online teachers have a desire to teach in the way they were educated. This shows that adult learners undergoing transition need to frame the context of their new learning experience within the context of their past experience (Mezirow, 2000). Program developers need to carefully design their induction programs to develop and nurture the qualities of online teachers so they become successful.

As principals develop their induction programs for adult learners, they should create space and time for the new teachers to learn specific program software, hardware, and practices. Even teachers who come to online learning with previous online experience need an induction process, so they can learn the specifics of local programs and undergo the transformation into new online work (Watson et al., 2011). Local programs should utilize their unique tools such as their own curriculum (built, bought or mixed), SIS, LMS, practices around interventions and curriculum modification to meet student needs, technology available in that particular school, and CMS. Each program has its own unique policies and practices (Watson et al., 2011). A vast array of SIS systems are available for schools to utilize, each having its own unique features to meet state, region, district, school or program goals. Online schools often have unique reports and SIS systems to capture online student attendance and participation in coursework. A SIS system is the program that stores attendance, grades, transcripts, student demographic information, course catalog, employee licensure, and other important operational data. LMS and CMS systems are used in online schools to store content and deliver to the students and parents online. These systems allow teachers to build, update, and publish 
online courses to students who are enrolled in the program. CMS programs are essential to building dynamic teacher created content, as they create an online classroom platform that teachers can easily manipulate to build content. Each of these unique systems need specific training so new candidates can learn the unique features of the programs.

There are many critical elements in designing effective induction programs for new online teachers. Program developers and administrators need to carefully select a blend of tools to encourage and support new teachers (Ingersoll \& Strong, 2011; T. Smith \& Ingersoll, 2004). The induction program developed specifically for online teachers should be partly or mostly online. Approximately $50 \%$ of online teachers in a recent study reported that they preferred ongoing training in a fully facilitated online mode with blended workshop formats a close second (Dawley et al., 2010). Thus, any new online teacher training should involve a blend of online and face-to-face components. Effective induction programs also connect with ongoing support systems, but typically must consist of carefully planned upfront focused support for new teachers (Ingersoll \& Strong, 2011). According to Wong et al. (2005) induction programs worldwide differ on specifics, but they all are "highly structured, focus on professional learning, and they emphasize collaboration" (p. 383). The following induction themes emerged from the literature and are listed in Table 6. 
Table 6

Induction Themes From Literature Reviewed

\begin{tabular}{|c|c|}
\hline Induction Themes & Explanation \\
\hline $\begin{array}{l}\text { Development of teacher } \\
\text { as professional lifelong } \\
\text { learner }\end{array}$ & $\begin{array}{l}\text { - Induction programs should emphasize building capacity in teachers to } \\
\text { be lifelong learners (Wong et al., 2005). Online teachers are specialists } \\
\text { in their field and induction programs should aim at reducing the stress } \\
\text { of transitioning and create a lifelong online teacher. This will reduce } \\
\text { turnover and training demands on online administrators. }\end{array}$ \\
\hline Peer Collaboration & $\begin{array}{l}\text { - Collaboration between peers helps adult learners going through } \\
\text { transitions, such as the major paradigm shift to teach online (Mezirow, } \\
\text { 2000). }\end{array}$ \\
\hline Mentorship & $\begin{array}{l}\text { Establishing mentor relationships helps connect inexperienced staff } \\
\text { initially and provides a platform for ongoing support (Ingersoll \& } \\
\text { Strong, 2011). New online teachers are dealing with being new to } \\
\text { teaching and new to teaching online. Experienced teachers will still } \\
\text { need to transition online. Teachers undergoing this stressful transition } \\
\text { need someone they can contact every day for support. }\end{array}$ \\
\hline Orientation & $\begin{array}{l}\text { - First training to calibrate and introduce new teachers to the local } \\
\text { program and larger context (Wong et al., 2005). The first training } \\
\text { needs to cover specific elements to the online school such as pedagogy } \\
\text { of teaching online, SIS/CMS systems, and overall operational } \\
\text { procedures for communicating with students/parents online. }\end{array}$ \\
\hline Observation & $\begin{array}{l}\text { Peer observation of live or recorded sessions will support new teachers } \\
\text { and help them understand what model teaching looks like (T. Smith \& } \\
\text { Ingersoll, 2004). Online teachers need to see several examples of } \\
\text { strong online content as well as teachers teaching live online courses, } \\
\text { so they can see how to manage online courses. }\end{array}$ \\
\hline District Level Support & $\begin{array}{l}\text { - In many programs districts will offer release time, large scale } \\
\text { workshops or seminars, and other supports that help support the new } \\
\text { staff (Wong et al., 2005). With online staff members this will be } \\
\text { critical to offer release time or reduced duties to allow new teachers to } \\
\text { settle into their roles. }\end{array}$ \\
\hline
\end{tabular}

Based on the literature reviewed, online administrators need to carefully consider delivery of their induction program. Online administrators need to consider the delivery of the training. The Going virtual series (Dawley et al., 2010) reported that more than $50 \%$ of online teachers prefer online training or blended workshops. Therefore, online administrators need to build as much of the content of the induction program online as 
possible and utilize the remaining time for face-to-face dialogue, collaboration, and reflection (Mezirow, 2000; Watson et al., 2011). Administrators can use digital technology to host online meetings or use online asynchronous classes to cover the basics for new teacher training. A basic program would include the mission and vision of the program, policies pertinent to instruction, system tools such as LMS and SIS components, and any curriculum training needed. When administrators join staff members face to face, they should build in multiple opportunities for collaboration and discussion with peers as well as any necessary training that would be done more easily in a live setting, such as first aid or safety training (Dawley et al., 2010). By creating an environment of flexibility through online technology and also mixing in face-to-face time when appropriate, an online administrator can ensure new online teachers have the support they need. After deciding on delivery strategies, administrators should then consider what learning paradigm they might use for their new online teachers.

Online school leaders should begin building their induction program by considering the learning paradigm they plan to use as a foundation. According to Lincoln and Guba (1985) "a paradigm is a worldview, a general perspective, a way of breaking down the complexity of the real world. As such paradigms are deeply embedded in the socialization of adherents and practitioners; paradigms tell them what is important, legitimate, and reasonable" (p. 15). Of the paradigms available a constructive studentcentered approach would have much to offer new online teacher induction programs. Creswell (2009) stated that the constructivist, "holds assumptions that individuals seek understanding of the world in which they live and work" (p. 8). The goal of induction programs aligned with the constructivist paradigm would be to understand the 
participant's views of learning and add to their knowledge bases by increasing understandings within the learning community as a whole (Creswell, 2009; Lincoln \& Guba, 1985). Using a constructivist paradigm creates an environment that assists in the transformational experience of moving into online teaching. Mezirow (2000) reported that adults going through a transformational learning experience need to fit their new learning into the context of their past learning/experiences. If the online administrator views teachers as professional lifelong learners and not empty vessels to be filled, they will validate the learners' previous experiences and use it to build new knowledge as a community (Wong et al., 2005). The Going Virtual (Dawley et al., 2010) series pointed out that teachers moving into online learning most likely have online or previous classroom experience. By valuing their previous experience, administrators will create an environment in which they can add value and make important connections between teachers' past experiences and their new experiences online (Mezirow, 2000). New online teachers can often be "overwhelmed by the enormity of the task" (R. Smith et al., 2005, p. 59). Effective induction programs should create an environment of support, collaboration, and reflection to help reduce the enormity of the task. Once online administrators have a perspective that carefully considers delivery and paradigm orientation, they are ready to build an induction program.

Before new online teachers begin working in the virtual class, administrators need to deliver a carefully planned and highly collaborative orientation. Using a careful blend of online and face-to-face learning experiences appropriate to the program, the local orientation program should cover the basics of their particular system operations (Wong et al., 2005). The orientation must cover the technology, curriculum, and policies unique 
to the online school, such as a SIS, LMS, state or local policies, or purchased curriculum programs (Barrett, 2010; Watson et al., 2011). Since there are many possible participation and delivery models for online programs, each particular program will have unique approaches to online learning that both experienced and inexperienced online teachers will need to master. For example in a blended setting with a drop in space, a new teacher would need to see effective online learner support in a computer lab setting. The key in this setting is to coach and equip the learner to be self-reliant and help them find the answer on their own using the power of the internet. Before walking away, a master teacher would ask the student a question to check for understanding and then challenge the student to apply their learning in a new situation. Another example would be how to effectively manage online learner feedback on discussion boards while trying to demonstrate new content. Often online classrooms will have a text chat function that presenters can enable or manage to allow time for discussion and processing while covering new content. This requires specific skills, classroom management skills, and understanding of the online meeting technology. New teachers need to see these specific functions in action by a master teacher in order to be successful. After the orientation is delivered, teachers should have the fundamentals in place to begin teaching (Wong et al., 2005). During the orientation, time should be allocated to explain additional support elements that will extend into the year, such as staff meetings, collaboration opportunities, and mentorship expectations (Ingersoll \& Strong, 2011). In online settings it is important to plan ahead of time because of the massive amount of communication, tasks, and follow-up it takes to be an online teacher. Planning meetings ahead of time will make sure the time is protected and not over scheduled or forgotten. 
Mentorship was one of the most important elements of induction mentioned in the literature reviewed (Dawley et al., 2010; R. Smith et al., 2005; Watson et al., 2011; Wong et al., 2005). Since online schools often cover large geographic regions and are, in effect, state wide programs, online program leaders may want to consider mentorship models that would allow for distant relationships between mentors and mentees (Watson et al., 2011). One model that is emerging in the postsecondary field is e-mentorship and is defined by Thompson et al. (2010) as

a relationship that is established between a more senior and /or experienced individual (mentor) and a lesser skilled or experienced individual (mentee or protégé), primarily using electronic communications, and is intended to develop and grow the skills, knowledge, confidence and cultural understanding of the protégé to help him or her succeed. (p. 305)

E-mentorship, as part of a comprehensive ongoing professional program, helps to ensure the success of new online teachers. E-mentorship grew out of the need to train college professors in how to use online technologies, and it has found some success in its early stages. Participants in the study reviewed, reported that they would recommend the ementorship process to colleagues (Thompson et al., 2010). This delivery method can be replicated in K-12 systems by connecting all new teachers with a mentor teacher via email, phone, or virtual meetings. Administrators may want to consider some of the elements of the study about e-mentorship, such as compensation for the mentors and mentees for their time and efforts (Thompson et al., 2010). Once online administrators have finished their local induction and linked the new teachers to mentorship support, they can either transition the teacher into ongoing professional development appropriate to all staff in the program, or possibly continue a new teacher cohort if there are enough teachers with less than 1 year of experience. While ongoing support is not covered in this 
review beyond mentorship, administrators should not assume their work is done once the teacher moves into the virtual classroom. Leaders will need to build on their initial experiences with thoughtful planning to sustain and enrich the teaching experience.

Whether accomplished digitally or face-to-face, an induction program that does not connect new online teachers to ongoing support will most likely not impact the new staff member's learning and could make the transition more difficult. This initial level of support will reduce the stress and ambiguity of the new online position for the teacher and increase their chances of being successful in their first years. Induction programs are critical in developing online schools. Carefully designed induction programs combined with effective recruitment and hiring practices will lead to high quality teachers capable of ensuring long-term program and student success.

\section{Hiring Process Flowchart}

Literature reviewed in this study has given me enough information and topics to build a website framework and overall recruitment, hiring, and induction program for online school administrators. Based on my synthesis of the literature, the areas that administrators need the most help with are the following: building positions, job posting strategies, skills to look for in recruitment and hiring, and how to organize for interviews (Peterson, 2002; Watson et al., 2011). These recruitment strategies will allow administrators to attract the most effective instructors and provide the organizational tools for the hiring team to sort through candidates using the skills listed earlier in Tables 2 and 5. For hiring support the literature placed emphasis on general organization and implementation techniques for interviews as well using pre-interview and demonstrations (MacGregor, 2011; Peterson, 2002; Watson et al., 2011). Tools in the hiring area will 
give administrative teams the resources they need to conduct rigorous interviews that will give them the best chance to interact and understand their candidates. Finally, for the induction process there are several key tools necessary to provide initial support for new teachers. Although not a focal point of this study this section emphasizes creating or connecting new teachers with ongoing support beyond an initial induction. Induction and ongoing support are so critical for new teacher success that I could not build a resource on recruitment and hiring without including induction resources(Ingersoll \& Strong, 2011). The tools that emerged from the literature for induction support were to help administrators be more aware of the needs of adult learners, to build an initial orientation program, consider the value of an e-mentorship program, and to ensure there are other ongoing supports available (Ingersoll \& Strong, 2011; T. Smith \& Ingersoll, 2004; Thompson et al., 2010). Creation of these tools will give administrators easy to use resources to assist in building initial support and increase awareness of building on-going support systems. Overall the framework for these tools was the basis for my website and provided a robust set of tools for administrators to use to find teachers who demonstrate their effectiveness in the hiring process (see Figure 4). 


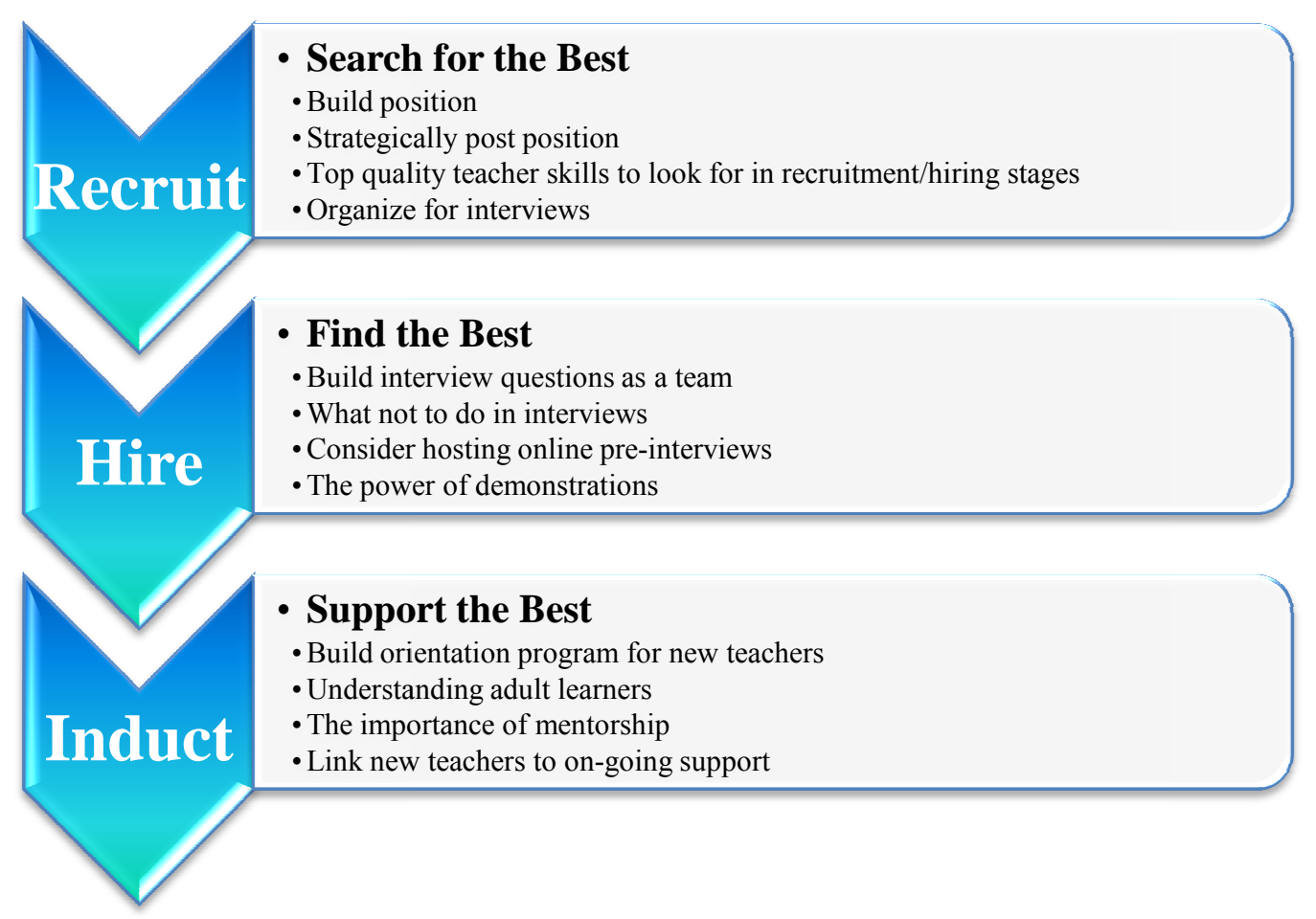

Figure 4. Recruitment, hiring, and induction flowchart. (C) All rights reserved.

\section{Limitations of Literature}

My purpose in reviewing the literature was to identify successful practices for K12 online administrators in recruiting, hiring, and inducting new online teachers. The literature covering online learning is new, and there is limited long-term experimental design research on student success. However, journal articles and research reports were incredibly useful sources in building a review of K-12 online learning literature. The literature was thin specifically with regard to recruiting and hiring new K-12 online teachers. For example, iNACOL (Patrick, 2012), which is a leading resource for K-12 online learning, has over 40 published resources in their online database with zero information covering recruitment and hiring specifically. This hole in literature and research about recruitment and hiring of online teachers is a critical gap in the literature 
base. Most of the research and articles about K-12 online learning points to the teacher as making the biggest difference in success of students in online schools (Cavanaugh et al., 2004; Picciano \& Seaman, 2009; R. Smith et al., 2005; Watson et al., 2011). Finding and supporting the right teachers is the most important job of new K-12 online programs, and currently, there is limited literature or support out there for administrators trying to build programs. Literature and research is catching up quickly as organizations like iNACOL, NEA, federal, state, ESDs, and local districts respond to the growing demand for K-12 online learning. The field of K-12 online learning is in its infancy. There are still many unanswered questions about the long-term success of online students. It is an important time to develop priorities in critical areas. Through this literature review, it was demonstrated that recruitment, hiring, and induction of top quality online teachers are critical areas of emphasis for ensuring student success.

Additional research needs to be conducted on recruiting, hiring, and supporting new K-12 online teachers. Research and teacher preparation programs across the nation are making a concerted effort to keep up with K-12 online learning (Barth, 2013). As educational opportunities, research, and professional development evolve, teachers who chose online learning as their specialty will be better prepared (Cavanaugh et al., 2004). Administrators will also develop in their use of a growing research base, new meeting and instructional delivery tools, and further education to improve their practices in recruitment, hiring, and induction of online teachers. Future research in the area of new teacher recruitment, hiring, and induction needs to focus on several areas: qualities of effective teachers; best practices in recruitment; hiring methods that yield top quality candidates; induction programs that support and impact new teacher longevity; the long- 
term success of teacher induction programs; and ongoing support systems for K-12 online teachers. For online learning to be successful and accepted in our nation, a deeper body of research is needed to identify and understand this rapidly growing field (Barth, 2013; Blomeyer, 2002; Watson et al., 2011).

Research studies that offer suggestions about professional development will not be useful if the candidate is not a good fit, nor will the best digital curriculum work in the hands of an instructor who cannot check their email or update a blog. To meet the massive staffing demand to teach online courses, leaders need to master techniques to identify, hire, and support K-12 online teachers. K-12 online learning is growing by 30 $40 \%$ a year, creating a demand for highly trained teachers to facilitate online learning (Picciano \& Seaman, 2009). Therefore, more research and literature development is needed in the areas of recruiting, hiring and inducting K-12 online teachers. This is one of our largest educational challenges.

\section{Critique}

I am a believer in the power of online education to meet the growing needs of many students in today's changing K-12 education landscape. I have seen success and witnessed amazing stories from the field over the last 5 years. My experience in administrating and researching K-12 online schools has led me to a very important conclusion: Hiring effective online teachers who can uniquely meet the needs of online students is the single most effective way to ensure the future success of online learning students and programs. Curriculum, program type, budgeting, administration, etc. are all important areas that should not be overlooked. However the most important factor for K12 online learning to find success is recruiting, hiring, and supporting the best K-12 
online teachers. I also believe there are some simple systems that administrators can apply to their local school system to facilitate a hiring process that result in the selection of effective candidates. Therefore, I critiqued the literature I reviewed to reveal the gaps in the literature surrounding recruitment, hiring, and support of new K-12 online teachers. In this section I also explored the strengths and weaknesses of the literature I reviewed.

The majority of the literature reviewed focused on key areas pertinent to K-12 online learning but it did not offer many recommendations about recruitment of online teachers. Though a valuable and popular resource for K-12 online program developers, Keeping Pace with K-12 Online Learning (Watson et al., 2011) did share a few comments about recruitment of online teachers. Since this article focuses on the state of $\mathrm{K}-12$ online learning around the nation as a whole, it does not provide detailed information and suggestions for program leaders and developers. Cavanaugh et al., (2004) and R. Smith et al. (2005) conducted respected and thorough studies offering information about many components of online learning but do not have many recommendations on how to recruit or hire K-12 online teachers. Other studies contain isolated information that a practitioner may identify, make inferences, and draw meaning from, in a hit and miss fashion. Unfortunately, there is not one source that focuses on what I would consider to be the most important step, selecting the best online teachers. Research in this area could help administrators avoid costly mistakes. The research proposed in this study should provide meaningful tools and make a contribution to the literature where it is lacking in a critical area. Administrators of online schools need field tested tools that help them scour candidates for the most effective online teachers. 
With regard to the specifics of actually hiring online teachers, the literature is even more vague and limited. Inasmuch as online learning is currently in a stage of its existence where its growth is outpacing current research and pre-service preparation programs, it is no surprise that hiring gets overlooked. It appears that researchers have conducted meaningful research in important areas, such as how does online learning impact student learning or what are the professional development needs of online teachers (Cavanaugh et al., 2004; Dawley et al., 2010; Rice et al., 2008). However additional research is needed on methods to recruit and hire online teachers. The mechanics of hiring quality teachers is a step that cannot be ignored in building a quality program (Peterson, 2002; Watson et al., 2011). A candidate may look amazing on paper, but once they demonstrate their technological skills live, a selection team might discover critical flaws in the candidate's ability to use technology or explain concepts clearly. In my opinion this is perhaps the most important gap in the research. Hiring is a subject that is given very little attention in administrator preparation programs. New online administrators may have never received any training in how to hire teachers, let alone new online teachers. Without reliable research to depend on, they need to learn on the job. This results in costly mistakes to the school districts and to K-12 online learning as a field. New online administrators need to attend human resources training or continuing education to learn about properly hiring online teachers (Scherer, 2005). Because many online programs start small and then grow fast, administrators need to wear many hats, often performing hiring and other duties typically handled by central office (Campbell et al., 2008). For online learning to be successful, online school administrators need to be masters of hiring top quality candidates. More research can also be done to close the gap 
in the literature for online school administrators in the area of hiring. Hiring research could support new online school administrators in their development of consistent and reliable techniques for hiring effective online teachers. The research proposed in this study was intended to provide research based tools to administrators struggling to hire the best online teachers.

The literature had much more to offer on the induction and support of K-12 online teachers. The Going virtual (Dawley et al., 2010; Rice et al., 2008) research series was quite helpful in understanding the state of professional development for K-12 online teachers. Ingersoll and Strong (2011) and Wong et al. (2005) provided valuable information about what is happening in induction programs around the nation and world. Though there are more sources on induction and new teacher support, this topic was included in the review because it is a process that often gets overlooked as administrators build their programs. Over the years my own induction program has grown tremendously, and it will continue to grow for years to come. I have personally seen the positive impact of providing an organized orientation for new teachers. Four years ago, prior to my creating a program, our teachers received no training, and now they receive two full days of training plus they get linked immediately to an e-mentorship program. Teachers report that given this support, the transition into online work is much easier. The teachers who had no training are now mentors, and tell me they wish they had this support when they started. Over the years I have built a customized New Teacher Training program that is now used to induct every teacher. Much of this program is very specific to the tools, such as our custom built SIS specific to a virtual charter school in Oregon; basic training in our many curriculum programs as applies to our current position; our overall pedagogy and 
theories about teaching online; and, our specific policies as they pertain to our instructional staff. While program specifics used in the training programs I have developed may not be generalizable to all online schools, I think it is an important element of research pertaining to teachers transitioning into online teaching positions.

While the literature about recruitment and hiring is limited, the literature is clear about the importance of mentorship in online settings. Mentorship is the cornerstone of any support system for new K-12 teachers (Ingersoll \& Strong, 2011; Ragins \& Kram, 2007; T. Smith \& Ingersoll, 2004; Thompson et al., 2010). Mentorship in combination with carefully designed induction program is a highly effective method to support new online teachers. As administrators are building K-12 online teacher support systems, they need to carefully focus on the literature available about K-12 online learning and the unique needs of new online teachers. With regard to training, the unique needs of online teachers are an area needing emphasis in further research. Going virtual (Dawley et al., 2010; Rice et al., 2008) provides a starting point, but future research needs to be combined with Mezirow's (2000) work on adult learners. For example, how do teachers deal with the paradigm shift, what emotions and complications are there for new online teachers? Future research may be able to identify burn-out factors or help teachers selfidentify that teaching online is not for them. Many online teachers come from brick-andmortar classrooms (Dawley et al., 2010) and need support designed specifically for that transition. Research in the area of new teacher induction should emphasize the perceptions of new teachers as they go through the transition to teach online.

By carefully considering recruitment, hiring, and induction for new K-12 online teachers, administrators will avoid costly mistakes and irreversible damage to student 
experiences. Based on my experience and research, new teachers who are the wrong fit or not properly trained can cause students to leave online learning for good. Had the teacher been the right fit and properly trained, they might have met their students' needs in a very unique and powerful way. A new mission within the field of K-12 online education must be selecting and supporting the best K-12 online teachers. 


\section{CHAPTER 3}

\section{RESEARCH METHODOLOGY}

\section{Chapter Overview}

For online learning to truly be successful our nation's online classrooms need high quality instructors. The demand for online programs is growing by $30-40 \%$ a year, creating a heavy burden on the current and pre-service teaching force for trained online teachers (Nagel, 2009). Postsecondary teacher training institutions are struggling to keep up with the demand placed on certification programs. As a result program administrators find themselves needing to train the next generation of online teachers at their school sites (Dawley et al., 2010). In the hurry to respond to the immediate demand for online classes, postsecondary pre-service programs and online administrators may be overlooking the most important factor of a successful program; the process of getting top quality teachers into online classrooms. Online programs or courses that are developed and facilitated by highly qualified, trained, and uniquely skilled instructors will have a better chance at improving student learning (Cavanaugh et al., 2004). Administrators and program developers need to have quality, dependable, and easy to use tools to assist in finding and supporting the best K-12 online teachers.

To provide a meaningful solution to the shortage of online teachers, I have designed a resource website with recruitment, hiring, and induction tools specific to working with K-12 online teachers. These tools are grounded in literature reviewed in this study and my personal experience in the field. The tools are similar to those I have 
used to hire a team of teachers that recently received a $100 \%$ satisfaction rating on our latest school survey (Appendix A). Eighty percent of our parents were extremely or very satisfied with the program with the remaining $20 \%$ being satisfied. The survey was distributed to all our Baker Web Academy students and parents. Approximately 60 parents and students responded to the survey out of the 330 students in the school. In the survey one parent said, "It is run beautifully, the administrators and teachers listen, each child can go at his or her own pace." Another parent said, "Great staff... they really care about the success of their students." Our school may not be perfect, but we have put a lot of effort into finding and supporting the best K-12 online teachers, and it has paid off. Some of our staff members have been working in our school for 5 years. Most staff members stay once they are hired and complete their first year. Having the right tools in place to get the best teachers in classrooms will solve numerous problems before they begin. My project was focused on evaluating the effectiveness of my resource website to impact administrative preparedness in the areas of recruitment, hiring, and induction of K-12 online teachers.

For the methodology section I discussed my reasoning for my unique approach to educational research using R\&D method (Borg \& Gall, 1989), PBL (Bridges \& Hallinger, 1995), and how these methodologies shaped my research agenda. In this section I clearly explain how my project aligns with each step of the PBL process. Next I discussed my data collection and analysis tools used in conjunction with the PBL research process. Finally, I outlined my plans for future R\&D of my online staffing resources for program administrators. 


\section{Research Design}

Based on the nature of my unique problem, I have elected to use Borg and Gall's (1989) R\&D methodology within the framework of Bridges and Hallinger's (1995) PBL model for my study. For busy practitioners, EdD programs focused on theoretical explorations of knowledge are often "devoid of any meaning for professional students" (Bridges \& Hallinger, 1995, p. 117). I feel my problem is relevant to the field of education, and the research I did should make a meaningful contribution to the field and provide timely solutions for leadership challenges. Therefore, I pursued a research design that was more applicable to the field and kept the work connected to practice. The goal of the R\&D process within PBL is to "apply knowledge from theory and research to problems of policy or practice" (Bridges \& Hallinger, 1995, p. 116). This methodology kept my work connected in a meaningful way to current problems of practice, and through the development and refinement of my resource guide, I was able make a lasting impact on the field of online learning in the state of Oregon.

\section{Research Questions}

To provide a meaningful solution to the shortage of K-12 online teachers, I developed a unique resource website for program administrators to recruit, hire, and support new teachers. The tool set was delivered through a functional website that contained tools for each specific area mentioned above. Following the first seven steps of the $R \& D$ process, and in order to analyze the effectiveness of these tools, I focused on three main questions to guide my research.

The website was designed to support administrators of online programs to recruit, hire, and support the most effective online teachers. The tools were based on the literature 
reviewed and focused on K-12 online learning. To ensure the website was properly addressing the problem of quality online teacher shortage, I used these questions to guide my research:

1. How can the website K-12 Online Staffing Solutions impact the practices of K-12 online school administrators in the areas of recruitment, hiring, and induction for new online teachers?

2. What tools in the website are perceived to be the most meaningful to administrators?

3. After using the site what recommendations do administrators have to improve the site for future use?

These questions provided the framework for evaluating the tools in the website in the effort to support administrators in recruiting, hiring, and inducting the best online teachers. My goal was to create tools that are effective and easy to use. It is imperative to get the best online teachers working in our online classrooms to ensure student success (Cavanaugh et al., 2004; R. Smith et al., 2005; Watson et al., 2011). My intention is that the tools within this website assist administrators across the state of Oregon as they do their best to build quality online programs.

\section{Role of Researcher}

Through this study my role was as a participant observer (Saldaña, 2009). In this role I was able to participate in the research activities while maintaining my role as an observer. Participants were aware of my role as a researcher but I was able to interact with them throughout the study. There are many benefits to using this method with such a small sample size. First of all it is important to network, cooperate and share best practices with other Virtual Charter School administrators in the field to improve our overall practice. Next since I work with these administrators on a regular basis outside of 
the study maintaining any other researcher role would be difficult. Finally since I was presenting the website during sessions I was able to constantly collect data during the study as I dialogued with administrators live.

\section{PBL}

Real problems need real solutions therefore, the Bridges and Hallinger (1995) PBL method for EdD students makes a lot of sense for my project. The traditional design of the $\mathrm{PhD}$ is more for researchers looking to move into higher education roles as it demonstrates they can "conduct independent research at acceptable standards. Both the process and the product prepare the student for the entrance into the professoriate" (Bridges \& Hallinger, 1995, p. 116). On the other hand the PBL approach represents a concrete demonstration of the bridge the student has constructed from theory to practice (Bridges \& Hallinger, 1995). Research with a PBL focus connects the student to meaningful work and real problems. K-12 online learning is an emerging field that is light years ahead of the existing research and current postsecondary training for teachers and administrators (Picciano \& Seaman, 2009). Because K-12 online learning is an emerging field, practitioners need meaningful research-based solutions to ensure a solid foundation is built for future generations of practitioners (Watson et al., 2011). In the PBL model researchers begin by identifying a problem in practice that they may or may not be struggling with in their current jobs. Once the problem has been identified, the researcher examines all of the literature available on the topic to provide a framework for the study. After the literature is reviewed, the researcher is able to place their problem into the context of the field, and respond to gaps in the research where additional contributions may be needed. To build the study, the researcher then creates a product 
that is implemented and analyzed in the field in order to explore solutions to the problem. An appropriate mechanism to develop and test the effectiveness of the product in the field is the R\&D cycle developed by Borg and Gall (1989). Once the R\&D cycle has been completed, the researcher can reflect back on their problem within the PBL framework and make conclusions or recommendations to the field for lasting impact. The R\&D process compliments the framework of the PBL model for use in EdD research.

\section{R\&D Process}

Through the R\&D cycle, the researcher performs multiple tasks leading to field testing and refining their product. The R\&D process was developed originally by Borg and Gall (1989) in the late 1980s. The stages of the R\&D process are: researching and information gathering, planning objectives and small-scale testing, development of initial product, preliminary field testing, main product revision, main field testing, operational product revision, operational field testing, final product revision, and finally, demonstration and implementation (Borg \& Gall, 1989). In this section I walk through the first 7 steps in the R\&D process, and describe what I do during these phases of the research process. Table 7 summarizes the main goal in each step. For the purposes of this study, I completed steps 1-7 as steps 8-10 are great extensions after dissertation defense. 
Table 7

R\&D Process From Bridges and Hallinger (1995)

\begin{tabular}{|c|c|}
\hline Step & Main Goals \\
\hline $\begin{array}{l}\text { 1) Research and } \\
\text { Information Gathering }\end{array}$ & $\begin{array}{l}\text { - "Preliminary literature review" } \\
\text { - "conduct "small-scale" research } \\
\text { - "The goal at this point is to develop a broader and deeper understanding } \\
\text { about the problem" (p. 120) }\end{array}$ \\
\hline 2) Planning and Testing & $\begin{array}{l}\text { - "Initial description of product components" } \\
\text { - "Considerations of the target audience" } \\
\text { - "The search for literature sources" } \\
\text { - "Develops a research proposal" } \\
\text { - "Develops a product prospectus" (p.121) }\end{array}$ \\
\hline $\begin{array}{l}\text { 3) Development of } \\
\text { Preliminary Product }\end{array}$ & $\begin{array}{l}\text { - "The outline or prospectus... is fleshed out into a fully developed } \\
\text { prototype" (p. 121) }\end{array}$ \\
\hline 4) Preliminary Field Testing & $\begin{array}{l}\text { - "Obtain an initial qualitative evaluation of the new educational product" } \\
\text { (p. 121) }\end{array}$ \\
\hline 5) Main Product Revision & $\begin{array}{l}\text { - "Product revision is based on the analysis of data collected during the } \\
\text { preliminary field test" } \\
\text { - "In practice, the researcher assesses the product using both formative } \\
\text { and summative evaluation methods" (p. 122) }\end{array}$ \\
\hline 6) Main Field Testing & - "Involves implementation of the product" (p. 122) \\
\hline $\begin{array}{l}\text { 7) Operational Product } \\
\text { Revision }\end{array}$ & $\begin{array}{l}\text { - The researcher will decide "whether an educational product is fully } \\
\text { ready for use in schools" (p. 122) }\end{array}$ \\
\hline 8) Operational Field Testing & $\begin{array}{l}\text { - "Collection of data from instructors using the product as well as student } \\
\text { participants." (p. 122) }\end{array}$ \\
\hline 9) Final Product Revision & $\begin{array}{l}\text { - Data collected from all stages leads to one final stage of product } \\
\text { revision (p. 123) }\end{array}$ \\
\hline $\begin{array}{l}\text { 10) Dissemination and } \\
\text { Implementation }\end{array}$ & $\begin{array}{l}\text { - In this step the researcher makes sure others are aware of their work } \\
\text { through dissemination efforts (p. 123). }\end{array}$ \\
\hline
\end{tabular}

\section{Action Plan}

Before breaking down each step, it is important to create a research action plan to determine what steps need to be taken to implement this research study. My research plan, outlined in Table 8, captures the key events throughout the process for both my 
dissertation and my product. The goal of this project is to develop a website tool, revise the product, and discover whether my website makes a difference on recruitment, hiring, and induction practices for K-12 online administrators. With the synthesis of the literature I completed, this plan should result in data that would make a difference in the online learning field. The field of online learning is so new, research is needed to fill holes in the literature and provide support to teachers and administrators struggling to meet the need for quality online options (Cavanaugh et al., 2004; Watson et al., 2011). The work plan kept me on track toward my goal to defend my dissertation in the spring of 2014. After reviewing the plan, I then break down each step individually.

Table 8

Research Action Plan

\begin{tabular}{llll}
\hline Month & Dissertation Goals & Product Goals & RD Process Stage \\
\hline $\begin{array}{l}\text { September 2012- } \\
\text { March 2013 }\end{array}$ & $\begin{array}{l}\text { Begin and finish } \\
\text { dissertation proposal } \\
\text { including abstract, table } \\
\text { of contents, preface, } \\
\text { literature review, and } \\
\text { methodology }\end{array}$ & $\begin{array}{l}\text { Bevise website based on } \\
\text { preliminary feedback from } \\
\text { participants }\end{array}$ & $\begin{array}{l}\text { Step 1 Information } \\
\text { Gathering and Step } \\
\text { 2 Planning and } \\
\text { Testing }\end{array}$ \\
$\begin{array}{lll}\text { Rarch 2013- Fall } \\
\text { Revise dissertation and } \\
\text { prepare for defense of } \\
\text { dissertation }\end{array}$ & $\begin{array}{l}\text { Recruit participants for project } \\
\text { and start gathering preliminary } \\
\text { feedback }\end{array}$ & \\
& & $\begin{array}{l}\text { Continue building website and } \\
\text { start adding tools to the }\end{array}$ & \\
& & resource section
\end{tabular}


Table 8 (continued)

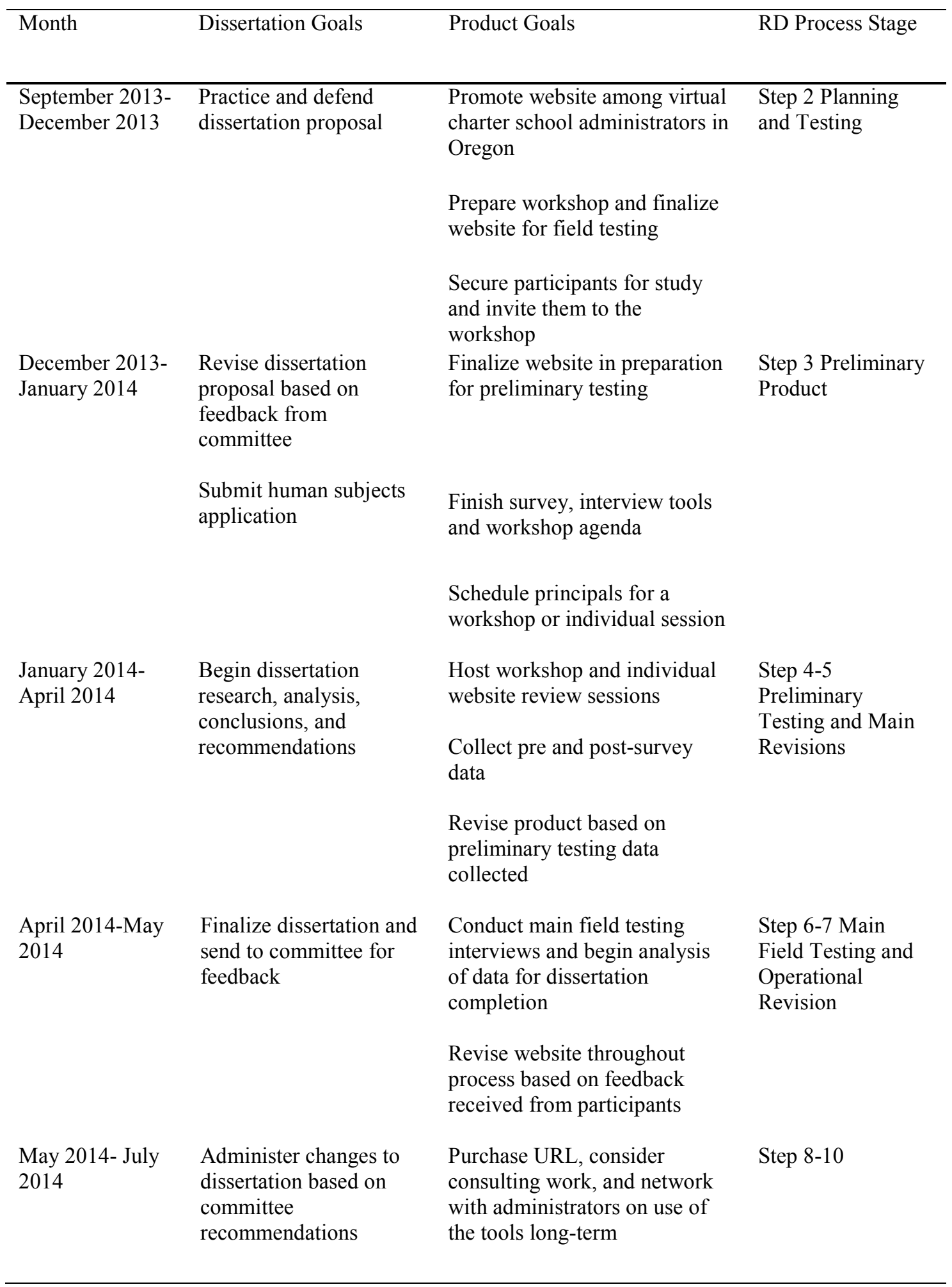




\section{Step 1: Research and Information Gathering}

During the first phase of the $R \& D$ process, there were several goals for the researcher:

1. Clearly define and understand the problem

2. Complete a preliminary literature review

3. Conduct small-scale research

For my project this phase began in the fall of 2012 and continued through the spring of 2013. During this time I completed my literature review on online teachers, and how to successfully transition them from classroom based training or experience into online roles. The literature review defined quality online instruction, examined the current field of online teachers, explored the current recruitment and hiring tools as they apply to online teachers, and concluded by reviewing induction programs around the country. This literature review provided the backdrop for my research and revealed gaps in the current literature. These gaps in the literature revealed where further research was needed in the field. This, in turn, provided additional opportunities for my research to assist practitioners. While working on the literature review, I began discussing with other online program administrators their experiences in hiring online teachers. I also had informal discussions with brick-and-mortar principals regarding their experiences with leveraging online resources for instruction. The literature review and informal meetings helped deepen my understanding of the issue and provided a platform for building a meaningful product for the field.

Near the end of the research and information gathering stage a solution began to emerge. A practical, easy to use website could help online school principals develop a 
hiring process that would help them identify top quality online teachers. From the literature reviewed, the topics of recruitment, hiring, and induction were all identified as possible key areas of resource development for the website. Each section could have several tools that could be updated regularly to make the tool useful and relevant for online school administrators. Instead of several in-depth handbooks focused on teacher best practices, a single powerful resource website would be a concise, easy to use, and dynamic tool offering a complete systematic approach to online teacher hiring.

During the research and information gathering stage, I began to discuss the research goals and direction with other online school leaders in Oregon and around the nation. At the fall iNACOL conference of 2012 I had the opportunity to talk with Cathy Cavanaugh, who wrote several of the pieces of literature I reviewed, and asked her what type of research would be the most meaningful to the field. She said that a study about recruitment and hiring of online teachers would be a good addition to the field. After discussing the original study design with other leaders at iNACOL, it was important to connect with local Oregon administrators, who may be interested in participating in the study. Virtual school administrators in Oregon also felt the website would be a valuable tool to support their work. Finally I ran my idea by Portland State University students in the EdD and Continuing Administration programs to gather their feedback. Using the combination of literature and conversations with educational leaders the focus on recruitment and hiring for the project was confirmed. The goal in the next stage of R\&D process was to start doing some small-scale testing and further planning of the website. 


\section{Step 2: Planning and Small-Scale Testing}

There are several important steps that the researcher completed in the planning phase of the RD dissertation:

1. Develop an initial description of the product

2. Consider how the product will address needs of target audience

3. Continuation of literature review and conversations with target audience

4. Develop a formal research proposal

During the planning and testing phase of my project, the website began to materialize as a result of my literature review and information gathering. Throughout this phase I remained connected to the literature and knowledgeable sources to ensure my product filled a needed void in the research around K-12 online teachers. To remain connected to the field, I attended the annual fall 2012 iNACOL (International Association for K-12 Online Learning) conference, continued literature review, had conversations with other online administrators, and was involved in my dissertation cohort group. Each of these sources added value to my overall project, and kept my work grounded within the field. Attending the iNACOL national conference each year has kept me connected with active researchers and practitioners in the field around the nation, as well as exposing me to the latest articles and resources available through iNACOL. The literature from iNACOL and other key online learning sources ensured my product solved relevant concerns with online staffing. In addition to attending conferences and literature during this phase of the project, I began reaching out to administrators and program developers within the virtual school realm in Oregon. I built connections and surveyed the field about their online staffing needs. This qualitative feedback helped shape my product. My 
involvement in the dissertation cohort also helped me work through the first stages of problem identification and product development. Our cohort is comprised of administrators, technology directors, state level employees, and other educational leaders. This group helped provide feedback from multiple levels to help in the development of a relevant product. Finally, in this phase of the project, I began constructing my dissertation proposal for Portland State University. The proposal followed the suggestions from Bridges and Hallinger (1995) using the platform of PBL. As my product began to take shape, I needed to develop a clear vision of who my audience is and what my tools looked like.

\section{Target Audience and Sample Size}

My target audience for the product was administrators directly involved in the leadership of K-12 virtual charter schools in Oregon. My ideal number of participants was 5-10 leaders who represented several of the virtual charter schools in Oregon. After choosing to focus on a small virtual charter school administration group in Oregon a criterion-based sample technique was used to narrow the participants to a group appropriate to the qualitative nature of the study. In criterion-based sampling, the researcher selects "times, settings and individuals that can provide you with the information that you need in order to answer your researching questions" (Maxwell, 2009 , p. 88). Using this technique the target audience of virtual charter school leaders in

Oregon was selected. This decision was based on my research and experience through the planning stage.

Within the online school domain there are several reasons for focusing on this group of leaders. First of all charter school leaders often wear many hats and perform 
much of their own recruitment, hiring and training (Campbell et al., 2008). The growth within virtual charter schools also outpaces brick-and-mortar charter schools and overall Oregon public schools. According to the Oregon Department of Education (Saxton, 2013) the growth rate of charter schools overall is $4 \%$ and more specifically the growth rate of virtual charter schools $12 \%$. As the Director of an online virtual charter school, I have seen that growth first hand. We have grown at 20-30\% a year over the last three years and have hired 2-3 teachers every year. Based on the rapid growth within this particular sector of Oregon's education system, it can be assumed there will be continued growth resulting in additional teacher positions. Yet, virtual charter schools in Oregon are operating under the same set of laws and perhaps have adopted similar operating functions. Given these conditions, virtual charter school leaders of Oregon are an appropriate target for this particular study.

According to the Oregon Department of Education (2014b), there are eight virtual charter schools in Oregon as well as at least three district charters with an online program. The total enrollment for this school group for the 2014-2015 school year is approximately 8,000 students up from 5,000 in 2009 (Oregon Department of Education, 2014a). Each program has one or two administrators, with the larger programs having several. Based on this information from the Oregon Department of Education (2014a), that would result in the possible participation of a total of 18 targeted virtual school leaders.

\section{Small-Scale Testing}

At the conclusion of step two, small-scale testing was done to advance the development of the product. During this stage I was able to create a working relationship 
with River Crest School District (pseudonym) in Oregon; River Crest that was developing an online component to their charter school. Through this relationship I was able to assist the district through their initial stages of setting up a virtual school, build district awareness of online teaching, and help develop guidelines to enhance the future potential of online teachers. Additionally, I was able to work with my own administrative team including the charter school board, principal, and dean of students in the development of my initial website concepts. Through these relationships I was able to develop a foundation and make field connections that would guide my product development and create an opportunity to enlist participants for the study. Finally, I was able to connect with other Oregon virtual charter school administrators at an annual meeting in April of 2013. During this meeting I had conversations with virtual charter leaders about the direction of my project. Each group during the small-scale testing provided support and an actual pool of future study participants. The goal of small-scale testing was not to collect data but to confirm the intent would be meaningful to the field and to create a network of future participants. Small-scale testing was completed during the spring and summer, and finalized by the fall, of 2013. With the literature review completed, the initial concept of the webpage developed, and small-scale testing completed, it was time to develop the entire website.

\section{Step 3: Develop Preliminary Form of the Product}

The main goal of this stage in the R\&D cycle was to develop a fully functional prototype of the product. With the information and research completed in the first two steps of the R\&D process, I was ready to begin developing a meaningful product. Themes discovered during the initial planning stages helped to create an initial concept for the 
website. The main themes of recruitment, hiring, and induction discovered in the literature review seemed like great topics around which to develop a set of tools during initial product development. Each topic represented a gap in the currently available literature, and, at the same time, had great importance toward developing quality hiring protocols in online schools. During the recruitment stage the school will attempt to find a pool of quality candidates. As the hiring process continues, the school will narrow down the candidates to a finalist. Finally, during induction the administrator will provide the initial support for the new teacher, while connecting them to ongoing support. Methods of ongoing support or professional development are not specifically addressed in this study because there are several resources available on how to support online teachers. Although not a point of emphasis for this study providing regular opportunities to train, discuss, and collaborate for online teachers is critical. On-going support systems for online teachers should continue to improve their best practices in communication, technology used for instruction, certification to teach online and instructional design and delivery. However in the literature reviewed and in my experience, having the right person in training is more important than the content or style of the training. Therefore, focusing on recruitment, hiring, and induction practices for product development would offer the best support to K-12 online school administrators.

In the recruitment phase the tools were focused on supporting virtual charter school administrators to find the best online teachers. The three main goals proposed for the recruitment phase were: (a) establish what type of teacher your selection team is looking for, (b) take advantage of technology available to find top candidates, and finally (c) sort candidates for hiring. The tools to accomplish these goals were: building 
priorities; job posting suggestions; teacher search tools; and skills to look for in online teachers. The tools to accomplish these goals included: determining school building priorities; job posting suggestions; top quality teachers skills to look for on resumes; and how to organize and host interviews. These tools are located in the resources section of the website that I am building. My thinking is that these resources would be webpages that can be easily updated based on feedback from participants.

For the hiring phase, the tools will focus on mechanisms of sorting candidates and locating the top candidates from the field. To help administrators sort the candidates down to the final candidate, my proposed goals were: (a) guide administrators through the hiring process and (b) provide methods to select the top candidate. Tools to meet these goals included: hiring team resources; an online pre-interview process; an interview questions bank; the power of demonstrations; and what not to do in interviews. This tool set helped administrators filter through the candidate pool acquired during the recruitment phase and select the final candidate.

During the final stage of the staffing process, the induction phase tools emphasized techniques to provide the initial support for teachers to make their transition into online work easier to ensure long-term success and viability. To develop a proper induction program, I suggested these goals: (a) guide administrators through creation of an initial induction, (b) increase their awareness about ongoing support, and (c) develop their awareness of adult learners needs. The tools I recommended to meet these goals were: orientation resources, adult learners' tools to increase awareness of adult learners' needs, mentorship tools, and ongoing support resources. The combination of these tools helped administrators build a quality induction program to provide the initial support new 
teachers need. Online staff members that are new will need additional support as they are going through all the normal new teacher transitions in addition to changing teaching environments (Mezirow, 2000; Watson et al., 2011). This paradigm shift for adults can be difficult. If new online teachers are not properly selected or supported, they will most likely fail within their first couple of years (Ingersoll \& Strong, 2011).

The complete set of tools used in this study is available through a website that I built during this product development phase. My first publication of the website was ready in March of 2013. The most current version of the website can be found here (http://goo.gl/1nczS). The website contains information about me, my research, the tool set, research on K-12 online learning, and methods to contact me. These resources are available through html internet formatting and Microsoft Word documents to keep the entire set of tools paperless. If they chose, administrators may print the tools via Word/PDF as a complete packet; however, the main delivery method is via the website. There are several reasons for building a webpage over a published handbook. By building a webpage, I was able to keep the content up to date and relevant. Information in online learning is constantly changing, and it's important to keep supporting documents up to date. Additionally, the website is accessible, relevant to the field and user friendly. For online school administrators who use websites and online technology every day, a website is much more fitting and appropriate than a printed handbook. The website's primary expectation was to offer general information and resources to support online administrators in their development of their recruitment, hiring, and induction processes. In building the website, it was also important to include some basic information about the researcher and the field of K-12 online learning as well as to explain the particular 
context for the study and website. There are also links for participation in the research as well as keeping up to date with its progress. Below is the framework of the website:

\section{Framework of Website}

- Home Page (http://sowle4030.wix.com/k-12onlinestaff) - The home page was designed to provide quick links to the core resources of the site and offer an explanation of what the website is about. There are also links to schedule meetings with me, or participate in my research. A slideshow near the top of the page displays activities, field trips, and outdoor events from my virtual charter school. Other schools in the region offer similar experiences as well. One of the reasons for this slideshow is to show users of the website that virtual education does not all take place in front of a computer.

- About Page (http://sowle4030.wix.com/k-12onlinestaff\#!about/cjg9) -The user will find information on the "About" page demonstrating what the site was created for, and further information about me. There is a link from the Home page directly to this section as website users often search for background data on the company with whom they are interacting (Yang, Cai, Zheng, \& Shou, 2005).

- Resources (http://sowle4030.wix.com/k-12onlinestaff\#!resources/cfvg) - The resources will contain a landing page to explain the main purpose of the recruitment, hiring, and induction sections as well as a list of the tools available. From this page the user can gather their thoughts before diving into the goals and link directly to the three main tools of the website. Alternatively, the user can link directly to the main tools from the top menu drop down. 
- Recruitment Section (http://sowle4030.wix.com/k-12onlinestaffH!homerecruitment/c1bl) - The recruitment section has its own landing page with another overview of the goals of the recruitment process which are: (a) establish what your team is looking for; (b) leverage the technology to find top candidates; and (c) sort candidates based on your preferences. Based on the literature reviewed and my experience, the tools provided in this section are:

- Hiring Committee Priorities (http://sowle4030.wix.com/k-12onlinestaff\#!searchteam-priorities/ciww) - In this section the user is guided through the process of building a hiring committee. Another feature of this section is selecting or refreshing their thinking about the type of online school: they represent. Is it fully online, blended learning, or supplemental? Each type of school may require different skills and teachers, which would influence the entire process. This page also contains resources about narrowing your focus on what you're looking for in a teacher. All tools contain hyperlinks at the bottom of the page that go back to the home page, recruitment main page, or back to resources.

- Job Posting Suggestions (http://sowle4030.wix.com/k-12onlinestaff\#!job-posting$\underline{\text { strategies/c1i7x }}$ - Resources available in this section offer leaders ideas about posting full-time versus part-time, whether to post benefits information, and which sources are available for posting jobs. More importantly it encourages leaders to be very clear in what they are looking for in teachers, so that they have a candidate pool who understands what is being considered. Being very deliberate with the pieces of the job that might not be enjoyable such as; sitting for long periods of time, long travel, or long periods of computer work, will provide 
candidates a clear picture of the job. If job posting only list the positive feature of the job candidates will not have a clear picture of what the work looks like.

- Critical Resume Skills (http://sowle4030.wix.com/k-12onlinestaff\#!desired-

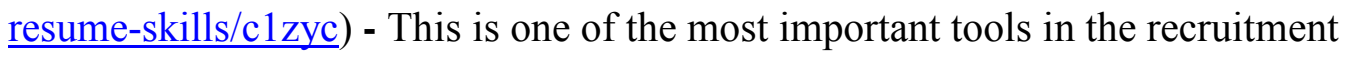
section. After careful review of literature, this section was developed to give administrator users a quick reference list of skills to look for when evaluating resumes and interviewing candidates for online teaching positions. The particular skills are summarized and synthesized from several sources including iNACOL (Treacy et al., 2011), NEA (NEA, 2003), and Keeping Pace with K-12 Online Learning (Watson, Murin, Vashaw, Gemin, \& Rapp, 2010; Watson et al., 2011). Providing a shortened list can streamline the resume reviewing process by helping administrators identify skills that a top quality online teacher would have. Below is a key graphic that was developed during the preliminary product creation that was used as a framework for identifying candidates, developing tools, and building training programs. The framework will be used in recruitment, hiring, and induction tools throughout the website and was developed as a result of this study.

- Interview Organization (http://sowle4030.wix.com/k-12onlinestaff\#! intervieworganization/c4zb) - In this section there are a number of number helpful tools to guide the administrator users through to developing a consistent, rigorous, and ethical hiring process. There are also tips about hosting online interviews versus. face-to-face interviews and practical guidance on setting up both. One of the focal points is ensuring a consistent process between candidates. Each candidate has to 
be asked the same questions, complete the same tasks, and experience the same process.

○ Hiring Section (http://sowle4030.wix.com/k-12onlinestaff\#!home-hiring/c15cl) - The hiring section goals are described as: (a) pre-interviewing, (b) hosting interviews, and (c) sorting candidates to select a finalist. During this stage in the process, the main goal is to select the best candidate from the interview pool.

- Interview Question Bank (http://sowle4030.wix.com/k-12onlinestaff\#! interviewquestion-bank/c5u3) - Within the interview question bank, there is a list of questions for administrators to build their own unique interview questions. The skills identified in the recruitment section will be emphasized in the interview questions. The categories of skills to look for the unique online teacher skills identified in the framework in Figure 5. These skills are unique to online teaching and are online learning experience, certification or professional development in how to teach online, mastery of multiple forms of communication, use of technology in online instruction and instructional design/delivery of online content. There are five to six questions in each of these categories. 


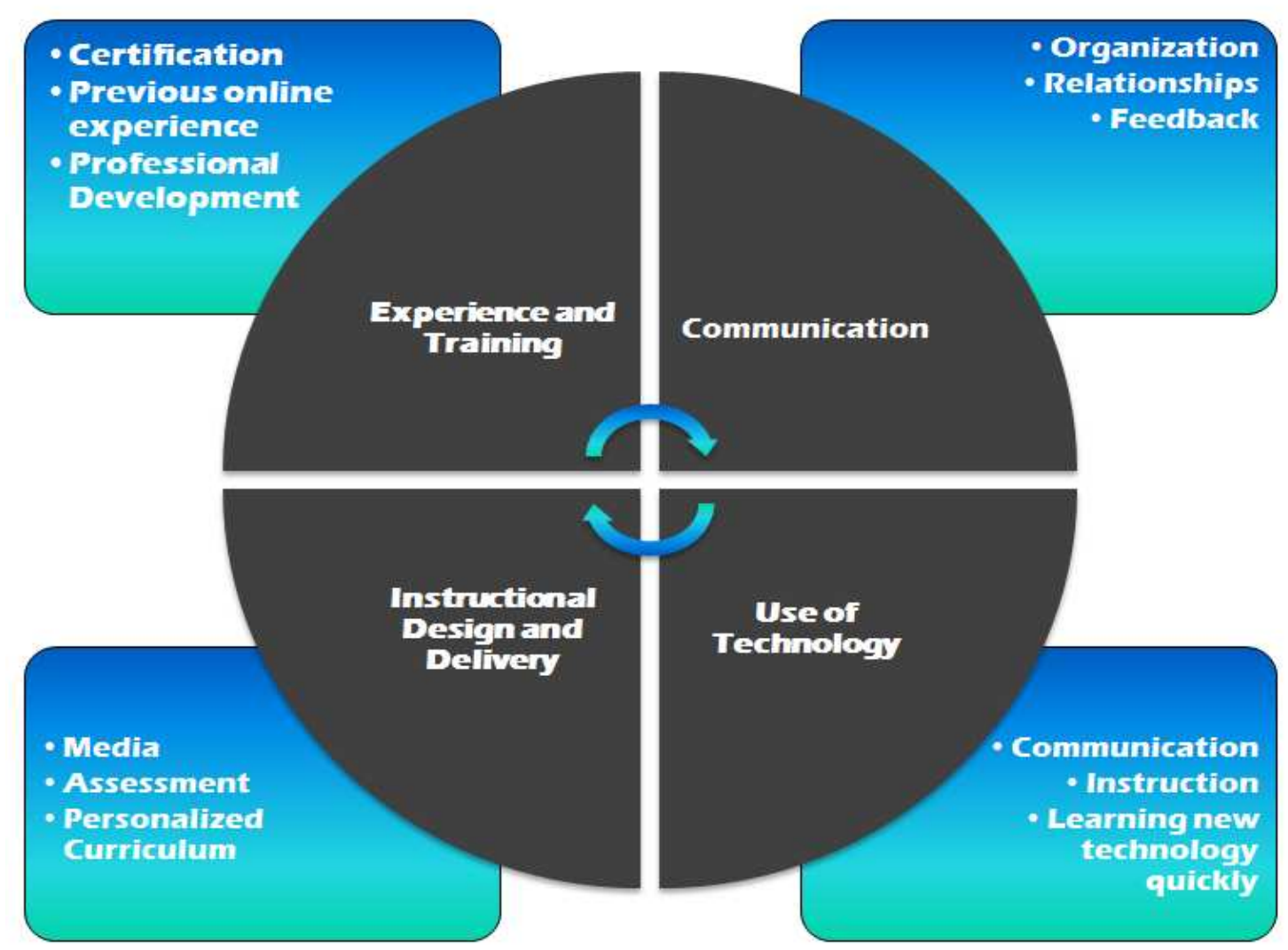

Figure 5. Online Teacher Qualities Framework. C All rights reserved.

- Interview Strategies (http://sowle4030.wix.com/k-12onlinestaff\#! interviewstrategies/cc2a) - Contained in this section are helpful hints of what to do and not do during interviews to be successful. For example, being consistent between candidates, as well as using intuition are valuable tools during interviews. The page warns about giving too much credit to intuition but also says to not ignore the value of intuition. This recommendation is consistent with my review of literature and experience (Peterson, 2002; Stronge \& Hindman, 2003).

- Online Pre-Interview (http://sowle4030.wix.com/k-12onlinestaff\#! online-preinterview/c20tg) - Here the content challenges users to host online pre-interviews 
to test the technology skills of candidates and narrow the candidates down to the top two or three.

- Demonstrations- (http://sowle4030.wix.com/k-

$\underline{12 \text { onlinestaff\#!demonstrations/c1zw3 }}$ ) the demonstration section is another key element of the website. Here the website encouraged administrators to use demonstrations in their interviews and provide examples of what the demonstrations may look like. There are three different types that are suggested as well as descriptions of each. The three types of demonstrations suggested are: on the spot tutoring, online lesson instruction, and product demonstration. Briefly on the spot tutoring is used to view how the candidate may support students who are struggling in a content area and how they would support them, the online lesson would be prepared ahead of time and delivered to the committee and finally product demonstration would challenge the candidate to explain how a piece of curriculum or technology works to the committee. Having a candidate show the hiring team what they know is always better than telling (MacGregor, 2011).

- Induction Section- (http://sowle4030.wix.com/k-12onlinestaff\#!homeinduction/c2vw) the induction section is important to simply remind administrators that immediately after going through a long process to hire a candidate, they need to provide some initial support and connect new teachers to ongoing long-term support. Listed below are some creative and effective approaches to assist administrators in developing an induction program for online teachers. 
- Adult Learners 101- (http://sowle4030.wix.com/k-12onlinestaff\#! adult-learners$\underline{101 / \mathrm{ce} 33}$ ) Adult learners are a unique group to teach and develop. This section reminds administrators of the special needs of adult learners. Adults try to fit their current experience into old experiences. In this process they need time to discuss, reflect, and collaborate with their peers in order to facilitate and support the new learning (Mezirow, 2000). When building professional development or training for adults it is important to keep these factors in mind. By having this reminder, administrators, who have never studied learning as transformation or other adult learning theories, have an opportunity to link to articles to brush up on their skills before developing training programs (Mezirow, 2000).

- Online Teaching Orientation Resources- (http://sowle4030.wix.com/k12onlinestaff\#! orientation-resources/cb4g) Included in this section is a sample orientation that can be downloaded, modified, and implemented at the school of the administrator using the website. The orientation focuses on the shift from classroom teacher to teaching online and goes through the skill categories framework that is a core to the website. Each skill of certification and training opportunities to develop as online teachers, what good communication in online classrooms looks like, how to leverage technology for instruction, and how to develop engaging digital content for students is explained and discussed so that the new teacher can begin their work by having discussions around best practices in online learning.

- Mentorship Resources- (http://sowle4030.wix.com/k-12onlinestaff\#!mentorshipresources/c206p) here the website presents a unique concept discovered in the 
literature review and applied in my own virtual charter school. The concept is e-Mentorship, which essentially means connecting a mentee and mentor on a regular basis using the internet and electronic communication as a primary format for meeting (Thompson et al., 2010).

- Ongoing Support- (http://sowle4030.wix.com/k-12onlinestaff\#!on-going$\underline{\text { support } / \mathrm{c} 1 \mathrm{kf} 0}$ ) the last tool of the website reminds administrators to provide ongoing professional development and support for new online teachers. It also provides links to helpful articles on professional development.

- Research- (http://sowle4030.wix.com/k-12onlinestaff\#!research/cijr) the research section includes links for participation in the study, selected resources cited in the literature review and suggestions for staying current with emerging research presented on the website.

- Consent- http://sowle4030.wix.com/k-12onlinestaff\#! consent/cy9d) as a sub heading in the research section includes a static copy of the informed consent form as a backup method to gather participant permission.

- K-12 Online Learning- (http://sowle4030.wix.com/k-12onlinestaff\#!about-online-

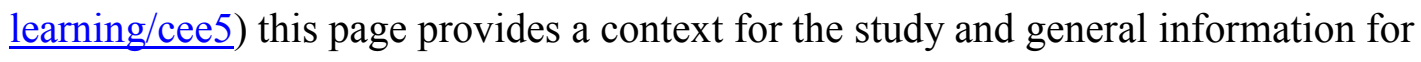
those not familiar with the field. Mainly the site discusses growth in online learning and the changing classroom. The page also points out that online learning is most effective when it is conducted in alignment with best practice.

- Contact- (http://sowle4030.wix.com/k-12onlinestaff\#! contact/c24vq) the contact page has a link to schedule appointments, my contact information including my PO Box in 
Portland for mailing needs, and a link to my professional website. Typically contact pages on websites include information about the company and how to contact pertinent staff. On every page there are links to social media connections to connect with me as the researcher, and find out more about my professional background.

During this time I also compiled my human subject's application prior to preliminary field testing. My projected timeline meant my human subject's application fell under the new Portland State University institutional guidelines for human subject's research. I was awarded a human subjects waiver for my study and was ready to begin research.

\section{Step 4: Preliminary Field Testing}

The primary goal during preliminary field testing was to obtain qualitative feedback on my product. After completing my dissertation proposal in the fall of 2013, I gathered interested parties to provide initial feedback on my website. During this stage of the research the researcher begins live testing of the product with participants in the target audience identified in stage two and three. In this section I discuss preliminary testing procedures carried out during the study. 
Pre-survey. In order to collect the knowledge base, assess needs, and gain consent I administered an online pre-survey prior to the participants viewing the website. The pre-survey consisted of 19 questions; four concerning demographics, five on recruitment, five on hiring, and five on induction. The goal of the pre-survey was to assess the prior knowledge, experience of candidates, gain consent, and explore needs within the topic areas of the website prior to viewing the site for the first time. All questions were semi-structured in nature with a specific, order, design, and purpose (Merriam, 2009). The survey was designed keeping user interface strategy in mind. User interface strategy is used by businesses in the development of software and web-based products to evaluate the end users experience with the product (Yang et al., 2005). By using user interface methods the researcher is able to establish how the product met the needs of the user. The pre-survey was administered to each participant prior to their viewing of the website for the first time. The survey is qualitative in nature seeking to collect the perceptions and understandings of the administrators, both before using my website. Demographic information collected will only be used to identify the participant's school format and their intended role in the hiring process. Distribution of the survey will be implemented under the guidance and procedures outlined in my Human Subject's application. The methods and techniques for these collections are discussed in further detail in the data collection section of this chapter. An example of the pre-survey can be viewed in Appendix C. 
Workshop/individual sessions. During the spring of 2014 I hosted a workshop to review the website with my targeted group of administrators. Prior to the workshop I led the participants to fill out a pre-survey to assess their current knowledge, gather information about their school, gauge how they would be involved in hiring, and to further understand their current awareness in hiring new online teachers. During the workshop I reviewed all the sections of the website with the administrators using the agenda in Appendix G. My role as a researcher in these workshops was a participant observer (Saldaña, 2009). In this role I was able to participate in the workshop, support administrators with their questions, demonstrate the website, and still maintain my role as the researcher. If participants were unable to attend the workshop I scheduled individual sessions. The individual sessions covered the same content, were delivered in the same manner and offered the same review of the website. These sessions were designed to increase awareness of the availability of the tool, show the participant all the tools available, and to discuss how the tools might be used in their unique situation. The workshop was recorded using Blackboard Collaborate for later analysis. Field notes were taken during individual sessions to capture data, discussions, and feedback for later analysis. 
Post-survey. After the workshop all participants immediately took a post-survey to determine how the website helped increase their knowledge regarding recruitment, hiring and induction support of new online teachers. During the pre- and post-surveys I was also able to collect feedback about possible modifications and assess which tools were the most impactful. An example of the post-survey instrument can be viewed in Appendix D. The post-survey consisted of 12 questions; five focused on recruitment, four on hiring, and three on induction practices. The target for the post-survey was to gather new learning, further needs, feedback on the usefulness of the website, and how the website review helped their practice. Once I have secured enough feedback, I will modify the website for main field testing. There were 10 participants in the preliminary field testing process.

\section{Steps 5 and 6: Main Product Revision and Testing}

Main product revision and testing were the most important steps in my research plan. During this phase I accomplished these goals based on Bridges and Hallinger's (1995) R\&D planning template:

1. Based on the feedback from preliminary field test participants, I modified the product for main field testing;

2. After modification based on the preliminary field test results, I showed the administrators the revised website and collected qualitative feedback through an interview tool as seen in Appendix E.

During this phase of the project, I revised and modified the website for administrators to use for their hiring process. I received initial feedback via the pre- and post-survey instruments in step 4, which improved my website tools and their application in schools. After working with an initial broader group of administrators in the 
preliminary field testing, I followed up with all participants to review website changes

after the workshop in one-on-one interviews via phone or in person. The main qualification for groups to participate in my research is that they should plan to be involved in the hiring process of new teachers at their school in the 2013-2014 or 20142015 school years. My goal is to find schools that have administrators who need these tools during the upcoming hiring season, so that the resources will have more impact and relevance to their practice. During the implementation of the tools, I explained how they work and offered support, but my primary role will be a s an observer and as participant where my "participation in the group is definitely secondary to the role of information gatherer" (Merriam, 2009, p. 124).

\section{Interviews}

During the main field testing in the spring of 2014 participants were interviewed after the initial use and review of the website. The purpose of the interview during main field testing was to gather more qualitative information, triangulate data collected in the study by collecting using multiple methods, and to provide a chance to interact directly with participants. Interviews are "a process in which a researcher and participant engage in a conversation focused on questions related to a research study" (Merriam, 2009, p. 87). Interviews are often a main source of data during a qualitative study as they provide ample qualitative data from participants. "Qualitative research is not primarily concerned with eliminating variance between researchers in the values and expectations they bring to the study, but with understanding how a particular researcher's values and expectations influence the conduct and conclusions of the study" (p. 108). The main field testing involved using the interview protocol in Appendix E as a guide to facilitate the 
conversation and ensure the research questions was addressed with each candidate. At the conclusion of the interviews in the spring of 2014 enough data were collected to begin operational revisions in the final stage of the research plan.

\section{Step 7: Operational Revision}

During the operational revision, I made one final round of revisions to my product based on the feedback received during main field testing. The survey and interview data were compiled, analyzed, and processed to help with one final round of revisions to the website. I coded and analyzed the qualitative data collected according to the guidance from Saldaña (2009). In order to draw meaning from the coded data, it should be noted that coding can help by categorizing and organizing transcripts for analysis. Of the coding methods available, I used descriptive coding, which is "appropriate for virtually all qualitative studies... summarizes in a word or phrase - most often as a noun - the basic topic of a passage of qualitative data" (Saldaña, 2009, p. 70). Descriptive coding allows the researcher to identify categories and themes within their data. Categories and themes that begin to emerge will have implications for the study. The goal was to identify patterns that may assist in answering the original research questions: (a) how did the website impact practice, (b) what tools were most meaningful, and (c) what needs to be modified to improve the website? Once the information was coded into categories and themes, using further methods of discourse analysis helped results and patterns emerge from the data. The themes and categories used in this process focused on frequency and language used by participants when discussing tools throughout the data collection and identifying impressions of improvements. The significance building tool found in Gee (2011) allows the researcher to "ask how words and grammatical devices are being used 
to build up or less significance" (p. 92). By first developing themes and categories, I then used the significance tool to discover which elements of the website were the most significant, where the website impacted practice the most, and developed a plan for further revisions based on the most critical areas. After analyzing the data using the constant comparison method, descriptive coding, and the significance building tool I made one final round of revisions to the website. After the final round of revisions, the website is ready for use in the field, should I want to extend the project beyond the dissertation.

\section{Steps 8-10: Operational Testing and Dissemination}

For the purposes of the EdD research project, steps 8-10 go beyond the scope of work, and are more suitable to a professional publication. In this final stage the researcher would involve additional participants, expand the data set, and disseminate the product on a larger scale. If I were to take this product to scale, there are several applications within the field of online learning where my website could make a difference. Since my research will focus on virtual charter schools, my work could be used wherever virtual charter schools exist across the nation. To disseminate my work I have submitted a Request for Proposal to iNACOL to present my findings at the fall 2014 iNACOL conference, which will have a national audience. Through leveraging digital communication technologies, I could support schools across the nation with building online programs and finding the best staff possible. Depending on the results of preliminary field testing and main field testing, I may pursue work to disseminate my website via consultation work after successfully defending my dissertation. 


\section{Data Collection}

The process of accurately and objectively collecting data is fundamental for research to make contributions to the field. In the field of K-12 online learning, there is much need for research and support from the academic community to ensure quality online instruction for future generations (Blomeyer, 2002; Cavanaugh et al., 2004). The rapid growth and demand for online classes, shortage of online pedagogy training in teacher preparation programs, and shifting cultural values has placed the burden on schools to find the qualified teachers to meet the demand (Alexander \& Boud, 2001). K12 online program administrators need resources to help them be successful in teacher selection and support (Watson et al., 2011). In this section I will discuss my methodology for data collection through the use of the R\&D research tool to build and modify a resource website specifically focusing on virtual charter school leaders in Oregon. First, I develop and explain my research design, then move on to make an argument for the constructivist paradigm, and finally, I discuss in detail my data collection methodology.

In developing a research agenda, an important first step is aligning your study to a paradigm (Krathwohl, 2009). According to Lincoln and Guba (1985)

a paradigm is a worldview, a general perspective, a way of breaking down the complexity of the real world. As such, paradigms are deeply embedded in the socialization of adherents and practitioners; paradigms tell them what is important, legitimate, and reasonable. (p. 15)

Selecting a paradigm will guide what types of research questions I explore, how I will collect the data, and provide a framework of analysis of the data (Guba, 1990). Of the paradigms available for research, I feel strongly that the constructivist paradigm has a lot to offer teacher recruitment, hiring, and induction environments. Creswell (2009) stated 
that the constructivist "holds assumptions that individuals seek understanding of the world in which they live and work" (p. 8). The goal of research within the constructivist field is to understand the participant's views of the situation being studied. Research with a constructivist perspective seeks to add to the knowledge base by increasing understandings within the focus area of the research (Creswell, 2009; Lincoln \& Guba, 1985). Within the constructivist paradigm, I will be adding to the knowledge and understanding around the best methods for finding and supporting high quality online teachers. The intent of this study is to increase awareness and understanding of recruitment, hiring, and induction practices of online school administrators by providing a field tested website tool. In this case the methodology and paradigm align because the intent of both is to seek understanding about participants experience and to increase awareness in the field of research. For these reasons the constructivist paradigm provided an appropriate paradigm to approach teacher recruitment, hiring, and induction settings.

Using the constructivist paradigm, I began my research in the preliminary field testing using qualitative methods. Bridges and Hallinger (1995) reported that the goal of preliminary field testing "is to obtain an initial qualitative evaluation of the new educational product”(p. _ ). After receiving IRB approval in the spring of 2014, I recruited online program administrators to participate in my preliminary testing. My goal was to secure about 5-10 administrators who would be willing to participate in my research. Merriam (2009) encouraged researchers to "force yourself to make decisions that narrow the study" (p. 171). I am limiting my preliminary group size to increase the amount of data I was able to collect from this first group. To ensure the validity of these claims, I was careful to avoid bias, triangulate data sources, provide rich data, and use 
respondent validation (Maxwell, 2005). Validity is a concern in qualitative studies, as research is generally completed by a single researcher on a small study group, so careful attention is necessary to reduce validity arguments in analysis and collection of qualitative data (Krathwohl, 2009; Maxwell, 2005; Merriam, 2009). To avoid bias I kept in mind that "Qualitative research is not primarily concerned with eliminating variance between researchers in the values and expectations they bring to the study, but with understanding how a particular researcher's values and expectations influence the conduct and conclusions of the study" (p. 108). One of the commonly used measures to ensure validity is triangulation. Triangulation of sources would mean that I would have rich data from several angles to back up claims and patterns (Maxwell, 2005). In the collection of the data, I used respondent validation, which is "systematically soliciting feedback about your data and conclusion from the people you are studying” (Maxwell, 2005 , p. 111) to ensure my bias was not influencing collection. Finally to increase validity I built a research plan that will gather survey, and interview data. "Data that are detailed and varied enough that they provide a full and revealing picture of what is going on" (Maxwell, 2005, p. 110). By having rich data, triangulation, and using respondent validation, I implemented three measures to increase validity of my arguments and research conclusions. After paying careful attention to validity I was able to begin collecting data.

For the preliminary field testing, I emphasized the use of pre- and post-survey instruments. Surveys are prefixed tools that can help to gather demographic data as well as initial perceptions of the website tools (Merriam, 2009). I used the online survey tool, Survey Monkey, to secure data that I analyzed, using descriptive and significance 
building tools mentioned above and made revisions to my product before main field testing. Participants took the pre-survey prior to reviewing the website for the first time. After completing the pre-survey participants reviewed the website and interacted with the researcher during a workshop or individual session. Immediately after the review of the website the participants took a post-survey to assess how the website impacted practice, which tools were the most meaningful and how the website could be revise. Face to face and digital interviews during the main field testing provided a more open ended sample of data that I recorded and took field notes on to collect rich data from the participants. In the interviews I had two goals: (a) receive candid qualitative feedback on my website after revisions are made from the preliminary results and (b) review changes from preliminary testing. In collecting this data I was taking on the role of a participant observer as defined by Merriam (2009), “The researcher's observer activities, which are known to the group, are subordinate to the researcher's role as a participant" (2009, p. 124). In this role I was present to observe and offer support for the use of the tools in the recruitment, hiring, and induction process based on my research and experience. My primary role was to support the hiring team in the use of the tools, while at the same time I was gathering data through surveys and interviews. In preliminary field testing I followed Krathwhol's (2009) advice, to be like a "sponge, soaking up all that is around and listening intently" (p. 266). After completing the preliminary field testing using mostly qualitative measures, I moved onto the main field testing, where I continued to use qualitative techniques.

During main field testing my goal was to collect "formative and summative evaluation data designed to shed light on both how the PBL project might be improved, 
and its efficacy as an instructional tool" (Bridges \& Hallinger, 1995, p. 127). The goal of these qualitative interviews was to gather further data after revisions are complete on my three main areas of research: (a) did the website inform your practice, (b) what parts of the website had the most impact, and (c) what could be revised to make the website better? The main platform for data collection was interviews, face-to-face or digitally, with the participants from the preliminary field testing. A list of interview questions can be seen in Appendix E. During the interviews I used my IRB approved interview questions to gather further qualitative data after revisions from preliminary field work have been completed. After the interviews were recorded, I began using qualitative analysis tools to begin to discover emerging themes in the data. During this phase interviews were recorded, field notes transcribed, and coded according to Merriam's (2009) approach to transcribe all the text of the interview, number all the lines, and then move into analysis methods. In addition to the workshop, interviews, and surveys, I spent as much time as possible with the final participants while they were using the tools during the spring of 2014. During these interactions I was a participant as an observer. My research purpose was known to the group, but my primary role was to support the hiring team in the implementation of the tools (Merriam, 2009). This role would be similar to the role of a consultant that a district might hire in order to have an expert sitting on their hiring team. This role allowed me to ensure the tools are used appropriately, and that the district was able to get the most out of the experience. At the end of the data collection process, I will have preliminary qualitative data from a pre- and post-survey and main field testing qualitative from interviews. By having multiple sources of data, I will be able to triangulate my sources. Triangulation is essentially 
"Collecting information using a variety of sources and methods" (Maxwell, 2005, p. 93). The data collected in this process should yield enough information to begin to work on analysis, and finally, build hypotheses and describe patterns.

\section{Data Analysis}

After data is collected in a research study, data must carefully and objectively analyzed to begin making inferences and conclusions. In the $R \& D$ process there are three focal points that drove analysis: (a) how the product impacts practice, (b) what tools had the most impact, and (c) what improvements could be made to the product (Bridges \& Hallinger, 1995). These focal points meant that the researcher was not only studying how

effective the product is, but also what can be learned by using the product that might have implications in other settings. For my study I sought to improve my website, but I am also interested in how the website can improve hiring practices for online administrators. Those focal points combined with my alignment with the constructivist paradigm will drive my analysis. In this section I discuss my plans for analyzing the data according to the focal points and my research paradigm. First, I discuss paradigms and analysis techniques. Then I explain my plans for using qualitative analysis in my preliminary and main field testing. I finally conclude by summarizing my research methodology and preparing for the next phase of the project.

My earlier argument for the value of constructivism and goals to add to the knowledge base for K-12 online education continued to guide how I analyzed the data collected. For qualitative analysis I feel the constant comparison method would complement the constructivist paradigm. The goal with the constant comparison technique is to constantly compare data until a theory emerges (Merriam, 2009). The 
theory that emerged added to the general understanding of the hiring process in online schools; therefore, the constant comparison method complements the constructivist paradigm. In the constant comparison model, the researcher does "just what the name implies - constantly compare. The research begins with a particular incident from an interview, field notes, or document, and compares it with another incident in the same set of data, or in another set” (Merriam, 2009, p. 200). The constant comparison technique allowed me to begin to categorize, sort, and make inferences on the qualitative data received through preliminary pre- and post -surveys, as well as the main field testing interviews and field notes. With the constant comparison method to being establishing an analysis paradigm I added in other measures of analysis throughout implementing the research plan.

For the preliminary and main field testing, I used qualitative data to help capture understandings and perceptions of the participants. According to my research plan, I had surveys and interviews that will need to be analyzed. In qualitative research, data such as interviews, field notes, and observations will need to be transcribed, labeled, and coded for analysis (Krathwohl, 2009; Maxwell, 2005). Since I was approaching analysis from the constant comparison model, I was looking for patterns or instances early on in my research (Merriam, 2009). Patterns that emerged in the preliminary or main field testing allowed me to form theories that led to conclusions or recommendations. Descriptive coding from Saldaña (2009) "summarizes in a word or short phrase-most often as a noun-the basic topic of a passage of qualitative data" (p. 70). Using this technique I was able to discover patterns and themes in the qualitative data. Next I used the significance building tool from Gee (2011) that allowed me to ask, "how words and grammatical 
devices are being used to build up or lessen significance (importance, relevance) for certain things and not others" (p. 92). Using descriptive coding and significance building, I was able to establish patterns and phrases that were the most important to participants. This enabled me to analyze which components of the website were more meaningful, impactful, and easier to use for participants. This process also allowed me to identify the components of the website that were weak, or not helpful to the administrator participants. Coding and analyzing qualitative data is an intensive process that took time to carefully accomplish. After completing the coding and analysis, I was able to begin to offer conclusions or recommendations from my study. These conclusions will have implications for other virtual charter schools around the country.

\section{Chapter Summary}

The value and depth of my research study produced valid data that could be used to make a difference in K-12 online education. By using a carefully designed qualitative study within the framework of the PBL process, the end product has the potential to make a lasting impact in the field. My goal was to be able to make claims about how my website positively impacted K-12 online school administrator's recruitment, hiring, and induction procedures. After my own experience, research and literature review, I have concluded that finding and supporting online teachers is the single most important effort in building quality online schools. Once an administrator has quality staff members, the staff can help design or modify the rest of the program. Quality teachers are the backbone of any school, especially online schools. Poor online teachers can cost schools thousands of dollars; cause students to dropout due to poor relationships or service; discourage students away from online learning; and cause students to slip through the cracks 
resulting in lost instruction time. I have concluded that for online learning to be successful in the K-12 setting, administrators need to fill online classes with top quality teachers who demonstrate the skills outlined in this paper. My mission is to make a lasting impact on the growing field of K-12 online education. I have focused my efforts on what I feel is the most important building block that will have a lasting impact: filling online schools with top-quality instructors. 


\section{CHAPTER 4}

\section{DATA ANALYSIS}

\section{Chapter Overview}

After the careful development of the website, K-12 Online Staffing Solutions and the creation of a thorough research design process, I was ready to begin my field testing my website with the hope of assisting online school administrators actually prepare for the upcoming 2014 hiring season. During the course of the field research I was able to recruit Oregon virtual charter administrators to participate in my research. Through pre/post knowledge surveys, a website use workshop, and follow up interviews, I was able to gather data from eight virtual school leaders representing 6 of 10 Oregon virtual charter schools. The number of students served by this group of leaders is about 3,000 representing $40 \%$ of the total students in virtual charter schools in Oregon (Oregon Department of Education, (2014a).

Using qualitative data collection, coding and analysis techniques discussed in chapter 3, I was able to identify trends and themes in the data. Results from the data collected revealed that the website was clearly able to assist administrators with the upcoming hiring season. Administrators reported changes in practices, immediate use of the tools, and encouraged use beyond the participants of the study. I also learned there were a number of similarities between best practice discovered in the literature review and the current practices of Oregon virtual school administrators in the field. For example all of the participants already had induction programs, although they varied in scope in 
format, each leader already used this valuable tool. Also the leaders had some tools or procedures already present for recruitment and hiring but the website expanded, improved, or developed new ideas for the leaders. Interestingly, practice in the field was often in alignment with recommendations from the literature. The findings of this study are significant for the overall field of K-12 online learning. The following discussion highlights the collection of data during the implementation of the website during the research process. The discussion concludes with final revisions made to the website as a result of data collection and explore the challenges I experienced through the process (Borg \& Gall, 1989).

\section{Implementation of the Website}

By following the first seven steps of the R\&D process as a guide, the website K-12 Online Staffing Solutions provided meaningful results. During the course of my research I was able to have rich dialogue with online school administrators about our experiences, both good and bad, in being pioneers in the virtual charter school field in

Oregon. The R\&D process was designed to keep research close to work in the field, yielding practical and useful tools to solve real problems in education (Borg \& Gall, 1989; Bridges \& Hallinger, 1995). Through the use of this model, I was able to discover meaningful information for the field of K-12 online learning. Additionally, the website I developed has the potential to extend beyond the nature of this research to impact the recruitment, hiring, and induction practices of online schools around the region and country. In the next section I carefully explain my design process following each step of the R\&D process during the course of my product creation, field work, and analysis afterwards (Borg \& Gall, 1989). 


\section{Preliminary Field Testing Results}

Preliminary field testing began in the winter of 2014 and continued until spring break of 2014. "The purpose of the preliminary field test is to obtain an initial qualitative evaluation of the new educational product" (Bridges \& Hallinger, 1995, p. 120). The overall design of preliminary field testing was to have the participants take the pre-survey before either a workshop or individual training session and complete the post-survey immediately following. This design would assess the participant's knowledge before and after using the site in order to determine how the site impacted practice, which tools were

the most useful, and how the website might be improved. In this section I explain how the participants in the study explore the pre-survey process, discuss the workshop and individual sessions, and finish by reflecting on the post-survey.

The preliminary participants of the study were a mix of virtual charter school leaders around Oregon, who represented a large portion of the students in Oregon virtual charter schools. Though the sample size is relatively small it was a representative sample of total virtual charter school administrators in Oregon. Table 9 is the preliminary participant list for the preliminary testing of $K-12$ Online Staffing Solutions.

The participants of the study were a significant representation of the overall leadership in virtual charter education in Oregon. According to the Oregon Department of Education (Oregon Department of Education, 2014a, 2014b) this group of participants represents about $60 \%$ of Oregon virtual charter school leadership. The leaders who participated in this study have an estimated impact on approximately 3,000 students in the $2014-2015$. That is roughly $40 \%$ of the total enrollment in virtual charter schools in Oregon during the 2014-2015 school year. The participants represented a mix of 
positions including: central office, principal, vice principals or dean of students. Although the administrators had experience in other settings, many were new to hiring online teachers. The original target of 10 administrators was met as well representing a wide range of experiences in virtual and brick mortar schools. This mix and coverage of administrators in the sample size was well-suited to meet the goals of the research.

Table 9

Preliminary Field Testing Participant List

\begin{tabular}{lllcc}
\hline \multicolumn{1}{c}{ School (Pseudonym) } & Gender & \multicolumn{1}{c}{ Position } & $\begin{array}{c}\text { Online Teacher } \\
\text { Hiring Experience }\end{array}$ & $\begin{array}{c}\text { Admin } \\
\text { Experience }\end{array}$ \\
\hline Cascade Virtual School & Male & Principal & 1 & 1 \\
Cascade Virtual School & Male & Dean of Students & 1 & 1 \\
City View Virtual School & Male & Principal & 2 & $20+$ \\
City View Virtual School & Male & Vice Principal & 2 & 5 \\
Digital Learning Virtual School & Male & Executive Director & 1 & 13 \\
Digital Learning Virtual School & Male & HR Director & 3 & 10 \\
Inner Mountain Virtual School & Female & Principal & 3 & 3 \\
Mountain Virtual School & Female & Principal & 3 & 3 \\
River Crest School District & Male & District Office & 1 & 6 \\
Valley Virtual School & Female & Principal & 1 & 3 \\
\hline
\end{tabular}

\section{Pre-Survey}

The pre-survey offered valuable information about the participants and assessed their current understanding of recruitment, hiring, and induction processes prior to using the website. Using a pre-survey is common when assessing the impact of a product on the participant's experience (Krathwohl, 2009; Yang et al., 2005). The pre-survey instrument's main purpose was to assess prior knowledge and gain consent to participate in research. Through this survey I was able to discover more about my participants and 
their current levels of understanding, as well as where they needed assistance. Responses received were coded using descriptive coding and significance building. Descriptive coding allows a researcher to establish categories and themes that emerge in qualitative studies, while the significance building tool can be used to draw out the level of significance by focusing on specific words like "very" or "extremely" (Gee, 2011; Saldaña, 2009).

Pre-Survey data that were collected prior to the workshop or individual sessions was coded and analyzed for emerging themes. The Pre-Survey data results are shown in Table 10.

Table 10

Pre-Survey Results Before Use of the Website

\begin{tabular}{|c|c|c|c|}
\hline Questions & Responses & & \\
\hline $\begin{array}{l}\text { Are you planning on being } \\
\text { involved in the hiring process? }\end{array}$ & Yes- $10 / 10$ & No- $0 / 10$ & \\
\hline $\begin{array}{l}\text { What type of virtual } \\
\text { school/program do you work } \\
\text { for? }\end{array}$ & $\begin{array}{l}\text { Charter fully online- } \\
4 / 10\end{array}$ & Charter hybrid- 6/10 & \\
\hline $\begin{array}{l}\text { How long have you been } \\
\text { involved in the hiring process? }\end{array}$ & First Year- 7/10 & $\begin{array}{l}\text { One year experience- } \\
1 / 10\end{array}$ & $\begin{array}{l}3 \text { or more years' } \\
\text { experience- } 2 / 10\end{array}$ \\
\hline $\begin{array}{l}\text { Do you feel like your current or } \\
\text { planned recruitment methods } \\
\text { yield top quality teachers? }\end{array}$ & Yes- $7 / 10$ & No- $3 / 10$ & \\
\hline $\begin{array}{l}\text { Have you or do you plan to use } \\
\text { demonstrations in your interview } \\
\text { process? }\end{array}$ & Yes- $5 / 10$ & No- $5 / 10$ & \\
\hline $\begin{array}{l}\text { Do you currently have any new } \\
\text { teacher training after they are } \\
\text { hired? }\end{array}$ & Yes- $10 / 10$ & No- $0 / 10$ & \\
\hline
\end{tabular}


Themes that came out of the pre-survey helped assess the participant's prior knowledge and their needs coming into the workshop/individual review sessions. Unfortunately only two administrators filled out the pre-survey allowing me enough time to process, code, and evaluate their surveys prior to the workshop. Eight or a majority of the 10 participants filled out the pre-survey just before reviewing the website. From the pre-survey one theme that emerged was that many of the candidates already felt confident in their ability to hire top quality teachers. Of the responses collected, 7 out of 10 believed their current recruitment process would result in top quality candidates. Three out of 10 administrators did not currently feel they were able to recruit and hire great online teachers. Though participants represented some confidence in their hiring skills, one candidate shared they, "would like more strategies for assessing online teacher quality during the interview process". This insight was incredibly helpful in developing tools later in the study as I was able to build tools to identify top quality online teacher skills. The administrators who participated in the study had some ideas and experience but needed specific support and practical advice to refine their practice. Those who did not have confidence in their process also had much more room to grow and could also benefit from using the website.

Another theme that emerged from the coding of the pre-survey data was the use of demonstrations. From the pre-survey it was reported that only 5 out of 10 of the participants said they currently used candidate led demonstrations in their interview process. The literature placed a lot of importance on the use of the demonstrations to identify top candidates (MacGregor, 2011). Because the literature placed importance on this practice and only five participants already used the process, it would be assumed that 
this would be an area the website could really benefit participants. In fact after collecting data further in the study, this was one of the most improved areas with 10 out of 10 participants desiring to use them after using the website. Collecting this data in the presurvey helped to shape future revisions and refinement of the demonstration section to meet participant needs.

An important area that was observed in the data collected was doing some skills checking before any interview time actually occurred. Candidates had ideas to do a "bit of pre-orientating and skill-checking before any actual time is invested in the interview itself." This candidate went further to say, "screening out unskilled applicants by creating a bit of a challenge might yield a better candidate pool.” These comments along with other comments that were similar showed that the administrators wanted some prescreening tools that candidates could complete before the interview. These skills tests could be integrated into the website and hiring practices adjusted to include them in the application process. Since all virtual schools are public equal opportunity employers, administrators would have to be careful about placement/use and determined appropriation of these skill assessments. It would make the most sense to have the candidates selected for an interview all complete the skill tests and submit them before the interview. In this manner all candidates are selected based on the merits displayed on their resume such as experience, education, and training.

In the area of induction it was reported that 10 out of 10 administrators already had an induction program in place. This was not surprising as the literature has more resources focused on professional development and training of online teachers than how to hire them. The focal point of the website was to shed a new light on the subject of 
teacher recruitment and hiring, and give the administrators some creative ideas for modifying their existing induction processes. In response to the question, "What is your current understanding of new teacher needs after they are hired?" administrators demonstrated that they already had a decent understanding in this area. Using descriptive coding, a number of induction topics emerged such as: support, school procedures, hardware, mentoring, account access, and observing online instruction. These were topics that also emerged in literature reviewed (Means et al., 2013; Watson et al., 2011). From the variety of topics mentioned that reflected the literature, it would seem that administrators already have good awareness regarding new teacher induction needs. One participant shared, "I have ideas for how to streamline the hiring and induction process. They're untested, though, and who knows what will happen to them when they meet the actual conditions of hiring new staff." The participants show that they have ideas and need specific support to guide those ideas into implementation of successful induction programs. Another administrator shared, "Teacher need to be trained in the practices of the school. Most new teachers need a mentor or an experienced resource. They need extra time to become family with the school and procedures." This participant understands the basic needs of training new staff members on "practices and procedures". The pre-survey revealed a lot of valuable information about the participant's current knowledge, which will provide a great baseline to build from during the study.

The pre-survey provided a great window into participant's current knowledge and experience but also provided an opportunity to identify new themes in the data. From the data collected several findings emerged: (a) a technology pre-quiz would be a valuable resource in addressing many of the needs expressed by the administrators; (b) more 
resources were needed in the recruitment section to increase the number of recruitment tools, (c) demonstrations were not being used by all participants and would be a possible area for improvement in the online teacher selection process, and (d) online teacher skill identification would be a significant component of the recruitment process based on the needs expressed by participants. These findings combined with the data collected indicating the importance of recruitment, demonstrations, and induction topics were a great learning platform to take into the workshop or individual sessions.

\section{Workshop and Individual Sessions}

In the preliminary field testing process, the workshop and individual training sessions provided a significant opportunity to present the website, interact with participants, and gather valuable data for revising the product. The goal of the workshop and individual sessions was to show the website to the participants while building their capacity for future participation in the study. By hosting a workshop or meeting one-onone with participants, their future participation in the study would be more meaningful. Many of the administrators may not have taken the time from their busy schedules to fully review the website. Therefore it was important to meet in person with the participants to ensure the entire site was explored, explained, and discussed. To accomplish this task both the workshop and individual sessions shared mostly the same agenda as seen in Appendix G. However, the individual sessions were more personalized due to the one-on-one nature of the review and lacked the teamwork/discussion pieces. The original workshop was held before spring break and had four participants. After spring break individual sessions were scheduled with the remaining six administrators. The workshop was scheduled to be approximately three hours in length, and the 
individual sessions lasted anywhere from one to two hours, depending on the time schedule of the administrators. By hosting these opportunities in person to review the website, the number of participants was increased and the quality of their experience was superior. One participant said that, "I feel way more confident and continue to grow all the time. It was helpful to spend the time discussing the process. It is time we might have never spent otherwise." Because of the literature review and my leadership experience, I was aware of the needs of adult learners to discuss as they learn new content (Mezirow, 2000). Therefore having a discussion based field test was critical in effectively implementing my website. Before the workshop and individual sessions I asked the candidates to do the pre-survey and to complete the post-survey upon completing the review of K-12 Online Staffing Solutions.

\section{Post-Survey}

After completing the pre-survey and website review sessions, the post-survey data were analyzed. Looking back at the significant topics that emerged from the pre-survey of recruitment, demonstrations, and induction, I observed changes in all of these areas after the first use of the website. Table 11 summarizes the data collected in the postsurvey.

\section{Table 11}

Post-Survey Data After Use of the Website

\begin{tabular}{lll}
\hline Questions & Responses & \\
\hline After reviewing the website do & Yes- 10/10 & No- 0/10 \\
you now feel like your modified & & \\
recruitment methods will yield & & \\
top quality candidates? &
\end{tabular}


Table 11 (Continued)

\begin{tabular}{|c|c|c|c|}
\hline Questions & Responses & & \\
\hline $\begin{array}{l}\text { Will you plan on using } \\
\text { demonstrations in your interview } \\
\text { process after reviewing the } \\
\text { website? }\end{array}$ & Yes- 10/10 & No- $0 / 10$ & \\
\hline $\begin{array}{l}\text { After reviewing the website do } \\
\text { you feel like you still need help } \\
\text { with hiring online teachers? }\end{array}$ & Yes- $0 / 10$ & No- $10 / 10$ & \\
\hline $\begin{array}{l}\text { What new teacher training will } \\
\text { you add or change after using the } \\
\text { site? }\end{array}$ & e-Mentorship- 6/10 & Orientation- $3 / 10$ & Adult Learners- $1 / 10$ \\
\hline
\end{tabular}

The post-survey data revealed improvements in most of the areas addressed by the website. Seven out of 10 of the participants reported that they were confident in their ability to recruit top quality candidates A. After the website review sessions there was a $33 \%$ increase to 10 out of 10 . This was quite significant since prior to using the site there were 3 out of 10 participants who did not feel confident in their recruitment process, and who gained understanding after using the website. A significant quote was shared by a participant, "The website has made me feel much more comfortable with recruiting online teachers. I am sure that I will use it as a resource for hiring online staff." Another participant shared, "I am very impressed with the website. The available resources and processes will be very useful in our future efforts." Next in the pre-survey, only 5 out of 10 of administrators reported that they use demonstrations in their hiring process. After reviewing the website 10 out of 10 reported they would want to use demonstrations. This is another significant increase in the commitment of participants to use demonstrations in the hiring process. One participant said, "I really liked the discussion about demonstrations in the interview process. It gave me a lot of ideas for future hiring." 
Finally, my initial observation that many of the administrators had induction resources I prior to reviewing the website was confirmed. While most of the participants already had induction programs in place I wanted to focus on adding new ideas or concepts to their current practices. The post-survey data revealed that 6 out of 10 mentioned e-mentorship after reviewing the site. The website resources focused on e-mentorship inspired the administrators to add an e-mentorship program into their induction processes. After learning about e-mentorship, one participant mused, "I have been doing all the mentoring/training; but I would like to pass that duty on to a teacher-leader." A teacherleader could easily use e-mentorship to support the new teacher in the field. The website appeared to be making a difference by getting their thought processes for improving practice going even before main field testing began. The next step was to evaluate the survey data and gather suggestions for new tools, revisions, or additions to the website.

The process of the preliminary data collection provided a great deal of rich data to make modifications and improvements to the website. In addition to continuing to provide data about the website, I continued to gain valuable information about how the participants were progressing in their awareness of recruitment, hiring, and induction practices for K-12 online schools. During the process of preliminary testing the data collected was building momentum for main product revisions and providing additional perspectives not achieved through literature review or my experience. Interactions through this process increased my awareness and overall perspectives of what virtual charter school administrators actually need in the field. Based on the data collected in the preliminary testing online administrators need the most support in recruitment and hiring stages. While they demonstrated growth in the induction process, the biggest gains in 
practice were in recruitment of top quality teachers, using demonstrations in the selection process, and utilizing an e-mentorship program.

\section{Main Product Revisions}

Through the process of preliminary field testing data received from the pre- and post-surveys provided enough data to formulate significant revisions to the website. The changes and selected quotes from preliminary testing are summarized in Table 12

\section{Table 12}

Summary of Main Product Revisions From Preliminary Testing Data

\begin{tabular}{lll}
\hline $\begin{array}{l}\text { Survey Data } \\
\text { Gathered }\end{array}$ & Quotes & Action \\
\hline Recruitment & $\begin{array}{l}7 / 10 \text { reported they felt confident in their } \\
\text { current hiring process. }\end{array}$ & $\begin{array}{l}\text { Created a Facebook page to alert } \\
\text { participants of updates regularly, Linked } \\
\text { In, and Google + Profiles were linked to } \\
\text { the page to update community on } \\
\text { revisions. }\end{array}$ \\
& $\begin{array}{l}\text { "Have the resources on the webpage } \\
\text { updated on a regular basis to follow any } \\
\text { changes." }\end{array}$ & \\
& $\begin{array}{l}\text { "I would like to gain more knowledge of } \\
\text { the qualities to look for in an effective } \\
\text { online teacher." }\end{array}$ & $\begin{array}{l}\text { Included a brick and mortar versus } \\
\text { online instruction grid. }\end{array}$ \\
& $\begin{array}{l}\text { "I would like more strategies for } \\
\text { assessing online teacher quality." }\end{array}$ & $\begin{array}{l}\text { Put in demonstration examples that } \\
\text { principals can easily use. }\end{array}$ \\
& $\begin{array}{l}\text { "I would like to know how to advertise } \\
\text { position better so that I have a larger } \\
\text { pool of candidates." }\end{array}$ & $\begin{array}{l}\text { Updated recruitment tools and built a } \\
\text { sample job posting and job description. }\end{array}$
\end{tabular}


Table 12 (continued

\begin{tabular}{lll}
\hline $\begin{array}{l}\text { Survey Data } \\
\text { Gathered }\end{array}$ & Quotes & Action \\
\hline Hiring & $\begin{array}{l}\text { 5/10 currently use demonstrations } \\
\text { "Examples of what types of interview } \\
\text { demonstrations work well during the } \\
\text { interview process." }\end{array}$ & $\begin{array}{l}\text { Updated demonstrations to include } \\
\text { examples in each subject area. }\end{array}$ \\
& $\begin{array}{l}\text { "Identify who is comfortable with } \\
\text { technology." }\end{array}$ & $\begin{array}{l}\text { Added a new pre-screening technology } \\
\text { quiz in the hiring section. }\end{array}$ \\
& $\begin{array}{l}\text { "Pre-screening part that would filter out } \\
\text { people who are lacking in the area of } \\
\text { technology" }\end{array}$ & $\begin{array}{l}\text { Included additional pertinent questions } \\
\text { in the pre-screening technology quiz. }\end{array}$ \\
& $\begin{array}{l}\text { "I feel getting to know how the new hire } \\
\text { related with families and other teachers } \\
\text { is an area would be the most helpful." }\end{array}$ & $\begin{array}{l}\text { Included relationship questions in the } \\
\text { technology pre-quiz. }\end{array}$ \\
$\begin{array}{l}\text { "Getting a technology demonstration of } \\
\text { some kind from a candidate." }\end{array}$ & $\begin{array}{l}\text { Confirmation of pre-screening tool } \\
\text { developed already. }\end{array}$ \\
\hline $\begin{array}{l}\text { Induction } \\
\text { "Reviewing adult learners from time to }\end{array}$ & $\begin{array}{l}\text { Will ensure topic is covered and } \\
\text { emphasized in main testing. }\end{array}$ \\
$\begin{array}{l}\text { "I loved the e-mentoring development } \\
\text { piece." }\end{array}$ & $\begin{array}{l}\text { Added a follow up link to the source } \\
\text { article and added an example of our } \\
\text { mentorship program rules. }\end{array}$ \\
$\begin{array}{l}\text { "Face-to-face has been the most } \\
\text { teactive method of training new }\end{array}$ & $\begin{array}{l}\text { Include face-to-face training in induction } \\
\text { resources. }\end{array}$ \\
\hline
\end{tabular}

Product revisions made as a result of the preliminary field testing significantly improved the website. Multiple administrator perspectives with varied field based experience improved the website and proved to be incredibly enriching. Implementing 
the $R \& D$ process added great depth, quality, and relevance to the website by promptly utilizing feedback from the participants through on-going revisions of the website. Revisions made in each section of the website included significant resources and greatly improved the quality of the overall website.

The revisions made to the recruitment section increased the ability of administrators to recruit top quality candidates. In my conversations with the participants it was shown time and time again that as one participant shared "We are all doing the same work, let's not re-create the wheel." Other virtual charter school administrators are now working to build these tools at the same time I am developing them. This project brought us together and provided participants with tools that could greatly improve their recruitment success. The tools that were added during this stage were a sample job posting, job description, a brick-and-mortar versus online teacher skills grid, and created a Facebook page to compliment the site as well as connecting to my Linked In and Google + profiles for further networking. Many of the techniques and tools I have developed for this study are now able to be downloaded, customized, and used at the participant's schools. By including free downloadable samples administrators can create their own version of the tools for their school. In the recruitment section adding in these samples and functionality helped improve the site greatly before the main field testing.

Revisions made to the hiring section added to the methods participants can use to interview candidates for online teaching positions. One of the biggest impacts of the study was the use of demonstrations in online teacher interviews. Demonstrations give hiring committees the chance to see candidates in action using technology and best practices for online instruction. These tasks can be very revealing of a candidate's true 
abilities beyond resumes, letters of reference, and regular interview questions. During the main product revisions a demonstration test item bank was added into the website. This demonstration item bank could be used by participants to build a practical demonstration on any high school content area including; math, biology, history, language arts, and health. Each subject has one to two questions with the answers provided from a digital content provider that is linked to the applicable instructional standards. Figure 6 is a screen shot from the demonstration tool bank located on the website (http://sowle4030.wix.com/k-12onlinestaff\#!demonstrations/c1zw3)

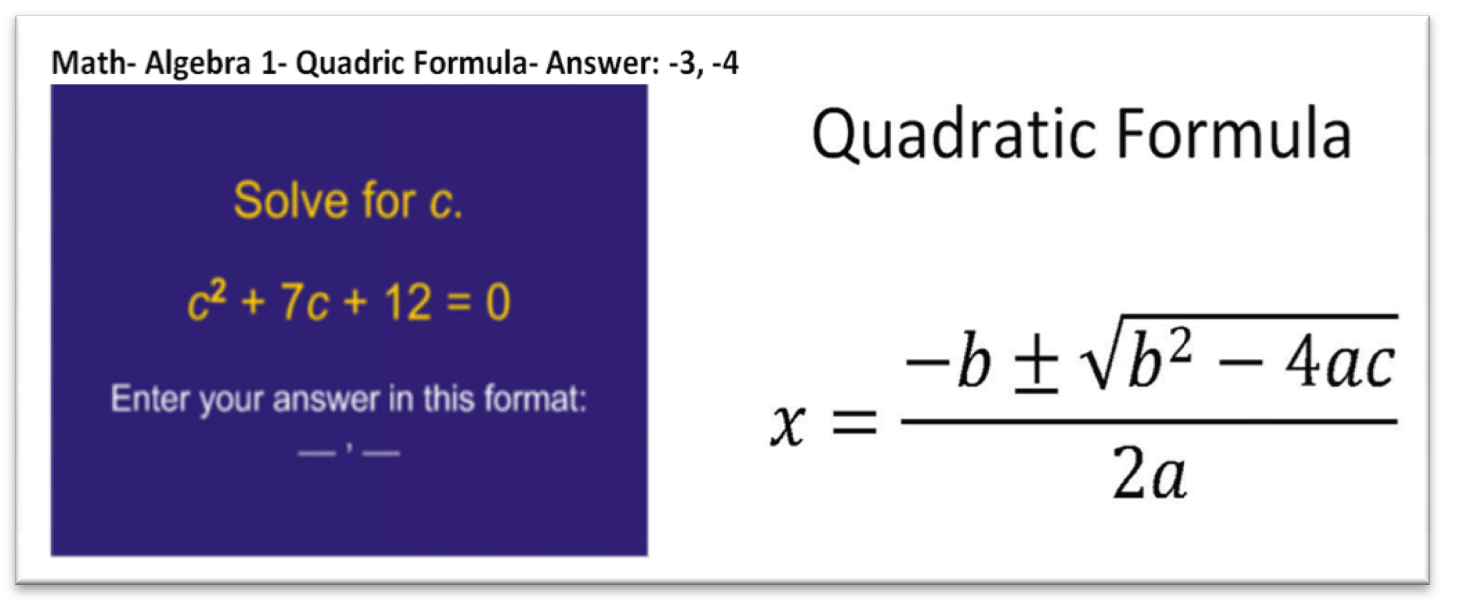

Figure 6. Demonstration item screen shot.

Our school has used this item to hire online math teachers. In this example the candidate is asked to solve the equation and then explain it to the interviewing team like we are students in a computer stuck on this problem. It gives our team a chance to view their content knowledge but also their instructional practices in how they instruct the staff. In my experience this example is very revealing and has made the difference in several of our key new hires. Candidates who are exemplary engage the student by asking 
questions, reflect back on the studying/resources they were using, review the solution to the problem, provide a practice problem to check for understanding, and review what was learned. Candidates who have been able to demonstrate that level of proficiency were hired and successful in our online school.

Another useful addition made during the main product revisions was the online technology pre-quiz. Using descriptive coding I observed that participants kept requesting a way to measure technology skills prior to interviewing a candidate. As a result a technology pre-quiz was added in asking the candidate to complete three basic technology tasks prior to the interview. Those tasks are as follows: (a) download and install Jing (a screen capture tool) to make a 3 minute introduction to the teacher, (b) upload the resume into Google Docs and share with the committee, and (c) create a Prezi summarizing how you have used technology for instruction. These tasks all show the committee the candidate's skills ahead of time.

Finally revisions made to the induction section added value to the tools administrators may use to improve their induction programs. The tool that had the biggest impact on the participants was the e-mentorship program. As a result of that impact a link to the source article was included in that section of the website. Participants also requested to view a sample of a possible mentorship program so they could gain understanding in the area. There is now a sample mentorship program in the mentorship resources section. Another useful tool in the induction section that was added during the main product revisions was a customizable orientation. This orientation focuses specifically on assisting teacher's transition from classroom instruction to online 
instruction. The presentation is loaded using Google Docs and able to be modified as needed. This presentation can be viewed in Appendix N.

After all of the main revisions were completed the main field testing and began to gather another round of feedback from participants. The revisions made during this stage also greatly improved the website's quality, relevance, and usefulness.

\section{Main Field Testing Results}

After completion of the preliminary field testing and product revisions, main field testing began in the spring of 2014. The purpose of this section of the research "involves implementation of the new product and collection of data concerning its application." Through this section of the research I met with participants one-on-one over the phone, in online meeting space, or in person to conduct a synchronous interview. The purpose of the follow up interview was to collect rich data from the participants after their actual use of the website. During the interviews I asked each participant the six questions below;

1. Tell me about your experienceK-12 Online Staffing Solutions? How has website impacted your practice?

2. Do you feel website was easy to use and resources accessible?

3. Which tool was most impactful in your opinion?

4. Can you describe your feelings about hiring new online teachers after using the website?

5. What suggestions would you have for other tools to the website?

6. What other improvements would you suggest for the website? 


\section{Interviews}

The interview and site follow-up process provided additional rich and meaningful data. The pre-and post-survey instruments only provided information related to the predetermined online survey questions asked with no opportunity for follow-up. Interviews are dynamic and live so the interviewer can clarify use respondent validation and ensure both the interviewer and interviewee understand one another. The interviews conducted were one to two hours in length and focused on six qualitative questions listed above. The agenda for the meetings was to review previous changes made during the preliminary field test and so the participant would know I was already applying changes. Reviewing the changes also was used a respondent validation to ensure I was understanding feedback thus far. After the review of revisions was completed we then moved into the new interview questions. During this series of meetings, I was able to meet with 7 of the administrators who participated in the preliminary testing at length to review the website and ask the newly developed interview questions. Although a small sample size, these administrators represented the larger schools in the original preliminary testing group so it was still a quality sample. The feedback from these interviews was illuminating after the administrators had a chance to initially interact and use the website. Timing for the interviews was beneficial since the administrators actually had positions posted and were in an active hiring cycle in preparation for the 2014-2015 school year. Table 13 summarizes demographic characteristics of the main field test participants. 
Table 13

List of Participants During the Main Field Test

\begin{tabular}{lllcc}
\hline School (Pseudonym) & Gender & Position & $\begin{array}{l}\text { Online Teacher } \\
\text { Hiring Experience }\end{array}$ & $\begin{array}{c}\text { Admin } \\
\text { Experience }\end{array}$ \\
\hline Cascade Virtual School & Male & Principal & 1 & 1 \\
Cascade Virtual School & Male & Dean of Students & 1 & 1 \\
City View Virtual School & Male & Principal & 2 & 20 \\
City View Virtual School & Male & Vice Principal & 2 & 5 \\
Digital Learning Virtual School & Male & Executive Director & 1 & 13 \\
Digital Learning Virtual School & Male & HR Director & 3 & 10 \\
Valley Virtual School & Female & Principal & 1 & 3 \\
\hline
\end{tabular}

One of the main targets of the interview questions was to identify how the website impacted their practice and what tools were most useful. Virtual charter school administrators are busy people and I wanted to build a relevant and practical tool to help them make better hiring decisions (Campbell et al., 2008). In Table 14 is a summary of the first four questions and selected quotes from participants; 
Table 14

\section{Interview Questions}

\begin{tabular}{|c|c|}
\hline Interview Question & Selected Quotes \\
\hline \multirow[t]{3}{*}{ 1) Impact practice? } & $\begin{array}{l}\text { "Helped us streamline and make our hiring process more in depth } \\
\text { and proficient at finding the right candidates." }\end{array}$ \\
\hline & $\begin{array}{l}\text { "I have been hiring teachers for over } 20 \text { year and I have never seen } \\
\text { someone so young understand the process so clearly and have all the } \\
\text { tools in one easy to use site." }\end{array}$ \\
\hline & $\begin{array}{l}\text { "I downloaded it all last night and was using it this morning for a } \\
\text { position opening I have right now." }\end{array}$ \\
\hline \multirow[t]{3}{*}{ 2) Accessible and easy to use? } & "For sure it was way easy to use!" \\
\hline & "It is easy to go back and forth and use resources you need." \\
\hline & "Yes it was easy to use." \\
\hline \multirow[t]{3}{*}{ 3) Most impactful tool? } & $\begin{array}{l}\text { "The pre-interview technology piece was great to get a feel for the } \\
\text { candidate's ability to use technology and show us their strengths." }\end{array}$ \\
\hline & $\begin{array}{l}\text { "I really appreciated the brick and mortar classroom teacher versus } \\
\text { online teacher skills comparison." }\end{array}$ \\
\hline & $\begin{array}{l}\text { "The hiring tools made the most difference as we are hiring right } \\
\text { now." }\end{array}$ \\
\hline \multirow[t]{2}{*}{$\begin{array}{l}\text { 4) Describe feelings about } \\
\text { hiring teachers after using the } \\
\text { site. }\end{array}$} & $\begin{array}{l}\text { "This process makes you think about how much time and effort gets } \\
\text { lost if you don't make the right call. The student and families } \\
\text { suffer." }\end{array}$ \\
\hline & "I feel a lot more confident after using the tools." \\
\hline
\end{tabular}

The data collected in the interviews during main field testing resulted in further insight on how the website was impacting practice. One of the main benefits of the interview process was using respondent validation by seeking feedback about data collected and conclusions made during the study. Using this technique provides for clarification and reduces the chance for any bias of the researcher. In regards to the 
question if the website impacted practice 10 out 20 of the participants listed several meaningful impacts on their practice. In the quotes listed above, one candidate downloaded the tools that night for a position they had open. Another candidate was extremely interested in the induction tools as he was working on building their own induction program. Immediately after the interview a follow up session was scheduled to have further conversation around the tools in the website. Other participants stood up in an annual Virtual Leaders Meeting in Hillsboro and said that my tools need to be incorporated into our practice and meetings. All participants indicated in the main field testing that the biggest impact on their practice was the use of demonstration in the hiring process. By using significance building tool, words such as "huge difference" and "we will definitely use that" show that the demonstrations were new ideas the participants would most likely use. All of the participants reported that the website was easy to use, with the appropriate resources available, and all tools that are needed. Finally all participants reported feeling more confident about their hiring process after reviewing the website and getting a chance to use the tools. With field testing completed, collected data were processed and a final round of revisions completed.

\section{Operational Revisions}

The last two questions of the interview schedule asked participants to provide additional revisions or tool suggestions to further revise the website. Revisions as a result of data collected are summarized in Table 15. 


\section{Table 15}

\section{Interview Questions Continued}

\begin{tabular}{|c|c|c|c|}
\hline Interview Question & Feedback from participants & Topic & Action \\
\hline \multirow[t]{10}{*}{$\begin{array}{l}\text { 5) What other tools } \\
\text { would you suggest } \\
\text { for the website? }\end{array}$} & $\begin{array}{l}\text { More information about job } \\
\text { descriptions on the website }\end{array}$ & Recruitment & $\begin{array}{l}\text { Added information and updated } \\
\text { skills list on job description } \\
\text { sample }\end{array}$ \\
\hline & $\begin{array}{l}\text { Resources about hiring full- } \\
\text { time versus part-time }\end{array}$ & Recruitment & $\begin{array}{l}\text { Added information about hiring } \\
\text { part- versus full-time into the } \\
\text { section }\end{array}$ \\
\hline & $\begin{array}{l}\text { Information about using } \\
\text { substitute teachers as a } \\
\text { method of teacher } \\
\text { recruitment }\end{array}$ & Recruitment & $\begin{array}{l}\text { Added sub pool information to } \\
\text { recruitment section }\end{array}$ \\
\hline & $\begin{array}{l}\text { Add word of mouth as a } \\
\text { recruitment tool }\end{array}$ & Recruitment & Added this as a recruitment tool \\
\hline & $\begin{array}{l}\text { Tell candidate ahead of time } \\
\text { what to expect }\end{array}$ & Hiring & $\begin{array}{l}\text { Sample Candidate Letter was } \\
\text { added as a tool }\end{array}$ \\
\hline & $\begin{array}{l}\text { Tools about who is on the } \\
\text { interview committee }\end{array}$ & Hiring & $\begin{array}{l}\text { Added a new tool-Pros/Cons of } \\
\text { various committee members }\end{array}$ \\
\hline & $\begin{array}{l}\text { Include time for } \\
\text { demonstration in the } \\
\text { interview question sheet }\end{array}$ & Hiring & $\begin{array}{l}\text { Modified and updated interview } \\
\text { questions examples to include } \\
\text { time for demonstrations }\end{array}$ \\
\hline & $\begin{array}{l}\text { Modify rating system in } \\
\text { sample interview questions } \\
\text { to a ranking system }\end{array}$ & Hiring & $\begin{array}{l}\text { Modified and updated interview } \\
\text { questions to include a ranking } \\
\text { system }\end{array}$ \\
\hline & $\begin{array}{l}\text { Time before interviews to } \\
\text { review pre-screening } \\
\text { technology quiz }\end{array}$ & Hiring & $\begin{array}{l}\text { Modified and updated interview } \\
\text { questions to include time to } \\
\text { review pre-screening materials }\end{array}$ \\
\hline & $\begin{array}{l}\text { Time to process each } \\
\text { candidate in the overall } \\
\text { process }\end{array}$ & Hiring & $\begin{array}{l}\text { Modified and updated interview } \\
\text { questions to include time in } \\
\text { between candidates for } \\
\text { discussion }\end{array}$ \\
\hline
\end{tabular}


Table 15 (continued)

\begin{tabular}{llll}
\hline Interview Question & Feedback from participants & Topic & Action \\
\hline & $\begin{array}{l}\text { Include an example of } \\
\text { mentorship protocols }\end{array}$ & Induction & $\begin{array}{l}\text { Included a sample mentorship } \\
\text { program in the website }\end{array}$ \\
$\begin{array}{l}\text { 6) Other } \\
\text { suggestions for the } \\
\text { website? }\end{array}$ & $\begin{array}{l}\text { Keep updated with revisions } \\
\text { in the website }\end{array}$ & General & $\begin{array}{l}\text { Built Facebook, Google }+ \text { and } \\
\text { Linked In accounts to go with } \\
\text { page }\end{array}$ \\
& $\begin{array}{l}\text { Feedback page to provide } \\
\text { feedback }\end{array}$ & General & $\begin{array}{l}\text { Built feedback tool to provide a } \\
\text { method participants could give } \\
\text { feedback on the website }\end{array}$ \\
\hline
\end{tabular}

The operational revisions significantly improved the site. Due to the open-ended nature of interviews there was more time for dialogue, clarification, respondent validation, and a chance to ask follow up questions. The limitations of the surveys were that the participants were busy, distracted, and only offered information from the provided questions. At times responses would be about the wrong topic thereby reducing the data available for that question. In the interviews there were at least two hours to dialogue with the participants about website updates and to answer interview questions. In the recruitment section there were a great deal of additional tools and strategies added that were not found in the literature review or included from my own experience. For example using substitute teachers as a pool for future hiring positions is something we have done for two years but in an interview with another principal that concept emerged and it was included in the website. In the hiring section the feedback received from one participant resulted in the demonstration item bank creating a "grab and go", as he referred to it, tool for the principals. Since the literature around hiring or interviewing 
online teachers is so limited the feedback from the participants around the interview tools were invaluable to this study. The interview tool is much stronger as a result of the feedback. Finally for the induction section a participant mentioned that "we are all building this on the fly with no systems in place" for their induction program. By adding in a mentorship program example in the website there was an immediate response and turn around for the participant. Here again using a website rather than printed material increased the relevance of the tool and met the participants needs more quickly than a print version of the tool.

After the main field testing revisions were completed, the website had improved tremendously from my initial template in the winter of 2014. Even though I had experience and had done an extensive literature review to prepare the website for the field, the feedback from the participants helped to contribute to significant improvements to the website. The improvements are a reflection of how successful the R\&D process is at creating relevant and meaningful products and solutions to problems in the field. By keeping the research connected to participants who are key players in the field and continually seeking feedback and data throughout the project, there is an assurance the final product had meaning and impact. While the website functionality improved over course of the project, so did its ability to impact administrator practices. As the website became more refined and easier to use it helped participants improve their selection process, and many of them began using the website tools immediately for their upcoming searches. The website had the most impact on recruitment and hiring practices of participants overall. In the next section I will discuss the challenges of the study and then move into the final chapter. 


\section{Challenges}

Throughout the data collection process and analysis there were a number of challenges and barriers to overcome before reaching the final stages of the study. Yet, in my journey to work with Oregon virtual charter school administrators, I actually ended the process with a greater respect for those working in the field and also with a far superior website than I would have ever been able to construct on my own.

Coordinating with busy school administrators is not an easy task. Working with busy virtual charter school administrators is even more challenging. They wear many hats, often doing their own hiring, training, marketing, business development, supervision and curriculum and instruction oversight. Having walked in their shoes for the last six years, I knew it would be difficult to enlist participants and ensure there was sufficient time to interact with virtual school leaders. Even with that prior knowledge, I was surprised that some of the key participants I wanted to be involved in this study declined to participate. Moreover, for those who did participate, it was difficult to schedule time to fit their schedules and find time to review the website. Often, I would set up meetings across the state at times that were convenient for the participants, but not for my own schedule. Since I am still the Director of two relatively large schools that cover the whole state of Oregon, coordinating the many meetings took a great deal of communication and reminders. My first struggle was getting participants to the workshop. Originally I had anticipated all the participants attending either online or in person on the same day, but many of them were not able to attend on the scheduled day. Consequently, I had to start scheduling individual review sessions, which added greater time and coordination efforts to the study. Field test scheduling and conducting longer interviews were difficult to pin 
down. My original design assumed that all preliminary participants would join the follow-up main testing. Unfortunately, I was only able to work with 7 of the 10 preliminary participants for the main field test. Beyond the difficulties of working with busy virtual school administrators, there also was the time frame in which the study fell to be considered. Since the study was conducted at the end of the year, it was difficult for participants to give the study priority over many pressing tasks that occur. While the study was perfectly timed to give the administrators support for their current searches, it came at a time when they were trying to wrap up the current year and plan for the next. During this time of year administrators must contend with teacher observations, budget development, planning meetings, program evaluations, and many more tasks. Although the time frame of the school year was not ideal, many of the participants felt the time was worth it. One participant reported that, "I downloaded everything last night and am using it for a position I have open right now." Another mentioned that, "The time spent discussing this process is time we may not have spent otherwise, and it was worth it." Although the timing was great to prepare for the hiring season, some of the administrators would have liked to use the tools during the summer and over a couple of hiring cycles, so they were more familiar with the product.

Another challenge experienced during the study was the short duration of the study. Since the study began in the winter and went through the spring of 2014 there was not a long duration of time to collect data. A possible extension of the study would be to follow the participants as they use the tools over the summer and continue to receive feedback. Although the study faced many challenges, there was enough time provided to 
collect the data needed and confirm the goals of the study. However, more time with participants may have led to improving the overall quality of the study (Maxwell, 2005).

Perhaps one of the most frustrating complications occurred when using openended questions and the participants answered a question with the wrong content. For example, some of the open-ended questions about induction were answered with content from the hiring section. To avoid this I had built in explanations of what each section was in the online surveys. I believe the time constraints for busy school administrators schedules made them rush to complete the survey and get back to their primary many duties. Therefore, one valuable lesson I learned is to ask a variety of questions types to get at the same data. That way if one question was not read thoroughly or answered correctly, you do not miss a valuable piece of data in the process. For example there was a question in the post-survey about induction and the participant answered about the completely different topic of demonstrations. The answer did not fit the question at all and the data were lost. For this participant demonstrations were very meaningful but data were lost as a result of using open-ended questions. Fortunately this happened during the preliminary field work and further data could be gathered in the follow up interview process during the main field testing.

Although there were challenges conducting this study, the data collected and process overall proved to be well worth the time and effort. The R\&D process was found to be incredibly powerful in creating a product that has been tested, modified, and improved for use in educational settings. By taking the time to plan, the researcher develops a product that is the best reflection of the literature and their experience in the field. When participants begin to provide feedback on the product, new perspectives and 
stories added to the product's development bringing about changes not possible through one researcher's perspective. The product grows in quality and relevance as the researcher collects data from participants and make revisions. I believe that I would have never been able to create the website on my own without rich feedback and dialogue with other virtual school administrators in Oregon. The collective view of the problem and solutions from a group of talented leaders is always better than one person's notions or assumptions. In this process I gained a lot of respect for virtual charter school leaders in Oregon and developed a tool that can make a difference in our field.

\section{Chapter Summary}

The chapter began by clarifying the study's research goals, and then explained the process of implementing the R\&D methodology in the field. Data were collected, analyzed, and interpreted throughout. Along the way there were a few surprises, but the end result was a confirmation of the problem that administrators of online programs need support in their recruitment and hiring of top quality teachers. Administrators who carefully develop a thorough, rigorous and revealing hiring process have a much higher success rate at bringing quality teachers into the field of online education. The mistake I see many schools making is putting a teacher, who has been unsuccessful in the classroom, into a computer lab to work with students. Then stakeholders wonder why the online program is not being successful. Online classrooms and students need top quality teachers (Watson et al., 2011). K-12 Online Staffing Solutions was designed to help give administrators the tools they need to be successful. Through the use of this website and the $R \& D$ process, I was able to make a difference in the practice of the administrators who participated in my study. 


\section{CHAPTER 5}

\section{CONCLUSIONS, SPECULATIONS, AND RECOMMENDATIONS FOR LEADERSHIP}

\section{Chapter Overview}

The demand for online options in K-12 education has created a need for available resources to meet the need. One of the key components of building a successful online program is having top quality teachers in online classrooms. Online teachers are unique masters of learning, demonstrating proficiency in general teaching strategies as well as leveraging technology to make instruction come alive for students. To meet the growing need for online options in K-12 education, administrators need resources to help locate, identify, and support new online teachers within the current teaching force. After reviewing the literature, it became apparent that there was a gap in tools available and those needed for the recruitment, hiring, and induction of online school teachers. Providing tools for online program administrators, who desperately need them, became the goal of this study.

A possible solution emerged in K-12 Online Staffing Solutions; i.e., the website built for this study. The website was designed to provide research based, and useful tools for online school administrators. Virtual charter school leaders in Oregon were the target audience for the study. Virtual charter school leaders were selected because of their unique needs, which often involve areas traditional administrators may not be responsible for such as teacher recruitment, hiring, marketing, and web design. This pioneering group does their best to lead quality schools while initiating and implementing emerging virtual 
programs and practices. According to the Oregon Department of Education, virtual charter schools have grown at about a $12 \%$ yearly rate over the last 5 years. (Oregon Department of Education, 2014a). Within this growing field, administrators need timely, easy to use, and relevant tools to support their efforts in finding top quality online teachers. The website $K-12$ Online Staffing Solutions was built with this group of administrators in mind. It includes tools in the areas of recruitment, hiring, and induction for new online teachers. Also included are samples, templates and links for further program enrichment and study. Beyond the core framework of tools, the website includes information about the field of K-12 online learning, numerous online resources, and further information about this study. The website was shown to make a difference in the practice of virtual charter school leaders over the course of the study.

Through this study I partnered with 10 virtual charter school leaders in Oregon and tracked their interaction with K-12 Online Staffing Solutions. The study was designed to examine how the website impacted practice and which tools made the biggest difference. The R\&D process was selected as a study design within the theoretical framework of PBL to create a product that was closely tied to needs in the field (Borg \& Gall, 1989). Using the R\&D process, the website was developed, assessed and revised through a series of steps over several months with virtual charter school leaders in Oregon. Preliminary field testing using surveys and website reviews indicated that the website was useful and made a difference for the administrators. After processing feedback and making extensive revisions, the website was taken through the main field testing stage using in depth interviews. By the end of the study the website had undergone significant revisions and improvements that were the result of following the 
$\mathrm{R} \& \mathrm{D}$ process. The end result is a website that clearly has the potential for further use and implementation in both Oregon and the nation. This chapter analyzes the conclusions of the study based on the data collected. In addition the chapter explores possible extensions beyond this study for the website use in Oregon and the nation. The chapter concludes by offering recommendations for virtual school leadership.

\section{Overall Conclusions}

Based upon data collected during the course of the study, it is clear that the purpose of this study was achieved by providing tools that were useful and impacted the recruitment, hiring and induction practices of K-12 online school administrators. Through the preliminary and main field testing process, numerous ideas for revising and improving the website were discovered. Valuable data on how the product impacted practice of educational leaders was revealed. From the study it was clear the website impacted the practice of the participants. The website had the greatest impact on recruitment and hiring practices, the focal point of the study, but also added some valuable tools for induction practices. During the field testing administrators provided a great deal of positive feedback on the website and began using its tools immediately in their selection practices. The following discussion explores the study's primary conclusions and reflects on the process as a whole.

The process of completing the preliminary field testing provided a wealth of information for product improvement and its impact on practice. The preliminary field test involved a 19 question qualitative pre-survey that was completed before reviewing the website. This survey gauged the experience, current understanding, and roles of the participants. After completing the survey participants either attended a live workshop or 
scheduled a one-on-one session to review the site. Immediately after reviewing the website a 12 question qualitative post-survey was completed. Conclusions were drawn and the following revisions were made:

- Brick and Mortar versus Online Teacher Skills: A comparison grid between brick and mortar and online teacher skills was added to the critical resume skills page. Online teachers need a solid understanding of classroom teaching, but also must demonstrate the ability to use those skills in the new format of online learning.

- Technology Pre-Quiz: Many of the administrators wanted to quickly assess a candidate's technology proficiency through a practical method before interviewing the candidate. During the preliminary testing and after some reflection, a technology pre-quiz was added to the pre-interview page. Virtual school administrators need a means to assess candidate technology skills.

- Demonstration Item Bank: While examples and brief descriptions were helpful, administrators need actual demonstration test items they could pull from when preparing for interviews. Accordingly, a bank demonstration items by subject was added focusing on high school level Algebra 1, biology, US and World History, Biology, and Health/PE.

- Updates to the Website: Participants felt a need to be notified of upcoming revisions or changes in the website. During this process a Facebook page was built to provide a way to keep participants up to date on the website, and how it would be changed in the future.

After completing the preliminary field test it was clear that just reviewing the website and providing feedback was a valuable process for the administrators. Prior to reviewing the website only 7 out of 10 of the participants thought their process would yield top quality candidates, and afterward it was increased to 10 out of 10 . Their confidence level increase was significant; the administrators now had tools and were able to discuss their selection procedures, one participant reported, "I feel way more confident and continue to grow all the time. It was helpful to spend time discussing the process. It is time we might have never spent otherwise." One positive outcome of the use from the 
website is that it can impact the level of confidence administrators have in their hiring process to obtain top quality online teachers. In addition to increasing administrator confidence in their selection process, using teacher led demonstrations in the hiring process also made a huge impact on participants. Prior to reviewing the site, only 5 out of 10 reported using demonstrations such as live lessons, practice tutoring or curriculum demos in their interview process, but that number increased to 10 out of 10 after reviewing the website. Therefore, the website was able to alert administrators just how helpful demonstrations can be in the selection process. Another conclusion is that demonstrations are an essential element of the online teacher hiring process. Of all the induction tools presented to participants, the one that made the biggest difference was eMentorship. E-Mentorship is the practice of using technology to connect mentors and mentee's more frequently than traditional face to face support methods. Prior to reviewing the site administrators did not report any prior knowledge of using eMentorship, but afterward 6 out of 10 of the participants said they would use it in the future. Administrators were also impacted by the mentorship program I had set up in my own online school that used teacher leaders as mentors and provided those leaders with an increased professional development stipend. One participant reported, "I have been doing all the mentoring/training, but I would like to pass that duty on to a teacher-leader". Busy administrators do not always take the time to stop and think about their practice. Setting aside the time to participate in the preliminary field work of this study generated a great deal of thought and provided timely tools for their current open positions. A final conclusion from the preliminary testing is that e-Mentorship is a valuable tool for online school administrators. 
After a rewarding preliminary field test experience, it was time for the main field testing and revisions. During this stage individual interview sessions were scheduled for each of the preliminary field test participants with the goal to review the website changes and go through the interview questions in Appendix E. Due to scheduling challenges and the approach of the end of the year activities, only 7 of the original 10 participants were able to participate in this process. After observing some preliminary questions were not answered correctly in the online surveys, it was helpful to be able to interact directly with the participants and use respondent validation to clarify intent and purpose of statements. Although these interviews took more time and were tough to schedule, it was worth the time. The discussions that took place during the main field testing interviews provided rich feedback for the improvement of the website as well as information on how the website was currently impacting the actual practice of participants.

During this process when asked the question, how has the website impacted your practice, one participant reported that, "I downloaded it all last night and was using it this morning for a position opening I have right now." Other participants reported that it helped them "streamline our process to be more proficient at finding the right candidate." The website was clearly impacting their practice and improving their selection procedures. In addition to this impact, all of the participants reported that the site was easy for them to use. The website impacts practice and is easy to use. To demonstrate this point one participant said "I have been hiring teachers for more than 20 years and I have never seen someone so young understand the process so clearly and have all the tools in one easy to use site." One of the main goals of the interview tool was also to identify the most important tool to participants. The tools that were the most useful to candidates 
were: 4 out of 10 preferred demonstrations; 3 out of 10 the pre-interview technology quiz (performance tasks prior to the interview), 2 out of 10 online teacher skills (list of skills to look for in online teachers), and 1 out of 10 e-Mentorship (mentor and mentee meeting through technology). While each of these tools was mentioned in the interview process, the tool that received the most comments throughout the research was the demonstration tool. Demonstrations are relatively new to educational hiring and using them in online teacher interviews is a concept barely covered in the literature (MacGregor, 2011). In fact, after hiring online teachers for the past 4 years, I only began using demonstrations recently. Participants reported, "I really liked the discussions about demonstrations in the interview process. It gave me a lot of ideas for future hiring." Therefore, the same conclusion reached in the preliminary field testing was discovered again in the main field testing proving that demonstrations are a critical component for developing a rigorous and successful online teacher hiring protocol. Throughout the study demonstrations had the largest impact on administrators who participated in the study. They should be a vital part of any rigorous online teacher interview process.

\section{Speculations About Future Research}

Dissertations typically call for future studies and present deeper questions on the problem explored. Currently there are no longitudinal studies on the long-term effects of K-12 online learning on students. The few meta-analysis pieces available are shorter in length, but they do offer some promising trends in K-12 online learning (Cavanaugh et al., 2004; Means et al., 2013; R. Smith et al., 2005). Further research should begin and continue over a period of 20 or more years to follow students who participated in online education over their early postsecondary life and into the first 10 years of their careers. 
Within the study data should be collected in regards to teacher experience, training, and longevity to establish any correlations between teacher quality and student academic achievement. The study should include a side-by-side comparison to brick and mortar only students to establish a control group. Leveraging current studies like the Longitudinal Study of American Youth might be a starting point to gather comparison data (Miller, 2011). Beyond researching student academic achievement in virtual schools, there are still many important questions with online teaching to be explored. Specifically within the area of K-12 online recruitment, hiring and induction practices there are still important questions that need to be researched further to ensure administrators, teachers, and students have all the tools they need to be successful. This section offers suggestions for further study and follow-up.

First and foremost, a long-term study on the use of the website $K$-12 Online Staffing Solutions would be an important future study. Forming a focus group that would meet regularly over the years and discuss use of the website and its tools would add great depth and further refinement to the website. Qualitative studies of long-term duration add to the depth and richness of data collected, and allow for a deeper analysis of the question at hand (Maxwell, 2005). Long-term studies can also increase the validity of the study, as they allow for further refinement of the product and deeper data collection and analysis. My recommendation would be to follow administrative participants as they use the tools over 2-3 hiring cycles and have regular meetings to review changes in the tools. Data collected during this study may be the springboard for developing a common set of recruitment and hiring tools eventually available to administrators from the state department of education or University system. 
In addition to a long-term study on the use of the tools, it would be powerful to complete a long-term study of the candidates hired before and after the tools were implemented in a school. An important question to consider would be: over time would the quality of candidates using a common evaluation metric be better or worse than the teachers hired before the tools were used? On a personal level as I developed these tools, my leadership team thought and discussed our own hiring process, which lead to vast improvements in our own procedures. We gradually refined our processes and grew far more successful at finding top candidates. The hiring process we have developed is far more rigorous, illuminating, and planned than what we had before. Over time it would be interesting to compare the evaluations of teachers who were hired before the implementation of the website and its tools with those hired after its development. Such a study might provide additional data about the overall effectiveness of the website at supporting administrators in their quest to find top quality online teachers.

Finally further revisions and dissemination of the product may have a long-term impact on the quality of online instruction in Oregon and perhaps nationally. This study confirmed that K-12 Online Staffing Solutions made a significant difference in the practice of the participants. Several areas such as; using demonstrations in interviews, eMentorship as a tool to support new teachers, and pre-interview technology tasks to identify candidates who have mastered important technology, all increased participant awareness by $30-50 \%$ as a result of their participation in the study. A product that is able to increase awareness levels of experienced administrators to that degree is worth consideration. One administrator in the study said, "You need to take this and market it to the districts. Districts can even use these tools to hire brick and mortar teachers.” My goal 
in this research is not motivated by marketing or monetary considerations, but rather by a deep belief in the power of online education and a desire to see students have the best learning experiences possible when they try online learning. After spending five years of my life pursuing this topic as both a practitioner and researcher, I have a story and product that can help other leaders. To begin the process of disseminating this product, I submitted an application to present at the fall 2014 iNACOL conference in Palm Springs, CA. After that I plan to experiment with consultation in Oregon and perhaps regionally to share my study results, website, and lessons learned about online teacher hiring. Given the feedback and encouragement I received from participants it appears the interest is there for further dissemination, implementation and development of the product. Another possible extension of the product is to coordinate with the Oregon University System to ensure an awareness of online education and what online teacher quality looks like. Several of the study's participants reported a desire to create universal tools and procedures to assist educational leaders all over the region. Building opportunities to present or teach at the University level may begin to build the bridge between traditional preparation and online school preparation for teachers and administrators. I would consider it a huge success if there was a certificate program for teachers to teach in an online school, as well as a certificate for online administrators to operate online schools. Due to the unique nature of online learning and its rapid growth, this type of alternative certification, could help to greatly increase the quality of online learning experiences in the future. Overall, the website responds well to the needs of online school leaders looking for new answers and a means to prepare children for work and college in the $21^{\text {st }}$ Century. 


\section{Recommendations for Leadership}

First and foremost, administrators, both new and experienced, should be aware of the implications of hiring top quality staff for online schools. Teacher selection is a topic that can often be overlooked in administrator preparation programs in the effort to cover law, budgeting, supervision, reform, and other pressing topics. Typically these programs also focus mostly on leading in brick and mortar environments, leaving leadership without key knowledge coming into online positions. I have found through my years of experience, having the right person in the online classroom was more important than any level of training or teaching I could do. Finding the right teacher for each position is one of the most important tasks a leader can do (Peterson, 2002). As one participant said in the study, "This process makes you think about how much time and effort gets lost if you don't make the right call. The students and families suffer." Taking the time to find the right person has to be a top priority when building quality online schooling options for K12 students. A great classroom teacher can boost a student's learning, and a poor teacher can set them back. Poor online teachers can even be worse than a poor brick and mortar teacher. They can assign their students with excessive chapter readings, not provide them with timely feedback, and even fail to answer their basic communications. If administrators are not paying close attention, teacher complaints do not arise until the students and parents are really upset. In a brick and mortar school the students can at least walk up to the teacher's desk and ask for help. If an online teacher doesn't answer their phone or email, the student has no place to go. Therefore, it is critical that administrators make the right call when hiring online teachers entrusted with the education of K-12 students. 
To begin the recommendations for school leaders, here is a top 10 list culled from this study to provide an easy path forward toward process improvements;

\section{Top 10 List of Leadership Recommendations}

Recruitment Process Recommendations:

1. Build a hiring committee that lines up with your purpose

2. Be descriptive and clear in recruitment processes

3. Know what you are a looking for in an online teacher

4. Use a technology pre-quiz prior to interview

Hiring Process Recommendations:

5. Plan ahead for interviews and communicate with candidates

6. Build your interview tool to include pre-interview, demonstrations, and other items as needed for your position

7. Use some form of teacher led demonstrations in the hiring process Induction Process Recommendations:

8. Know the unique needs of adults and new online teachers

9. Build orientation and on-going support systems

10. Use e-Mentorship to support new teachers

To meet the demand for online options administrators should start by focusing on finding the best teachers through improvements in the recruitment process. As mentioned above in administrator preparation programs there is normally little training on hiring teachers (Peterson, 2002). First and foremost administrators need to organize a hiring committee that has a shared vision and understands what to look for in new teachers. Using the website can support administrators greatly in this process through synthesizing 
key resources to condense information into a usable format. Participants in this study felt that a resource like this was "easy to use" and made them feel "way more confident" in their ability to recruit top quality teachers. Finding great teacher begins by understanding what your team is looking for in a top quality online teacher and clearly stating that on recruitment materials. Finally using online pre-interview technology tasks can really refine the recruitment process. Three out of 10 participants said pre-interviews were the most useful tool in the website. These tasks can have the teacher demonstrate key technology that is important to the school. Using these simple steps should increase the quality of your schools recruitment process.

Once the candidates have been selected for interviewing, careful attention should be paid to the hiring procedures. During the hiring process the team needs to be careful to make the right call. One participant said, "This process makes you think about how much time and effort gets lost if you don't make the right call. The students and families really suffer." Before the candidates arrive for interview time should be spend organizing for the interview by creating forms, organizing location, and sending out pre-interview materials. Participants who used the website presented in this study found the most growth in awareness and intended use of the demonstrations tool. Taking time to observe online teachers in a setting that is as real to what their job will be is incredibly revealing. There have been numerous times the interview was decent and the candidate perfectly executed a live lesson and got offered the job. Demonstrations made a difference for the participants of this study.

Finally administrators hiring new online teachers need to create a high quality induction program to support their new staff members. The most important piece for 
leaders to understand about induction for new online teachers is to understand the nature of adult learners. One of the participates said that it was a "good reminder" to go over the work of Mezirow (2000) to understand unique adult learner needs. New virtual school teachers are going through a difficult transition to adopt new practices, technologies, and methods. Of the participants in this study, e-Mentorship was the most useful tool in the area of induction. E-Mentorship is leveraging technology to connect a mentor and mentee to support the new teacher (Thompson, Jeffries, \& Topping, 2010). Most participants in the study had never heard of this technique before. Additionally they were intrigued by the unique approach to mentorship I implemented in our virtual school. Leveraging professional development funds rather than giving stipends can add dividends back to your program. Staff members grow professionally by attending conferences, adding endorsements, and increase the commitment to school. Using these quick concepts and improvements will lead to a more thorough process to find and support the best online teachers.

Even when an online school has selection concepts or tools in place, using the website can be a practical solution for streamlining the hiring process. Many of the participants in this study previously had some selection tools or procedures in place. The tools in the website can be easily formatted to fit the needs of online programs all over the country. Any program that is growing and needing online teachers could benefit from these tools. While the study focused on virtual school leaders in Oregon, results achieved in this study could apply to other online schools across the nation. 


\section{Implications for Higher Education and State Policy}

The findings of this research should provide a catalyst for changes and improvements in current policy and education to better incorporate the development of professionals who are ready to teach and lead in online learning environments. For institutions of higher education there should be courses, required or optional, to more adequately prepare administrators and teachers to operate in fully or blended online models. Through the literature review in this study it was demonstrated that online learning can be a very effective method of instruction for some students and provides an environment worth investing in for innovative practices and the improvement of student learning. Demand has already outpaced preparation in this field and at this point it is critical for universities to invest resources for improving the preparation of K-12 online educators.

Online teachers and their specific skills are unique enough that policies should be developed to create online teacher certifications options. State licensing agencies should begin to support specific licensing steps to teach online. Using a metric of experience or educational training, online teachers should receive endorsements to teach in online environments. Early practitioners could then become experts and innovators in the field bringing further improvements and new online options. While it may be too early in Oregon to require teacher certification to teach in online schools, other states have considered this. Michigan, for example, has a six week course in teaching online that teachers must take before teaching in Michigan Virtual School. Michigan Virtual University provides professional development opportunities and certification programs for educators to develop their online teaching skills (Michigan Virtual School, 2014). 
Similar programs could be developed in Oregon with the cooperation between the University system, the legislature, and licensing agencies.

With higher education and licensing organizations embracing online learning, the K-12 education field will gain ground in an ever changing technologically advanced society. In the end students who choose online options in Oregon would benefit from improvements made in higher education.

\section{Assessment of Experience}

Through this experience I gained a great deal of knowledge about the research process as well as the topic of online teacher recruitment, hiring, and induction. I came to thoroughly appreciate the $R \& D$ process as a research tool. The $R \& D$ process keeps the research connected with the field to ensure it is meaningful, relevant, and useful to practitioners and researchers alike. When I began the process and studying Bridges and Hallinger 's (1995) work several years ago, it seemed like a simple and practical formula for a study. After completing a round of the R\&D process, I can testify to the power of the process to develop a more meaningful tool. In the next section I explore how the R\&D process helped me grow as a researcher and practitioner.

By completing the literature review, my knowledge was extended beyond the rough beginnings of my practical experience. I graduated from my Initial Administrator Licensure program and went directly into virtual charter school leadership. It was a tough learning curve, and I grew tremendously. After a year I began the EdD program at Portland State University and began to connect my experiences to literature and current practice. The process of completing the literature review itself increased my overall knowledge of the field. By exploring all the available literature regarding K-12 online 
learning, my knowledge of the field expanded. It was incredibly rewarding to find that early research was showing that online learning students were performing equally or slightly better than their peers in studies (Bernard et al., 2004; Cavanaugh et al., 2004). The literature provided a clear path forward to focus on recruitment, hiring and induction practices. Since there was an observed gap or lack of knowledge in these areas it became important to build tools to fill this need.

While the preliminary product was carefully developed, it was nowhere near the product it became following the R\&D process. Preliminary testing was a stark awakening, bringing me from reading hundreds of articles into the reality of practice and application in the field. During the study's initial website workshop I was operating on what I had found in the literature, small-scale research, and my own personal experience. The information and perspectives added by experienced online administrators helped shape my product in a way never possible working alone. The value of multiple perspectives brought greater richness to the study. The R\&D process was a perfect tool because it forced a meaningful connection with participants who were also working in the field of study. The data collection process forced me out of my pre-conceived personal and academic assumptions and allowed me to connect with the realities of the field. One of the surprises in this journey was that virtual charter leaders in Oregon have already discovered a great number of teacher selection methods by piecing together past brick and mortar hiring experience or learning through trial and error. I gained a growing of respect for my colleagues in the field through this study. Their feedback and participation grounded my research and provided motivation to leverage and build new tools to improve the field beyond this study. 
After completing the data collection and analysis portion of this study, I began to get excited about the future of this product. The study demonstrated the website made a difference in the practices of the participants. Moreover, participants encouraged me to disseminate my research and help other districts out. After investing a significant portion of my life in the development of the product, it was wonderful to arrive at the end of this journey and know the hard work was worth the effort. The validation received through this process, indicated that I had selected the right topic, built a meaningful tool, and that the desire is there for further use. This was a powerful reward I was not anticipating.

\section{Chapter Summary}

The website evaluated in this study did have an impact on practice and was shown through the course of this chapter to make a contribution to the field. The chapter began with conclusions arrived at as a result of the study's data analysis. Conclusions had implications and connections for future research. The results of the study showed that the right tool was developed and there is a great need in the field for this type of resource. One administrator who participated stood up in a group meeting of Oregon virtual charter leaders and said, "Dan has built a great tool, this needs to be a part of our future conversations." As an experienced administrator who has now gone through the full R\&D process, I can now offer numerous recommendations and support to new online program administrators. At the end of the chapter, I was happily able to reflect on the journey or process to get to this point. The affirmation and positive feedback from my peers helped validate the entire experience and provide a springboard for what may come next. 


\section{REFERENCES}

Alexander, S., \& Boud, D. (2001). Learners still learn from experience online. In J. Stephenson (Ed.), Teaching and learning online: Pedagogies for new yechnologies (pp. 1-15). Sterling, VA: Stylus Publishing.

Barr, R., \& Parrett, W. (2007). The kids left behind: Catching up the underachieving children of poverty. Bloomington, IN: Solution Tree.

Barrett, B. (2010). Virtual teaching and strategies: Transitioning from teaching traditional classes to online classes. Contemporary Issues in Education Research, 3(12), 17-20.

Barth, P. (2013). Virtual schools: where's the evidence? Educational Leadership, 70(6), 33-36.

Bernard, R. M., Abrami P. C., Lou, Y, Borokhovski E., Wade, A., Wozney, L., . . . Huang, B. (2004). How does distance education compare with classroom instruction? A meta-analysis of the empirical literature. Review of Educational Research, 74, 379-439. doi:10.3102/00346543074003379

Blomeyer, R. (2002). Virtual schools and e-learning in K-12 environments: Emerging policy and practice. Naperville, IL: North Central Regional Education Lab.

Borg, W. R., \& Gall, M. D. (1989). Educational research: an introduction (5th ed.). New York, NY: Longman.

Bridges, E. M., \& Hallinger, P. (1995). Implementing problem based learning in leadership development. Eugene, OR: ERIC Clearinghouse on Educational Management, University of Oregon.

Burns, M. (2013). Larry Cuban on school reform and classroom practice: Why online teaching requires rigorous training. Retrieved February 22, 2014, from http://nepc.colorado.edu/blog/why-online-teaching-requires-rigorous-training

Campbell, C., Gross, B., \& Lake, R. (2008, September, 8). The high-wire job of charter school leadership Education Week, 28(3), 57-58.

Cavanaugh, C., Gillan, K., Kromrey, J., Hess, M., \& Blomeyer, R. (2004). The effects of distance education on K-12 student outcomes. Naperville, IL: Learning Point Associates. 
Clark, G. (2007). A farewell to alms: A brief economic history of the world. Princeton, NJ: Princeton University Press.

Creswell, J. W. (2009). Research design: Qualitative, quantitative, and mixed methods approaches (3rd ed.). Thousand Oaks, CA: Sage.

Danielson, C., \& McGreal, T. L. (2000). Teacher evaluation to enhance professional practice. Alexandria, VA: Association for Supervision and Curriculum Development.

Dawley, L., Rice, K., \& Hinck, G. (2010). Going virtual! 2010 the status of professional development and unique needs of K-12 online teachers. Boise, ID: Boise State University.

Faucett, K. (2011). Virtual schoolteacher. Retrieved April 6, 2013, from http://educationnext.org/virtual-schoolteacher/

Gee, J. P. (2011). How to do discourse analysis: A toolkit. New York, NY: Routledge.

Goodwin, B., \& Miller, K. (2013, March). Evidence on flipped classroom is still coming in. Educational Leadership, 70(6), 78-80.

Greenway, R., \& Vanourek, G. (2006, Spring). The virtual revolution: Understanding online schools. Education Next, 6(2), 34-41.

Guba, E. G. (1990). The paradigm dialog. Newbury Park, CA: Sage.

Hirsch, E. (2001). Teacher recruitment: Staffing classrooms with quality teachers. Denver, CO: National Conference of State Legislatures.

Holstead, M., Spradlin, T., \& Plucker, J. (2008). Promises and pitfalls of virtual education in the United States and Indiana. Education Policy Brief, 6(6), 1-16.

iNACOL. (2011). The online learning definitions project. Retrieved from http://www.inacol.org/cms/wp-content/uploads/2013/04/ iNACOL_DefinitionsProject.pdf

Ingersoll, R., \& Strong, M. (2011). The impact of induction and mentoring program for beginning teachers: a critical review of the research. Review of Educational Research, 81(2), 201-233.

Jeffco Virtual Academy (Producer). (2011). National online teacher of the year [Video] Retrieved from http://www.jeffcopublicschools.org/online/video/kipp.html

Krathwohl, D. R. (2009). Methods of educational and social science research: The logic of methods (3rd ed.). Long Grove, IL: Waveland Press. 
Lincoln, Y. S., \& Guba, E. G. (1985). Naturalistic inquiry. Beverly Hills, CA: Sage.

MacGregor, K. (2011). The hiring process- successful demonstration lessons. Retrieved from http://www.winateachingjob.com/2011/08/hiring-process-successfuldemonstration.html

Maxwell, J. A. (2005). Qualitative research design: An interactive approach (2nd ed.). Thousand Oaks, CA: Sage.

Means, B., Toyama, Y., Murphy, R., \& Baki, M. (2013). The effectiveness of online and blended learning: A meta-analysis of the empirical literature. Teachers College Record, 115(3), 1-47.

Merriam, S. B. (2009). Qualitative research: A guide to design and implementation. San Francisco, CA: Jossey-Bass.

Mezirow, J. (2000). Learning as transformation: Critical perspectives on a theory in progress (1st ed.). San Francisco, CA: Jossey-Bass.

Michigan Virtual School. (2014). About us. Retrieved August 30, 2014, from http://www.mivu.org/About-Us

Miller, J. (2011). Longitudinal study of American youth. Retrieved May 20, 2013, from http://lsay.org/about.html

Mintzberg, H. (1979). The structuring of organizations: A synthesis of the research. Englewood Cliffs, NJ: Prentice-Hall.

Nagel, D. (2009). 10.5 million preK-12 students will attend classes online by 2014. Retrieved January 23, 2012, from http://thejournal.com/articles/2009/10/28/10.5million-prek-12-students-will-attend-classes-online-by-2014.aspx

National Education Association. (2003). Guide to teaching online courses. Retrieved from http://www.nea.org/assets/docs/onlineteachguide.pdf

Oregon Department of Education. (2014a). District estimates and warrants. Retrieved April 17, 2014, from http://www.ode.state.or.us/search/results/?id=344

Oregon Department of Education. (2014b). Oregon online schools. Retrieved March 26, 2014, from http://www.ode.state.or.us/search/results/?id=334

Owston, R. (1997). The World Wide Web: A technology to enhance teaching and learning. Education Researcher, 26(2), 27-33.

Patrick, S. (2012). About iNACOL. Retrieved April 14, 2012, from http://www.inacol.org/about/overview 
Peterson, K. D. (2002). Effective teacher hiring: A guide to getting the best. Alexandria, VA: Association for Supervision and Curriculum Development.

Picciano, A., \& Seaman, J. (2009). K-12 online learning: a 2008 follow-up of the survey of U.S. school district administrators. Newburyport, MA: Sloan-C.

Ragins, B. R., \& Kram, K. E. (2007). The handbook of mentoring at work: Theory, research, and practice. Los Angeles, CA: Sage.

Rice, K., Dawley, L., Gasell, C., \& Florez, C. (2008). Going virtual: unique needs and challenges of K-12 online teachers. Boise, ID: Boise State University.

Saldaña, J. (2009). The coding manual for qualitative researchers. Los Angeles, CA: Sage.

Saxton, R. (2013). Oregon state annual report card 2012-2013. Salem, OR: Oregon Department of Education.

Scherer, M. (2005). The right new teachers. Educational Leadership, 62(8), 7-7.

Smith, R., Clark, T., \& Blomeyer, R. (2005). A synthesis of new research on K-12 online learning. Napperville, IL: Learning Point Associates

Smith, T., \& Ingersoll, R. (2004). What are the effects of induction and mentoring on beginning teacher turnover? American Educational Research Journal, 41(3), 681-714. doi:10.3102/00028312041003681

Stronge, J., \& Hindman, J. (2003). Hiring the best teachers. Educational Leadership, $60(8), 48-52$.

Thompson, L., Jeffries, M., \& Topping, K. (2010). E-mentoring for e-learning development. Innovations in Education and Teaching International, 47(3), 305-315. doi:10.1080/14703297.2010.498182

Treacy, B., Baltunis, S., \& Swiderski, C. (2011). National standards of quality online courses (Vol. 2). Vienna, VA: International Council for Online Learning.

University of Wisconsin-Madison. (2011). Professional certifcate in online teaching. Retrieved January 8, 2012, from http://www.uwex.edu/disted/depd/ cert_benefits.cfm

University of Wisconsin-Stout. (2013). E-learning and online teaching graduate certificate. Retrieved October 1, 2013, from http://www.uwstout.edu/soe/profdev/ elearningcertificate.cfm 
Watson, J. (2008). Blended learning: The convergence of online and face-to-face education. Promising Practices in Online Learning. Vienna, VA: International Council for Online Learning.

Watson, J., Murin, A., Vashaw, L., Gemin, B., \& Rapp, C. (2010). Keeping pace with K-12 online learning: An annual report on policy and practice. Evergreen, $\mathrm{CO}$ : Evergreen Education Group.

Watson, J., Murin, A., Vashaw, L., Gemin, B., \& Rapp, C. (2011). Keeping pace with $K-12$ online learning: An annual review of policy and practice Evergreen, $\mathrm{CO}$ : Evergreen Education Group.

Wong, H., Britton, T., \& Ganser, T. (2005). What the world can teach us about new teacher induction. Phi Delta Kappan, 86(5), 379-384.

Yang, Z., Cai, S., Zheng, Z., \& Shou, N. (2005). Development and validation of an instrument to measure user perceived service quality of information presenting web portals. Science Direct, 42(4), 575-589.

Zimmerman. (2003). Providing effective professional development: What's holding us back? American Secondary Education, 31(2), 37-48. 
APPENDIX A

BAKER WEB ACADEMY SURVEY 


\section{Semester 1 Survey BWA}

*1. Please select your home room teacher $\square$

*2. What in your opinion is going good with Baker Web Academy?

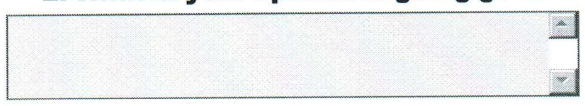

* 3. Where can Baker Web Academy improve?

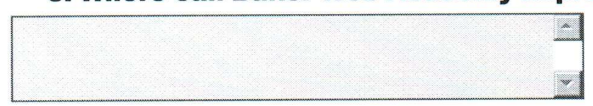

4. If you have a student using Advanced Academics how would you rate your level of satisfaction with the curriculum?

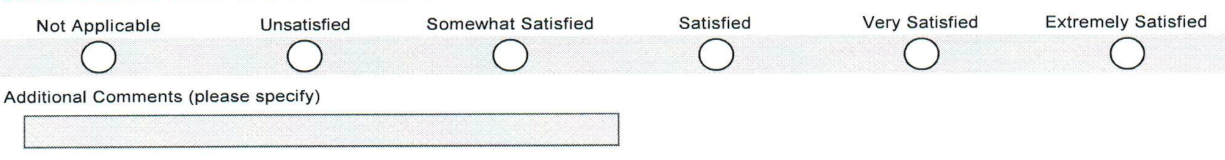

5. If you have a student participating in Compass Learning what is your satisfaction level with the curriculum?
Not Applicable
Unsatisfied
Somewhat Satisfied
$\bigcirc$
$\bigcirc^{\text {Satisfied }}$
Very Satisfied
Extremely Satisfied
Additional Comments (please specify)

6. If you have a student participating in E-Science Labs what is your satisfaction level with the lab kit?
Not Applicable
Unsatisfied
$\bigcirc$
Somewhat Satisfied
0
Satisfied
O
Very Satisfied
Extremely Satisfied

Additional Comments (please specify)

*7. Do you have any curriculum wants or comments?

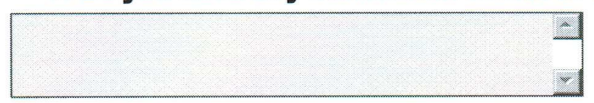


Semester 1 Survey BWA

8. What are your thoughts about the semester transition? What went well, what could be improved?

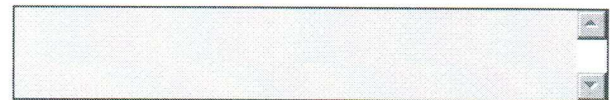

9. How would you rate your overall experience with Baker Web Academy?

Unsatisfied

$\bigcirc$

Somewhat Satisfied

O

Satisfied

$\bigcirc$

Very Satisfied

O

10. What would you say if a friend asked you about Baker Web Academy?
Extremely Satisfied

$\bigcirc$

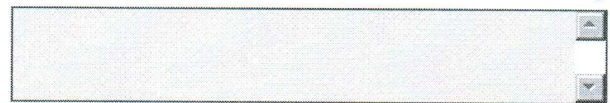


APPENDIX B

CONSENT FORM 


\section{CONSENT TO PARTICIPATE IN RESEARCH}

\section{REVIEW AND EVALUATION OF A WEBSITE- K-12 Online Staffing Solutions}

You are invited to participate in a research study conducted by Daniel Huld, a doctoral student at Portland State University in Educational Leadership: Administration. Mr. Huld is conducting this study for his doctoral dissertation. Dr. Tom Chenoweth is his faculty advisor for this project.

Your participation in this study is entirely voluntary. Please read the information below and feel free to ask questions about anything you do not understand before deciding whether or not to participate. You are being asked to participate in this study because you are a school or district administrator familiar with or connected to the recruitment, hiring, and induction of online teachers.

\section{- PURPOSE OF THE STUDY}

The primary purpose of this study is to examine the challenges of building a new workforce of high quality online teachers to meet the growing demand in the K-12 educational sector for online options. The study will focus on providing web based solutions for administrators in charge of recruitment, hiring, and induction of new online teachers by creating a website with tools to build administrative competencies.

\section{- PROCEDURES}

If you volunteer to participate in this study, we will ask you to do the following:

1. We will ask you to take part in 2 to 3 tasks over the course of approximately 3-4 weeks.

2. These tasks may include: (1) reading/reviewing the website and taking notes (to be explained by the researcher); (2) answering questions about the website and making 
suggestions; (3) participating in a group workshop to explore and analyze the website tools; (4) completing a post-survey regarding the effectiveness of the website; and (5) participating in follow-up interviews

3. At times the researcher will ask questions and facilitate the workshop website preview.

\section{- POTENTIAL RISKS AND DISCOMFORTS}

We expect that there will be no potential risks to you during the course of this study. If at any time you or any other participants feel uncomfortable, you may discontinue your participation.

\section{- POTENTIAL BENEFITS TO SUBJECTS AND/OR TO SOCIETY}

The end product of this study will be a useful tool to any administrator that is a part of building or supporting online programs in their schools. Competencies administrators are asked to often fall outside the scope of their training or sometimes their experience. Useful research based tools provide access and professional development opportunities for administrators to quickly gain information to help them in their work. Borg and Gall (1989) designed a 10-step process that studies the development and implementation of a product in a live setting. Data collected by the researcher will help improve the product for further use in the field. Feedback from participants will make the website more effective for future users building online options in K-12 settings. By using these tools administrators will have access to reliable information to help them build quality online options for students. 


\section{- COMPENSATION FOR PARTICIPATION}

You will not receive any payment or other compensation for participation in this study. There is also no cost to you for participation.

\section{- CONFIDENTIALITY}

Any information that is obtained in connection with this study and that can be identified with you will remain confidential and will be disclosed only with your permission or as required by law. Confidentiality will be maintained by means of a code number to let Mr. Huld and Dr. Chenoweth know who you are. Your name will not be used in any of the information obtained from this study or in any of the research reports. When the study is finished, we will destroy the list which shows the code number that is attached to your name.

Information that can identify you individually will not be released to anyone outside the study. Mr. Huld will use the information and data collected in his dissertation and in other publications. Information obtained from this study will be used for publication or education; however, any information used for publication will not identify you individually.

\section{- PARTICIPATION AND WITHDRAWAL}

You can choose whether or not to participate in this study. If you volunteer to be in this study, you may withdraw at any time without consequences of any kind. You may also refuse to answer any questions you do not want to answer. There is no penalty if you withdraw from the study, and you will not lose any benefits to which you are otherwise entitled. 


\section{- IDENTIFICATION OF INVESTIGATORS}

If you have any questions or concerns about the research, please feel free to contact

Mr. Daniel Huld

Principal Investigator

Doctoral Student

Portland State University

Portland, OR

(503) $780-5185$

dhuld@bakercharters.org
Dr. Tom Chenoweth

Doctoral Advisor

Educational Leadership \& Policy

Portland State University

Portland, OR

(503) 396-8044

chenowetht@pdx.edu

\section{- REFERENCES}

Borg, W. R., \& Gall, M. D. (1989). Educational research: an introduction $\left(5^{\text {th }}\right.$ ed.). New York: Longman.

\section{- $\quad$ RIGHTS OF RESEARCH SUBJECTS}

The Portland State University Institutional Review Board has reviewed my request to conduct this project. If you have any concerns about your rights in this study, please contact PSU Office of Research Integrity, $1600 \mathrm{SW} 4^{\text {th }}$ Ave., Market Center Building, Ste 620, Portland, OR 97207, phone (503) 725-2227 or 1 (877) 480-4400; hsrrc@pdx.edu.

I understand the procedures described above. My questions have been answered to my satisfaction, and I agree to participate in this study. I have been given a copy of this form.

Printed Name of Participant

Signature of Participant

Date

Signature of Witness

Date 
APPENDIX C

PRE-SURVEY INSTRUMENT 


\section{K-12 Online Staffing Solutions Pre-Survey<br>}

Dear Colleague,

Thank you for your interest in my study!

You have been invited to participate in a research study conducted by Daniel Huld, a doctoral student at Portland State University in Educational Leadership: Administration. Mr. Huld is conducting this study for his doctoral dissertation. Dr. Tom Chenoweth is his faculty advisor for this project.

Your participation in this study is entirely voluntary. Please read the information below and feel free to ask questions about anything you do not understand before deciding whether or not to participate. You are being asked to participate in this study because you are a school or district administrator familiar with or connected to the recruitment, hiring, and induction of online teachers.

Please read the consent agreement below before continuing. All survey responses are anonymous. No demographic inform ation will be collected. Thanks again for your cooperation with this study! 


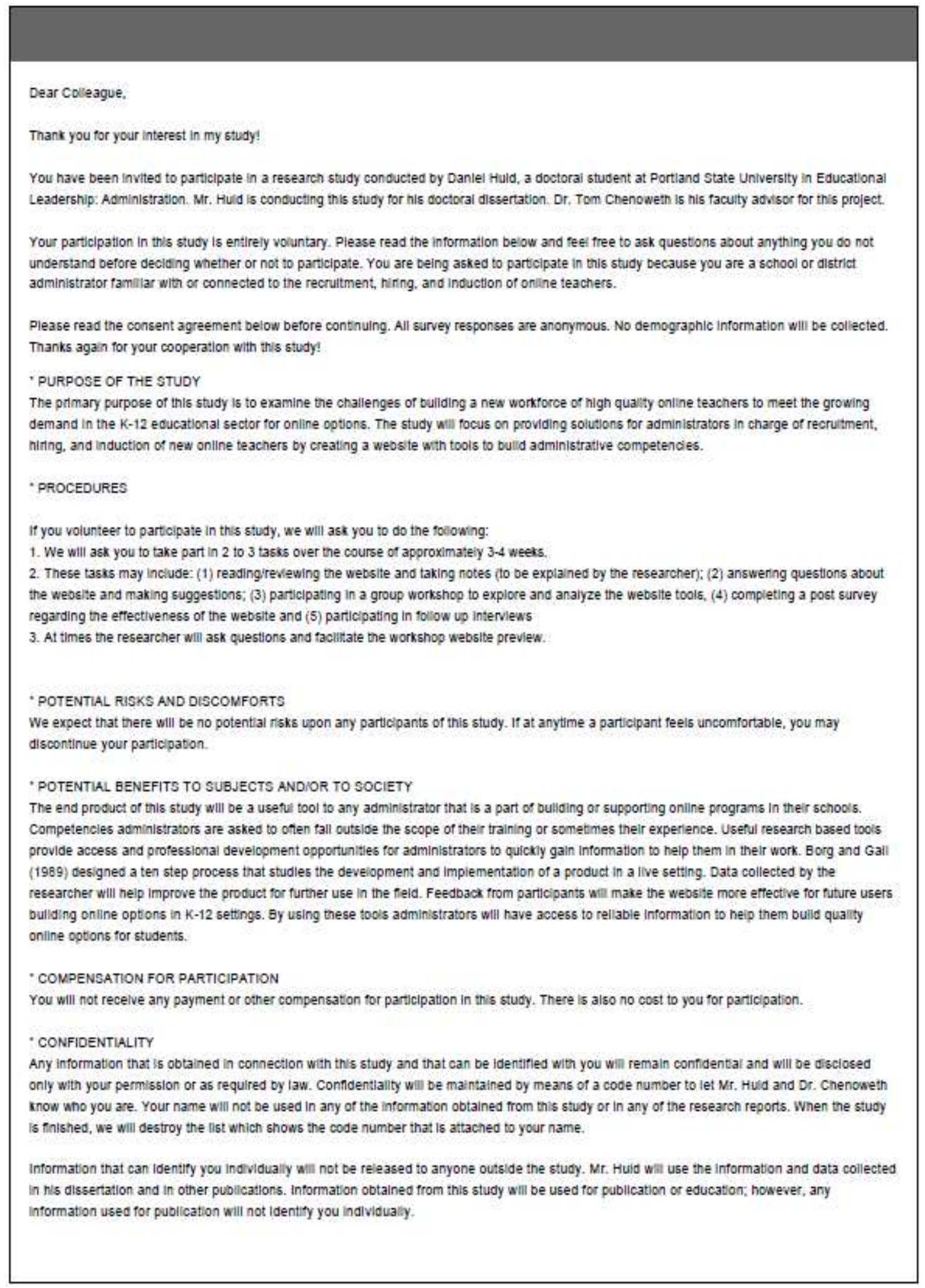




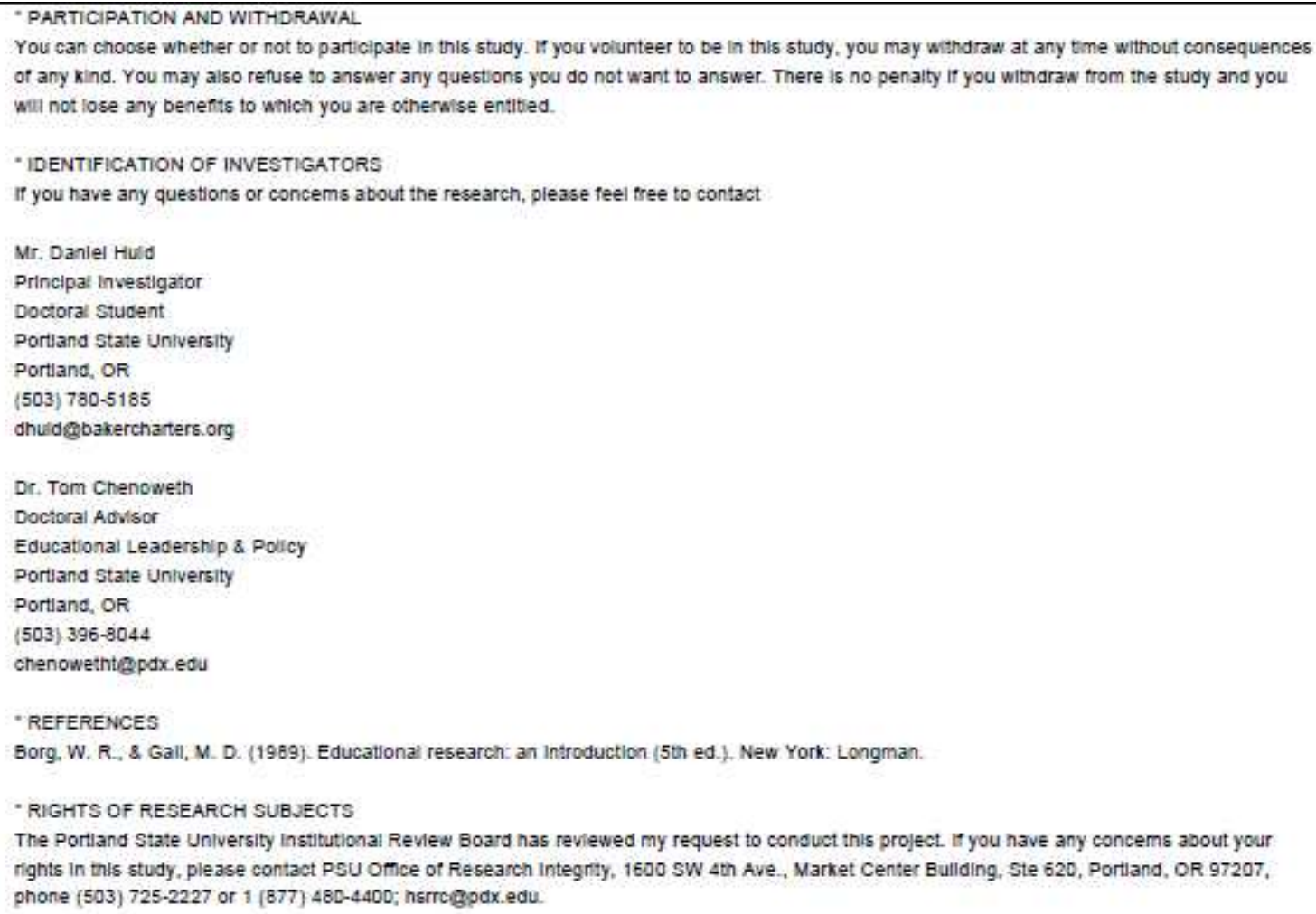

*1. I understand the procedures described above. My questions have been answered to my satisfaction, and I agree to participate in this study. I have been given a copy of this form.

\section{Copy available here: $\mathrm{http:} / / \mathrm{g} \circ 0 . \mathrm{gl} / 731 \mathrm{RIz}$}

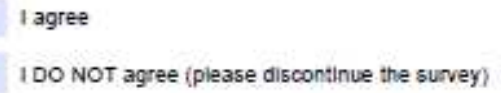




\section{K-12 Online Staffing Solutions Pre-Survey<br>}

* PARTICIPATION AND WITHDRAWAL

You can choose whether or not to particip ate in this study. If you volunteer to be in this study, you may withdraw at any time without consequences

of any kind. You may also refuse to answer any questions you do not want to answer. There is no penalty if you withdraw from the study and you

will not lose any benefits to which you are otherwise entitled.

* IDENTIFICATION OF INVESTIGATORS

If you have any questions or concerns about the research, please feel free to contact

Mr. Daniel Huld

Principal Investigator

Doctoral Student

Portland State University

Portland, OR

(503) 780-5185

dhuld@bakercharters.org

Dr. Tom Chenoweth

Doctoral Advisor

Educational Leadership \& Policy

Portland State University

Portland, OR

(503) $396-8044$

chenowetht@pdx.edu

* RefERENCES

Borg, W. R., \& Gall, M. D. (1989). Educational research: an introduction (5th ed.). New York: Longman.

* RIGHTS OF RESEARCH SUBJECTS

The Portland State University Institutional Review Board has reviewed my request to conduct this project. If you have any concerns about your rights in this study, please contact Portland State University's IRB department: Research and Strategic Partnerships, Market Center Building, 6th floor, 1600 SW 4th Ave, Portland OR 97201.

\section{*1. I understand the procedures described above. My questions have been answered to my satisfaction, and I agree to participate in this study. I have been given a copy of this} form.

\section{Copy available here: http://goo.gl/731RIz}

O Iagree

I DONOT agree (please discontinue the survey)

\section{K12 Online Stafifing Pre-Survey: Recruitment Section}

Recruitment is the process of advertising positions, reviewing resumes, and selecting top candidates for interviews

K-12 Online Staffing Solutions is a dynamic web based solution for educational leaders to recruit, hire, and induct top quality online teachers. Please feel free to visit the website anytime here: http://goo.gl/Or8s20. This survey is designed as a pre-survey to assess your current awareness of the recruitment process of online teachers BEFORE use of the website. 


\section{K-12 Online Staffing Solutions Pre-Survey<br>}

2. Are you currently or plan to be involved in the recruitment, hiring, or induction processes within your virtual public school/program in Oregon?

Yes

No

Other (please specify)

3. If you are involved in the recruitment, hiring and induction processes at your school for new online teachers how long have been a part of the process?

First year

1 year experience

2 years experience

3 years experience

4+ years experience

ONA

Other (please specify) 


\section{K-12 Online Staffing Solutions Pre-Survey<br>}

4. What type of virtual school/program do you work for? For this study blended means that students will report to a physical location at some point in their studies, fully online programs are those the student never reports to a physical location, and hybrid programs are those where the students may see staff face to face or online but not necessarily report to a physical location.

$\bigcirc$ District blended program

$\bigcirc$ District fully online program

District hybrid program

$\bigcirc$ Charter blended program

Charter fully online program

Charter hybrid program

$\bigcirc$ school level blended program

school level fully online program

School level hybrid program

Traditional public school

Other (please specify)

5. What is your current comfort level with recruitment of new online teachers? Do you feel confident in your process? Please answer in detail

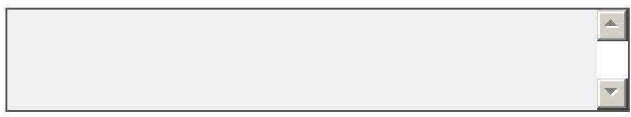

6. In regards to your skills in online teacher recruitment where do you feel you need to grow? Please be as specific as possible

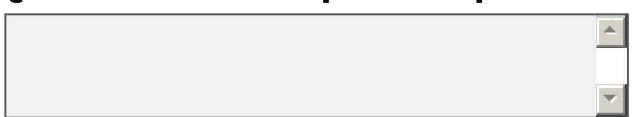




\section{K-12 Online Staffing Solutions Pre-Survey $<$ br $>$}

7. What recruitment tools are you currently or planning to use to locate new online teachers? Select all that apply

$\square$ EdZapp/Netchemia

$\square$ Newspaper

$\square$ Radio

$\square$ TV

$\square$ Website

$\square$ Job Fair

Word of Mouth

Other (please specify)

8. Are you specifically involved or plan to be involved in the induction process with new teachers?

Yes

ONo

Other (please specify)

9. Do you feel like your current or planned recruitment methods will yield top quality online teachers?

Yes

No

Other (please specify)

10. Do you have any suggestions or specific needs with the recruitment process for online teachers?

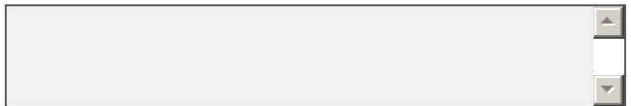

\section{K12 Online Stafíng Pre-Survey: Hiring Section}

Hiring is the process of conducting interviews, analyzing candidates, and selecting the finalist. 


\section{K-12 Online Staffing Solutions Pre-Survey<br}

11. In regards to the actual hiring of new online teachers where do you feel like you need the most help?

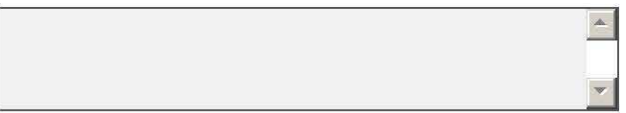

12. Have you or do you plan to use demonstrations in your interview process?

Yes

No

Other (please specify)

13. If you have not or do not plan to use demonstrations in your hiring process do you feel they would be useful to reveal more about candidates?

Yes

No

Other (please specify)

14. Please list the topics your current or planned interview questions will cover.

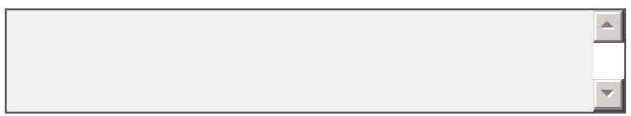

15. Do you have any suggestions for hiring resources in particular?

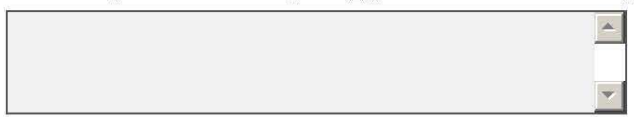

\section{K12 Online Stafíng Pre-Survey: Induction Section}

Induction is the process of having an initial orientation and connecting new teacher's to on-going resources

16. What is your current understanding of new teacher needs after they are hired?

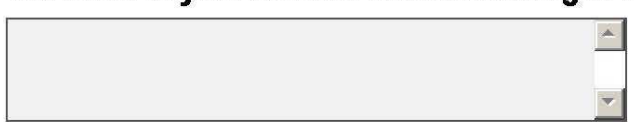




\section{K-12 Online Staffing Solutions Pre-Survey<br>}

17. Do you currently have any new teacher training after they are hired?

Yes

No

Other (please specify)

18. If you do have training, how long is your new teacher training?

1.8 hours

9.16 hours

$17-24$ hours

24 hours +

No training available

Other (please specify)

19. How is your new teacher training offered?

Face to face only (face to face in a physical location)

$\bigcirc$ Fully Online (online interaction only)

Hybrid (combination of online and face to face)

Other (please specify)

20. Do you have specific needs or suggestions for the hiring process of new online teachers? 
APPENDIX D

POST-SURVEY INSTRUMENT 


\section{Post-Survey K-12 Online Staffing Solutions}

\section{K12 Online Stafiing Post-Survey: Recruitment Section}

Recruitment is the process of advertising positions, reviewing resumes, and selecting top candidates for interviews.

1. After reviewing the website what is your new comfort level with recruitment of new online teachers? Do you feel confident in your understanding? Please answer in detail 音

2. In regards to your skills in online teacher recruitment where do you feel you still need support? Please be as specific as possible

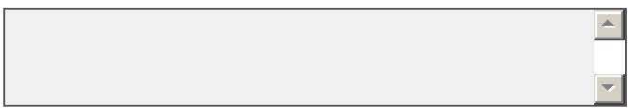

3. What new recruitment tools did you learn about during your review of the website? Choose all that apply

$\square$ EdZapp/Netchemia

$\square$ Newspaper

$\square$ Radio

$\square$ TV

$\square$ Website

$\square$ Job Fair

Word of Mouth

Other (please specify)

4. After reviewing the website do you now feel like your current or planned recruitment methods will yield top quality online teachers?

Ores

$\bigcirc$ No

Other (please specify) 


\section{Post-Survey K-12 Online Staffing Solutions}

5. Do you have any further suggestions or specific needs with the recruitment process for online teachers?

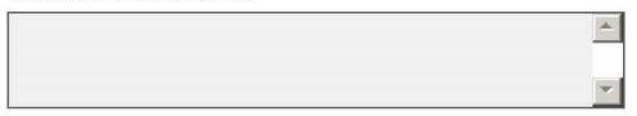




\section{Post-Survey K-12 Online Staffing Solutions}

\section{K12 Online Staffing Pre-Survey: Hiring Section}

Hiring is the process of conducting interviews, analyzing candidates, and selecting the finalist.

6. After reviewing the website do you feel like you still need help with hiring online teachers?

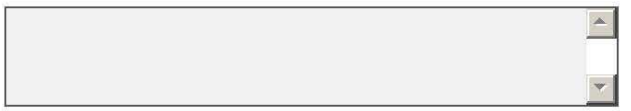

7. Will you plan on using demonstrations in your interview process after reviewing the website?

Yres

No

Other (please specify)

8. Please list the topics your current or planned interview questions will cover.

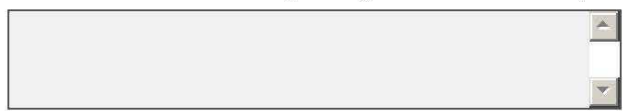

9. Do you have any suggestions for hiring resources in particular?

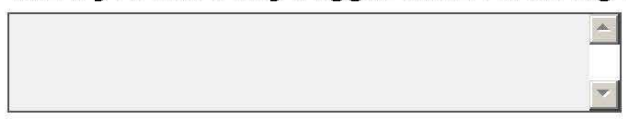




\section{Post-Survey K-12 Online Staffing Solutions}

\section{K12 Online Staffing Pre-Survey: Induction Section}

Induction is the process of having an initial orientation and connecting new teacher's to on-going resources.

10. Explain new learning you experienced in regards to new teacher induction and support. Use detail if possible.

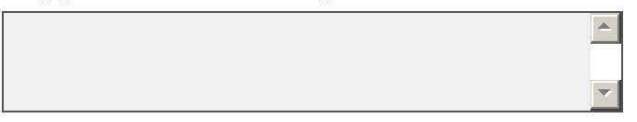

11. What new teacher training and support will you add or change after using the website?

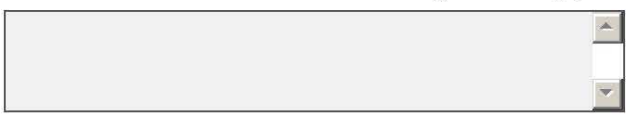

12. Do you have specific needs or suggestions for the hiring process of new online teachers? 
APPENDIX E

INTERVIEW QUESTIONS 


\section{Interview Guide}

Interviews will be conducted face to face or via phone/Skype after the March workshop to gather further qualitative data on the use of the website and how that has impacted the educational leader's work. Interviews will be recorded, coded, and analyzed.

7. Tell me about your experience with K-12 Online Staffing Solutions? How has the website impacted your practice?

8. Do you feel the website was easy to use and resources accessible?

9. Which tool was the most impactful in your opinion?

10. Can you describe your feelings about hiring new online teachers after using the website?

11. What suggestions would you have for other tools to the website?

12. What other improvements would you suggest for the website? 
APPENDIX F

OFFLINE WEBSITE PAGES 
Home Page URL- http://sowle4030.wix.com/k-12onlinestaff

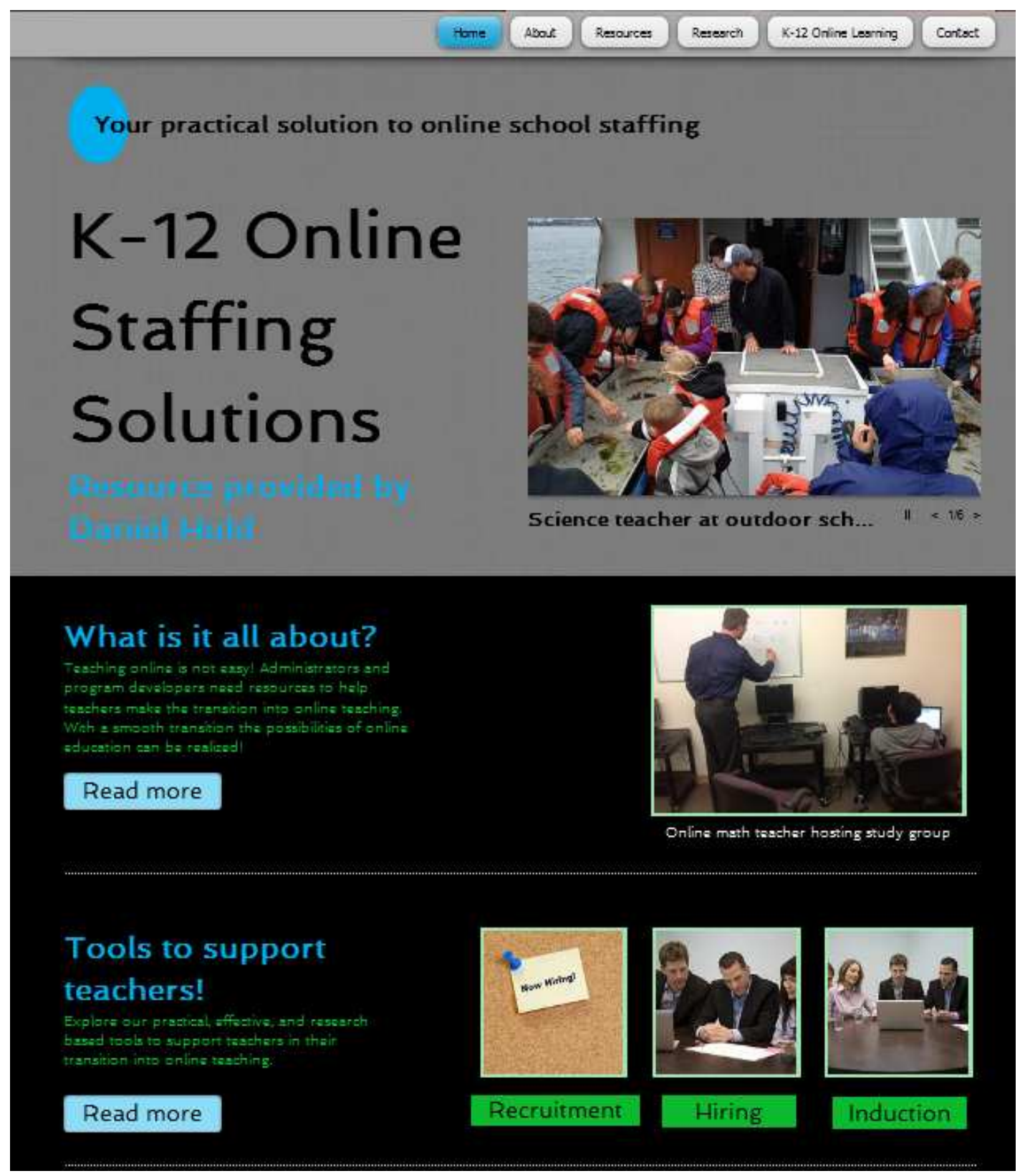




\section{About Website Page}

\section{About $\mathrm{K}-12$ Staffing Solutions}

This webpage was designed with busy administrators in mind! Demand for online programs is so strong administrators need quality. reliable and easy to understand resources to help them meet the need with quality teachers!

Quality teachers are at the core of great online learning

environments. By using the tools on this mebsite your team should be able to select top quality candidates to fill your online teaching roles.

I hope this website will be a useful and valuable component to building a quality online program!

\section{About Dan}

My name is Daniel Huld and I am currently the Director of Baker Charter Schools and an Ed.D. student at Dortland State University. I currently hold my Oregon Administrative and High School Biology Teaching Licenses, a MS in Geoscience, a BS in Biology Education, and an AA Degree.

Ten years ago I started my educational career as a math/science teacher at an alternative school in the North Clackamas School District. Opportunities eventually lead to administrative work for virtual charter schools in Oregon. Virtual education combined my passion for working with students with my love for science and technology. In my efforts to build quality programs I have spent many hours working with staff as they transition into online teaching.

The focus of my research and this website is providing administrators and program developers practical, useful, and research based tools to effectively support teachers in their transition into online teaching. Teaching online is not easy and the transition can be tough for classroom teachers and administrators. My goal is to assist teachers and administrators with that transition!
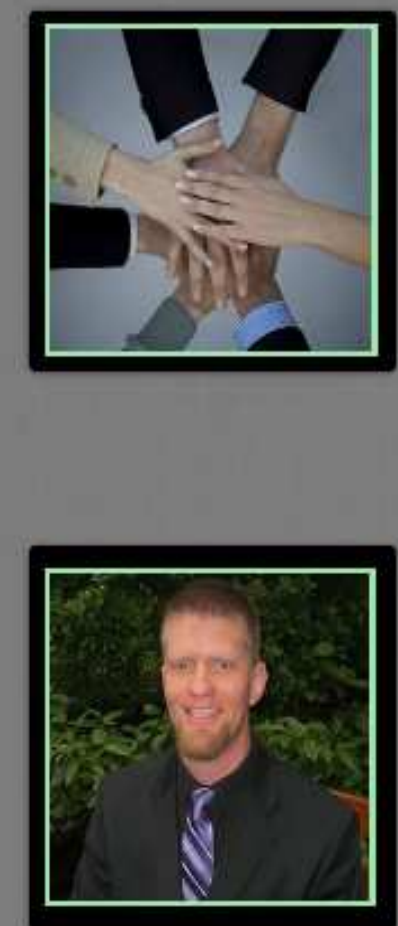


\section{K-12 Online Learning Page}

K-12 online learning is taking the nation by storm! Growth in online learning over the last 10 years has been

exponential. some

researchers are predicting that over 10.5 million students will be raking online classes by

2014. With this dramatic growth in the field of online learning the face of

education has changed

forever. Online learning has take the classroom from the confines of brick and mortar settings and revolutionized learning- By 2014 over 10 million students will take at least one class online. This represents a dramatic and historic shift in our education system.

The whole $\mathrm{K}-12$ system, post secondary preparation programs, and policy makers alike are struggling to keep up with the rapid growth and demand for online classes.

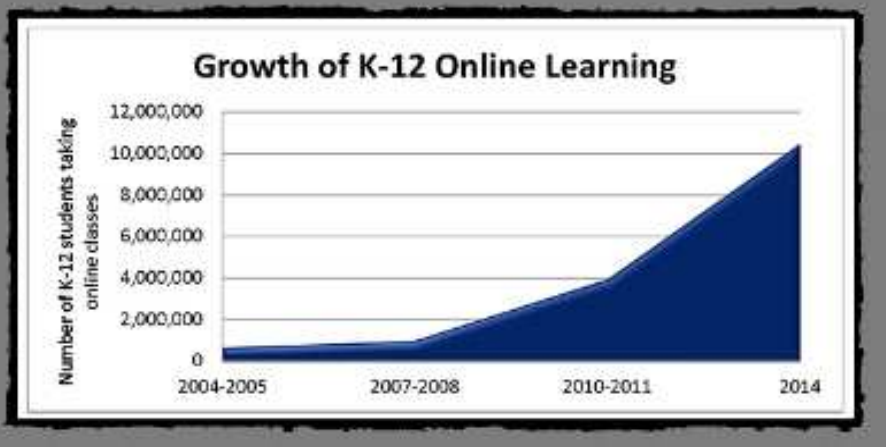
Much of the early work and research has created a solid foundation for the furure of dakhe EdEK 19drars of online learning we have learned these important lessons: 


\section{Research Page}

\section{RESEARCH}

Welcome to my research page! Here you can connect with the latest research in K-12 online learning as well as assisting us in our efforts to provide resources to administrators and program developers.

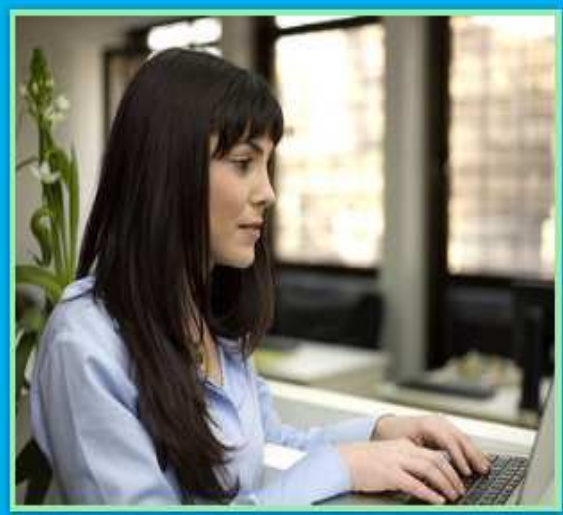

\section{Survey-Participate in our research study}

Take a moment to participate in our research study on how these materials assist your team in your efforts to build a quality online program.

- Participation Form-Fill out to Participate

- Pre-Survey-Take Prior to Using Site

- Post Survey - Take After Using Site

- Consent Form-Please review before participation

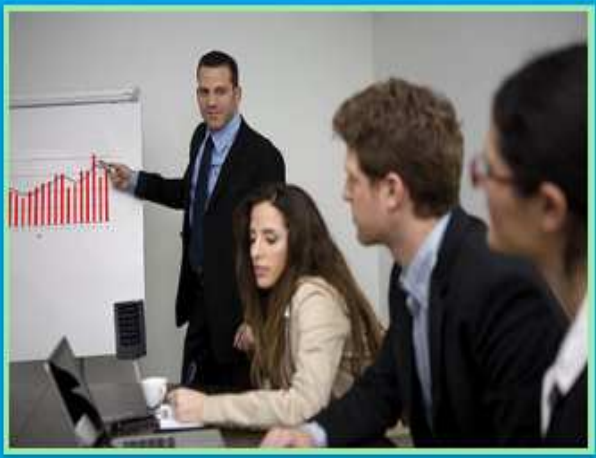

\section{Research-Keep up to date!}

Keep up to date with the latest research around $\mathrm{K}-12$ education. View these articles and links to support your work in building an online program.

- Keeping Pace with K-12 Online Learning

- iNACOL

- Effects of Distance Education on K-12 Student Outcomes

- Synthesis of New Research on K-12 Online Learning 


\section{Recruitment Home Page}

\section{Recruit the Best}

The goal of the recruitment process is to end with a pool of top candidates!

Recruitment Process Goals:

1) Establish what your team is looking for

2) Leverage technology to find top candidates

3) Sort candidates based on your preferences

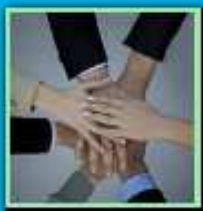

\section{1) Build your priorities}

Use these tools to help form your team and build your priorities

3) Critical Resume Skills

These tooks will help your find the skills your team needs

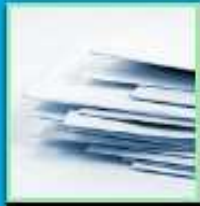

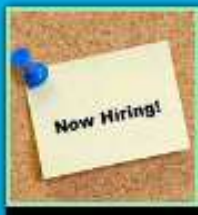

2) Job Posting

Suggestions

Use these posting

suggestions to capture top candidates

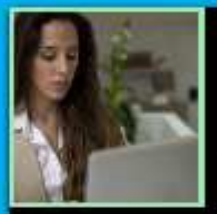

\section{4) Interview}

Organization

Tools to organize

professional interviews to

highlight the skills of

candidates

\section{Back to Home Page Back to Resources Back to Research}




\section{Hiring Home Page}

\section{Find the Best}

The goal of the hiring process is to pick the best candidatel

Hiring Process Goals:

1) Pre-Interview-Leverage online technology for a pre-interview

2) Host interview FZF (face to face) or online for finalists

3) Sort candidate to your top candidate- Offer job!
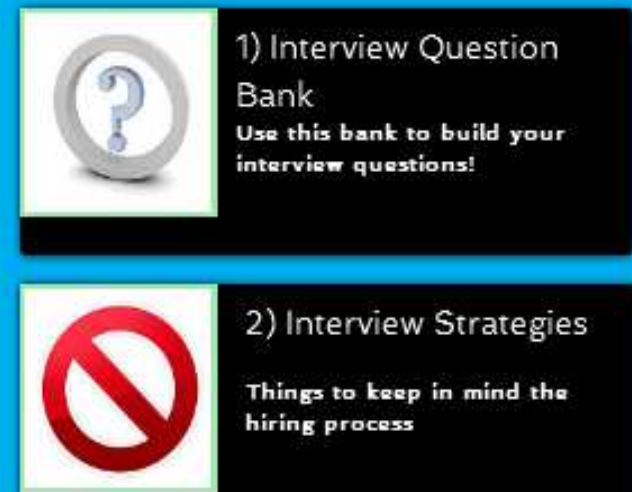

\section{2) Interview Strategies}

Things to keep in mind the hiring process
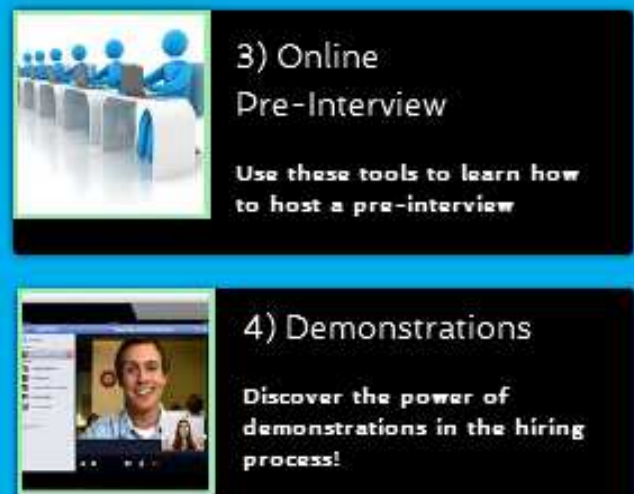

4) Demonstrations

Discover the power of

demonstrations in the hiring process!

\section{Back to Home Page Back to Resources Back to Research}




\section{Induction Home Page}

\section{Support the Best}

The goal of the induction process is to help the teacher transition into your school!

Induction Process Goals:

1) Provide initial orientation

2) Provide opportunities for collaboration and mentorship

3) Link to on-going Support
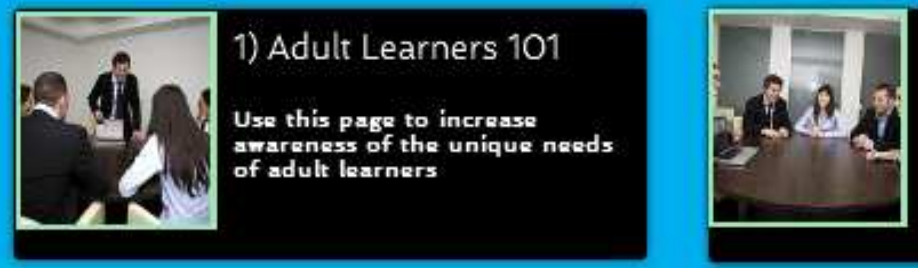

\section{2) Orientation}

Resources

Use these tools to help form

your team build a quality

induction orientation

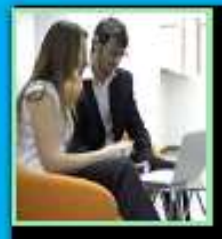

\section{3) Mentorship}

Resources

These tools will help build a mentorship program at your school

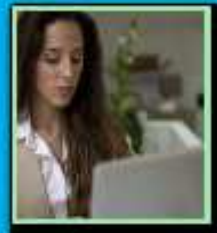

4) On Going Support

At the end of the induction process use these tools to connect your new teacher to ongoing training!

\section{Back to Home Page Back to Induction Back to Resources}


APPENDIX G

WORKSHOP AGENDA 


\section{K-12 Online Staffing Solutions \\ Website Review Workshop \\ Presented by Daniel Huld}

\section{Agenda Overview}

\section{Session 1}

- 5 min- Introductions

- 10 min- About K-12 Online Learning

- 15 min- About My Research

- 30 min- Recruitment Strategies

- 30 min- Hiring Strategies

\section{Break- 10 min}

\section{Session 2}

- 10 min- Review of Session 1

- 30 min- Induction Strategies

- 30 min- Walk Away's

- 20 min- Next Steps

The website review workshop may be modified as needed, but the intended time frame is 3-4 hours

Light refreshments and water/soda provided

\section{Online Participation Link \\ http://goo.gl/509Jni}

\section{Resources}

\section{Please take the Pre-Survey before participating}

http://goo.gl/Y57pLi

\section{Links to Website}

http://sowle4030.wix.com/k-12onlinestaff - To bookmark

http://goo.gl/Or8s20

Post Survey

http://goo.gl/jAg2Oc 


\section{Detailed Agenda \\ Introductions- 5 min}

http://sowle4030.wix.com/k-12onlinestaff\#!about/cjg9

Section Learning Target- Participants will understand each other's role in virtual education and get to know the presenter.

\section{Questions to ask-}

1) Quickly introduce yourself giving your name, role, and the school you work for

2) Share with the group one thing you have learned in virtual leadership

\section{About K-12 Online Learning- 10 min \\ http://sowle4030.wix.com/k-12onlinestaff\#!about-online-learning/cee5}

Section Target- Participants will know and able to identify factors leading to growth in K-12 online schools and what is working currently in the field.

1) Start at K-12 Online Learning link on website

2) Review content of the page
a. Growth
b. Changing Demographics of Classroom
c. Online Learning Works!
d. Teachers are a key part of student success

\section{Check for Understanding-}

Does that provide a good context for the study and why the topic was chosen? Any questions

\section{About my Research- 15 min \\ http://sowle4030.wix.com/k-12onlinestaff\#!research/cijr}

Section Target- Participants will be able to describe my research focus and intention.

1) Start at Research Section of the Website

2) Review content of page

a. Consent- Ensure all have completed

b. References- View quickly

c. Research

i. Forms and participation

ii. Other Resources

iii. View my research and stay up to date 
Check for Understanding- Any questions about my research goals and objectives?

\section{Recruitment Strategies- 30 min}

http://sowle4030.wix.com/k-12onlinestaff\#!home-recruitment/c1bl

Section Target- Participants will be able describe and apply recruitment strategies for new K-12 online teachers to their schools.

1) Start at Recruitment Home Page

2) Review Recruitment Step

3) Review Recruitment Tools

a. Priorities

b. Job Posting Suggestions

c. Critical Resume Skills

d. Interview Organization

Check for Understanding- What are some tools you have for recruitment now you didn't have before?

\section{Hiring Strategies- 30 min}

\section{http://sowle4030.wix.com/k-12onlinestaff\#!home-hiring/c15cl}

Section Target- Participants will be able to apply hiring techniques to their own school practices.

1) Start at Hiring Section Page

2) Review Content of Hiring Section
a. Interview Question Bank
b. Interview Strategies
c. Online Pre-Interview
d. Demonstrations

Check for Understanding- How many of you plan on using a tool from this section? Which tool do you plan on using?

\section{Break- 10 min}

\section{Review Session 1- 10 min}

Welcome back! Let's get settled in and finish up. You all have busy schedules and I want to respect that by covering all the content of the site and

\section{Questions to Ask:}

1) What recruitment tools do you plan on using?

2) What hiring tools do you plan on using? 
3) What do you know now you didn't know before?

\section{Induction Strategies- 30 min}

http://sowle4030.wix.com/k-12onlinestaff\#!home-induction/c2vw

Section Target- Participant will be to apply tools from the induction section into their induction program at their school.

1) Start at Induction Section Page

2) Review Content of Page
a. Adult Learners 101
b. Orientation Resources
c. Mentorship Resources
d. On-Going Support

Check for Understanding- Did you gain any knew knowledge around induction practices for K-12 online schools?

\section{Walk Away's- 30 min}

Section Target- Participants will discuss and analyze tools presented.

\section{Questions to Ask}

1) What tools do you think you might use at your own school?

2) What did you learn today?

3) What section was the most helpful and why?

Check for Understanding- Do you have any further walk-away's you learned?

\section{Next Steps- 20 min}

Section Target- Participants will plan in their teams on which tools they will use during the upcoming hiring season.

Directions- Take the next 15 minutes and spend some time in your team deciding on how the tools will be used in your school setting.

\section{Training Wrap Up}

Remember to take the post survey after the workshop is completed. The next step is to schedule a follow up interview and review of website changes. Please get one scheduled as soon as possible.

Thank you for your time today! 
APPENDIX H

COMMITTEE FORMATION 
PRO

\section{Board Members}

Voice of leadership

Involvement of board

Good for leadership positions

More objectivity

Check against bias

\section{Teachers}

Teacher voice heard

Buy in to positions

Perspective on content

More objectivity

Check for bias

\section{Support Staff}

Informal feedback

Relationship building observation

Knowledge of operations

Knowledge of office dynamics
CON

Board Members

Micromanagement

Take up volunteer time

Over involvement of leadership

Worry about admin duties

Bias in discipline process

\section{Teachers}

Take away from instruction

Emotional aspect

Worry about admin tasks

Bias in discipline process

\section{Support Staff}

Lack of training

Take away from important roles

Lack of content knowledge 
APPENDIX I

SAMPLE JOB POSTING AND JOB DESCRIPTION 


\section{K-12 Virtual Charter School Sample Job Posting}

SCHOOL is seeking qualified applicants that hold an Oregon Teaching License with a SPECIFIC LICENSE. Qualified candidates should be passionate about SUBJECT, online instruction, working with a wide variety of students, and collaborating with their peers to achieve district and school goals.

Duties would include online SUBJECT tutoring, online instruction, professional development, student/staff support, and data management in a true SCHOOL TYPE (hybrid, fully online, or blended) educational setting. The teacher would have regularly scheduled meetings with parents and students as well as posted online office hours and synchronous instruction duties to groups of students. Online SUBJECT tutors should have excellent SUBJECT knowledge, customer service, coordination of interventions and state testing as needed, be able to support home room (or Advisors) teachers and work in a team of staff. Candidates should be incredibly organized to ensure timely and thorough service to students, parents, and staff.

Candidates would need to be able to make it to SPONSOR DISTRICT/MAIN OFFICE CITY and other regions in the state for regular meetings as required. The teacher would also need to have the ability to carry and load computers and supplies into/from their car to assist in the delivery of supplies. Long periods of sitting, data entry, and computer use

are required activities for this position. Regular participation in professional development is also a requirement of the position. SCHOOL staff will work from their home for portions of their job so a quiet professional space will be needed in the home. Qualified applicants should have experience in online schooling, brick and mortar classes, working with a variety of students, paper/pencil curriculum and online curriculum, be knowledgeable about Oregon State Assessments and preparations for those exams and most importantly have a passion for working with children. Teaching for SCHOOL is a dynamic and non-traditional teaching job. We offer competitive compensation, benefits, and technology packages to all our employees. Training pre-service and in-service will help support new teachers into our system. 


\section{SCHOOL}

Teacher Position Description

TITLE: SCHOOL Teacher

JOB GROUP: Teacher

\section{QUALIFICATIONS AND ESSENTIAL JOB FUNCTIONS:}

1. Appropriate certification/registration

2. Successful student teaching, intern practicum, or past experience.

3. Ability to effectively communicate with parents, students, and staff.

4. Ability to maintain acceptable student behavior.

5. Ability to use appropriate assessment, instruction, and evaluation techniques.

6. Utilize effective practices to build a community of learners.

7. Understand child and adolescent development and apply knowledge to curriculum selection, use of instructional practices, and student learning needs.

8. Understand and utilize skills/strategies for meeting the diverse needs of students.

9. Understand the importance of relationships for teaching and learning.

10. Demonstrate a firm grasp of curriculum, teaching tools, and resources.

11. Utilize technology to aid instruction and meet building/district requirements.

12. Demonstrate the ability to design and monitor a continuing professional growth plan.

13. Daily come prepared to work and support Baker Charter Schools mission.

REPORTS TO: Assigned Administrator

JOB GOALS: Primary responsibility shall be the mentorship of students. Mentorship shall include student guidance, discipline, welfare, and safety as well as direct supportive instruction in subject areas for which they are highly qualified and guided access to teaching team members who are highly qualified in individual subject areas as appropriate to the student's needs. The teacher will plan for student success based on assessed needs. Each teacher will demonstrate empathy, rapport, objectivity, and listening skills. Teacher will be expected to assist the Baker Charter Schools efforts to plan, budget, implement, and evaluate school's program and do related work as required. In carrying out their responsibilities, teachers will follow Baker Charter School's policy, standard practices, and administrative unit regulations. Teacher will establish a professional growth plan and annually review progress.

\section{PERFORMANCE RESPONSIBILITIES:}

1. Create and maintain effective environments for student learning.

2. Use instructional strategies that are supported by research and engage all students in learning.

3. Implement and enhance the school's state assessment and local assessment agenda. 
4. Understand and organize subject matter for student learning.

5. Access and maintain the school's Student Information System

6. Provide weekly and periodic reports on student progress and work completed to their administrator

7. Assess and plan for student learning.

8. Grow in professional practice.

\section{TERMS OF EMPLOYMENT:}

191-194 day work year. The SCHOOL Board of Directors will establish salary.

EVALUATION:

Job performance will be evaluated in accordance with the SCHOOL policy on Evaluation and all applicable state and federal laws. 
APPENDIX J

SAMPLE CANDIDATE LETTER 


\section{SCHOOL Letterhead Here}

Dear Candidate,

Thank you for your interest in SCHOOL! We are pleased to invite you to an interview with our team. Please contact our lead hiring team administrator should you have any questions. Below are some details regarding our interview process and items to be completed prior to the interview:

\section{A) Pre-Interview Technology Demonstration}

a. Download and install Jing- Create a 3-5 minute introduction of yourself to send to the hiring committee

b. Load your resume into Google Docs and share with the committee or lead administrator

c. Build a quick Prezi to summarize your technology skills as they relate to teaching and learning

\section{B) Interview method}

a. Face to Face OR Online

\section{C) Interview location}

a. Face to Face: ADDRESS HERE

b. Online: Skype, Blackboard Collaborate, Google Hangout or other

\section{D) Items to bring to interview}
a. Resume
b. Cover Letter
c. References (at least 3)

\section{E) Demonstration}

a. During the interview you will be asked to complete a demonstration. Please come prepared to demonstrate $\mathbf{O N E}$ of the following:

i. On the spot tutoring in content area

ii. Live lesson on subject matter- topic and question will be mailed separately

iii. Product/Curriculum demonstration

We look forward to getting to know you better and wish you luck on your journey to become a part of our SCHOOL.

Sincerely,

SCHOOL hiring team

email@address.com

888-888-8888 phone

1234 NW Somewhere Street

Anywhere, OR 97220 
APPENDIX K

ONLINE TEACHER INTERVIEW BANK 


\section{Online Teacher Interview Question Bank}

\section{Process}

To build your own set of interview questions remember the online teacher recruitment tool below to guide your process. First select 1-2 questions from the question bank below in each category. Use those that will be the most useful to your team. After selecting questions add in program specific questions as necessary. When you're done share the questions use Drop Box, Google Drive, or other file sharing/cloud services as appropriate with your interview team.

\section{Job Description}

Begin every interview by describing the job duties and your format. This will help the candidate frame their questions to your unique situation.

\section{Online Teacher Recruitment Tool}

Use the visual below to keep your team focused on qualities to look for during the interview process.

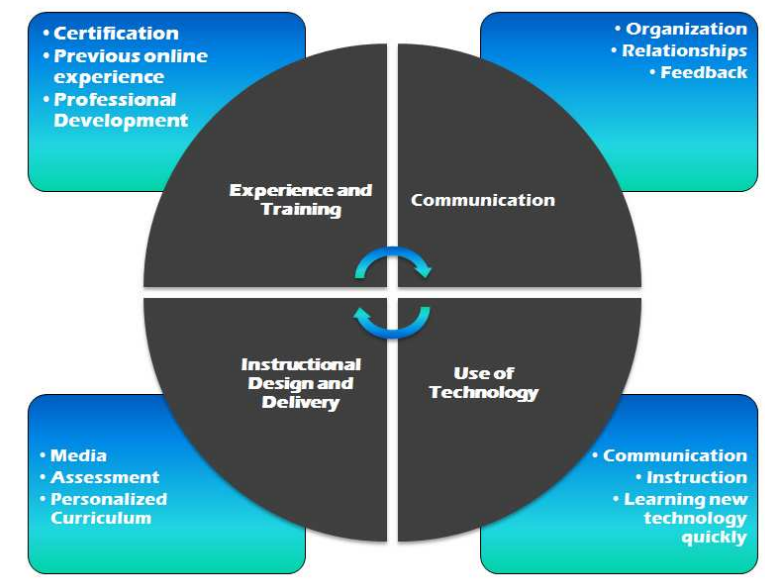

Online Teacher Recruitment Tool- (C) 2013-2014 all rights reserved Daniel Huld

\section{Example Questions}

\section{Standard 1- Communication}

1) Communication is critical in the work of a distance learning Instructor. Describe what good communication looks like.

2) Share with the team some examples of how you used communication to solve a problem.

3) Can you give us some examples of how you have used good communication to help a student understand a difficult topic?

4) How do you build meaningful relationships with students and motivate them to learn in the distance learning setting

5) Here is a scenario for you; you have a parent who is upset or not happy with the program. Tell us what steps you would take to resolve the situation and mend the relationship. 
6) Describe your experiences in working in a team as a teacher. What role do you assume as a team member? Use specific examples of how you have worked in a team lately to accomplish a common goal.

\section{Example Questions}

\section{Standard 2- Use of Technology}

1) We are a technology based school program. How have you used technology to enhance instruction? In this distance learning environment how would you continue to use technology?

2) Provide the team some examples of how you have researched, adopted, and implemented a new technology that impacts your practice.

3) What level of comfort do you have with emerging technologies? Provide an example of technology you use every day in your life.

4) Have you had any professional development in technologies as they apply to teaching online?

5) What technology are you using right now in your practice, and what is one technology you are considering for future use?

\section{Standard 3- Instructional Design and Delivery}

\section{Example Questions}

1) What are the benefits and drawbacks of online education in your opinion?

2) What does success for online students look like?

3) What experience do you have designing or developing online content for instruction?

4) Describe your current understanding of best practices in online curriculum development and delivery.

5) What, in your opinion, is the most effective way to assess student learning? How will you ensure they have learned the online material you taught them?

\section{Example Questions}

\section{Standard 4- Experience and Training}

1) What is your story and how does it lead to you applying for this job?

2) Describe your vision for an online teacher position. How does your unique skill set prepare you for this job?

3) What professional development opportunities have you received relating to online learning?

4) Have you ever taken college classes in online teaching pedagogy?

5) Where do you see yourself in 5 years academically and professionally? Does that vision fit with our current position and direction?

\section{Program Specific Questions}

Remember to add in questions as appropriate to fit your district/program goals or expectations. These questions will apply to the region and format unique to your school. 
These questions should include any specific programs the school uses, questions related to the program format: blended, hybrid or fully online, any specific operational items such as attendance, understanding of laws, etc. Here are some examples:

1) Our school uses the BLANK SIS system, what is your experience level using this program for grading, attendance, and student information?

2) Currently we have a drop in center for students to receive additional help and tutoring. What in your opinion is the best way to support students in a drop in facility? Do you have any experience this area?

3) In our state it is required to track contact information with students for attendance and progress monitoring, what experience do you have keeping track of academic records?

4) Currently we use BLANK CURRICULUM have you used this before? 
APPENDIX L

SAMPLE TEACHER INTERVIEW QUESTIONS 
Candidate Name:

\section{SAMPLE School \\ Teacher Interview Questions}

Date:

Interviewer:

Job Opening Being Interviewed For:

Position description and program explanation

Review Pre-Interview Materials

Rating: While filling out this sheet please use the following rating system: weak, average, and strong for each question on the scale below

Connect us with this moment- what is your story and why did you apply for this job?

1. Describe your vision for the hybrid online teacher position. How does your unique skill set prepare you for this position?

a. Key words: Flexibility, personalization, technology, one on one, communication with students and teachers

2. Communication is critical in the work of a distance learning Instructor. Describe what good communication looks like.

a. Key words: consistent, daily, building relationships, sharing, timely, frequent, compassionate, etc.

3. How do you build meaningful relationships with students and motivate them to learn in the distance learning setting?

a. Key words: clear expectations, listening, providing choices, prioritizing, consistency, engagement, etc

4. We are a technology based school program. How have you used technology to enhance instruction? In a Distance Learning environment how would continue to use technology? 
a. Key words: podcasting, Moodle technology, email as communication, video conferencing, web cam, versatility, keeping updated, internet based research, online discussion groups, etc

5. You have a parent who is unhappy or not satisfied with the program. Tell us what steps you would take to resolve this situation and mend the relationship.

a. Key words: listening, resolution, move forward, address concerns, communication, teamwork with staff

6. Describe your experiences working in a team as a teacher. What is your role? Use specific examples if possible

a. Key words: team player, part of a whole, work well with others, listening, etc

7. How would you arrange your weekly schedule to meet the needs of the families you will be working with?

a. Key word: prioritize, organize, balance, etc

8. What, in your opinion is the most effective way to assess student learning? How will you ensure they have learned the curriculum?

a. Key word: summative, formative, standards, variety of techniques, consistency, data, multiple intelligences, learning styles, etc

9. What does success as a distance learning teacher look like?

a. Key word: varies 
10. Perform Demonstration here

Weak

11. Do you have any questions for us?

Weak $>$ Strong $>$ Average


APPENDIX M

DEMONSTRATION ITEM BANK 


\section{Teacher Interview Demonstration Item Bank}

Use these items to build quality interview demonstrations for online teachers. Depending on your strategy you may want to send ahead of time to candidate for lesson preparation, or if you want to see on the spot tutoring, your team may just notify them there will be a demonstration.

\section{On the Spot Tutoring}

Use the items in this document to show to candidates during the interview. Role play that members of the interview team are students in a computer lab or online students who are stuck and don't understand the problem. Have the candidate study the content and develop a quick study session for the student to help them understand the question.

The purpose of on the spot tutoring is to:

1) See the candidate think on their feet

2) Replicate a computer lab support situation in a blended setting

3) View the content knowledge of the candidate

4) Observe the instructional strategies of candidates

\section{Lesson Demonstration}

Use the items in this document to send to candidates ahead of time. Have them build a 10-15 minute lesson to teach the item to students online.

\section{Purposes of Live Lesson Teaching-}

1) Observe candidates preparation abilities

2) Have candidate demonstrate technology and use of media

3) See the pedagogical knowledge of the candidate

4) See how the candidate presents themselves online

\section{Product Demo}

Use a piece of curriculum that parents would use such as a box of Calvert, Saxon, Teaching Text Books, or other printed curriculum to have the candidate demonstrate how to use the program. This item will depend on your specific position, curriculum, or program type. This demonstration will require preparation for the candidate ahead of time. Your team may want to send a link to the curriculum page for research ahead of time. Some examples could be similar to this YouTube Video on opening a box of Calvert http://youtu.be/eusqxyfli7E.

Purposes of Product Demonstrations

1) See how candidate explains curriculum to parents

2) Understand if the candidate knows the curriculum used by the school

3) Observe how they teach the parent and make sure the parent understands 
Demonstration Items by Subject

Math- Algebra 1- Quadric Formula- Answer: -3, -4

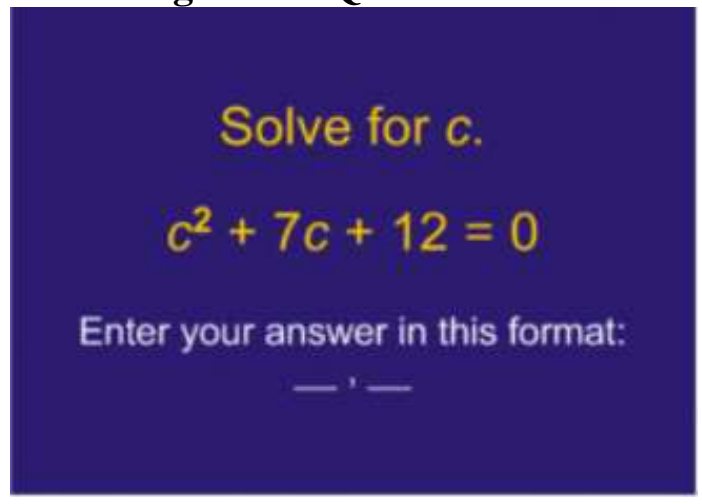

\section{Quadratic Formula}

$$
x=\frac{-b \pm \sqrt{b^{2}-4 a c}}{2 a}
$$

Algebra- Algebra 1- Order of Operations- Answer: 27

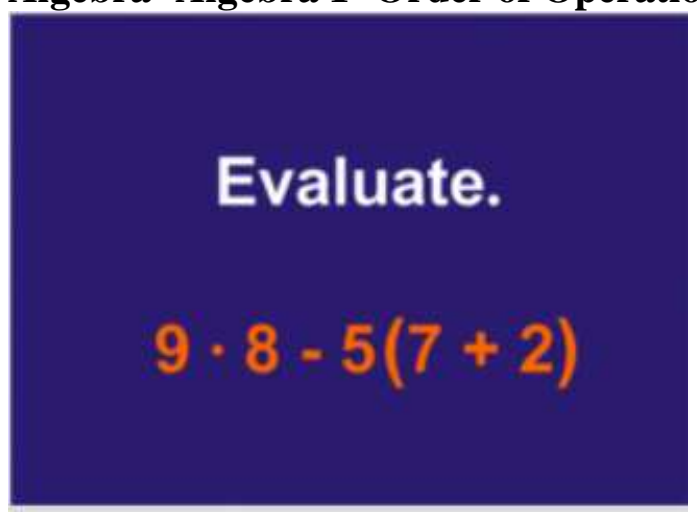

Science- Biology Answer: Carbon Dioxide

What gas is produced by plants and is used as a reactant during cellular respiration?

\footnotetext{
A nitrogen

B carbon dioxide

C oxygen
} 
High School Biology- Cell Organelle's- Blank out words for candidate
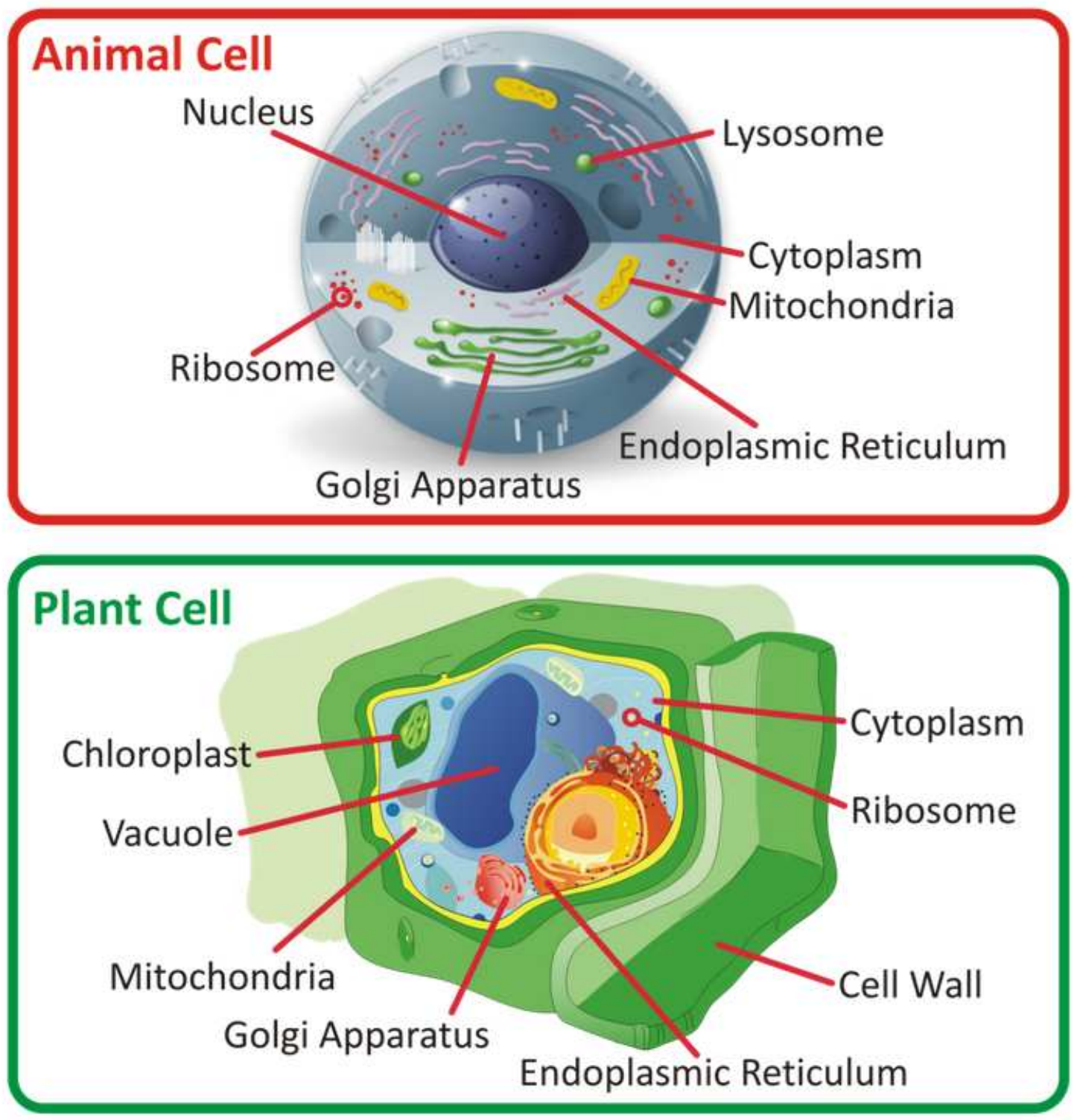
Language Arts- English 1- High School- Understanding Irony- Answer: A

Which situation is the best example of irony?

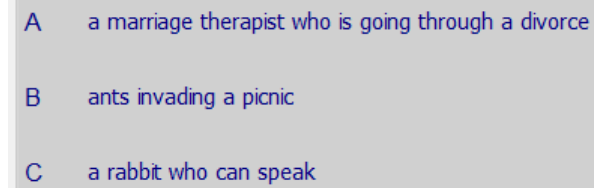

English 1- High School- Analogies- Answer: Creation

Match the relationship in the second pair of words with that of the first pair.

rendezvous : meeting invention :
A creation
B full
C wet

Social Science- US History 1- High School- Columbus- Answer: Gold

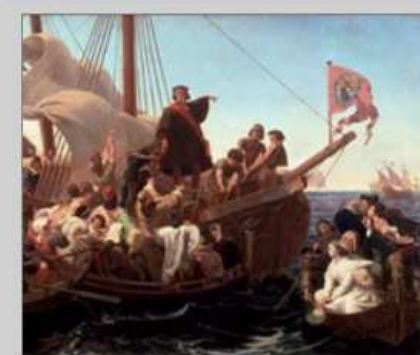

When Columbus explored for Spain, what item was he specifically searching for?

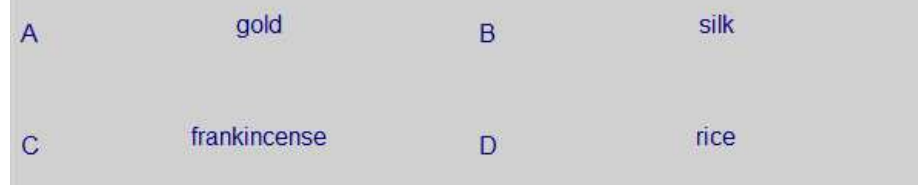


US History 1- High School- Territories- Answer: Farmland

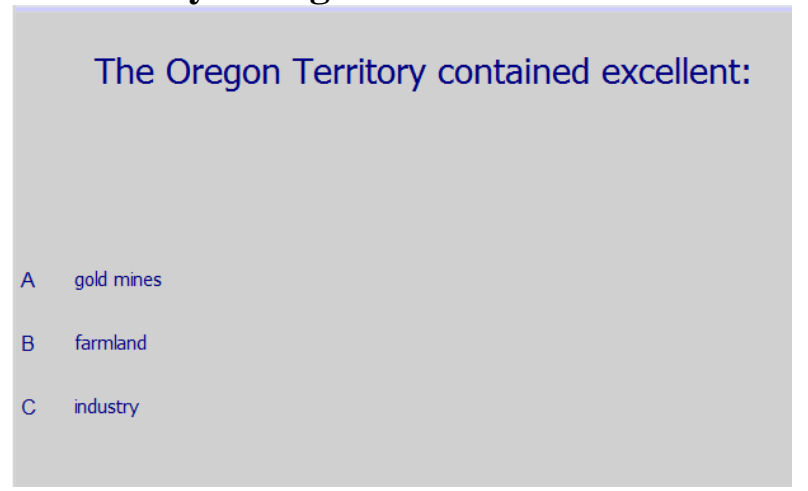

Health- High School Health- Family Health- Answer: B

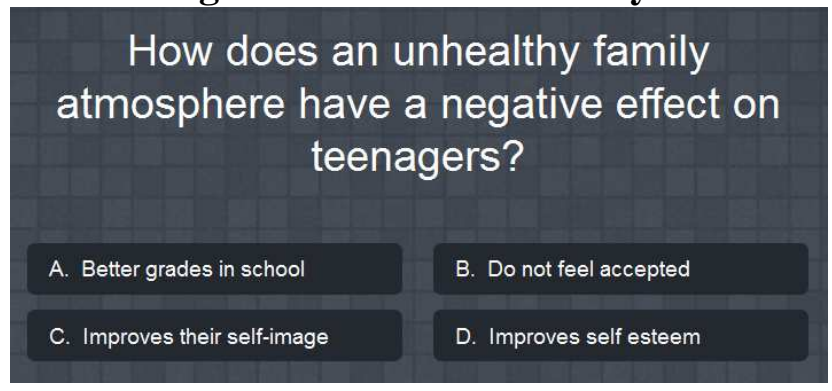


APPENDIX N

NEW ONLINE TEACHER ORIENTATION POWER POINT 
Presented by

New Online Teacher Training

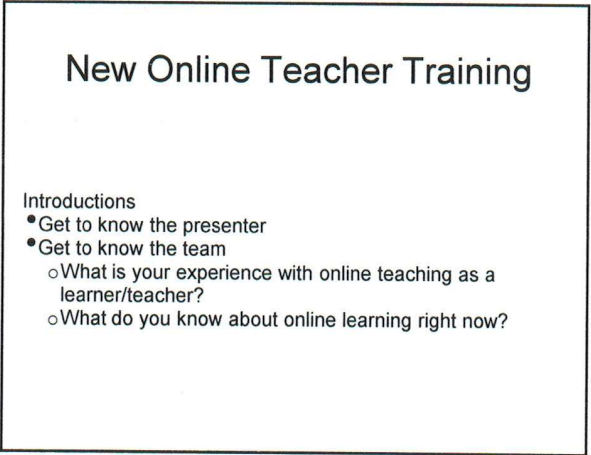

\section{What Happened to Education?}

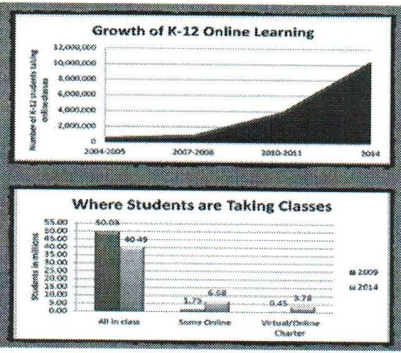

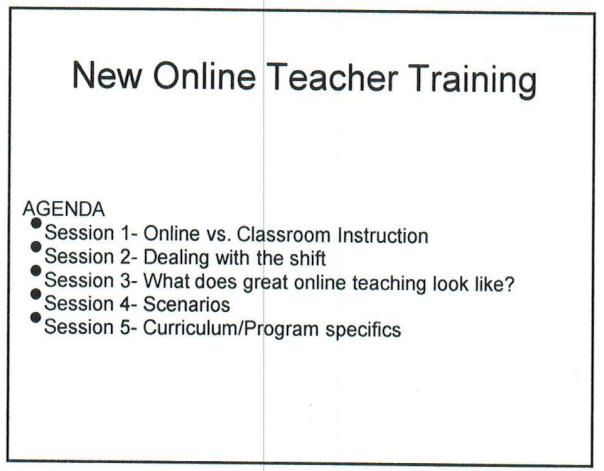

Session 1: Classroom

Teaching vs. Online

Teaching

Presented by

New Teacher Training

\section{New Online Teacher Training}

-With the rapid growth and demand for online classes it is important to fit online learning into the overall picture of $\mathrm{K}-12$ education

- Online learning is growing rapidly but how does it compare? How is it different and what does good teaching look like online? 


\begin{tabular}{|l|}
\hline New Online Teacher Training \\
-Section Review \\
\hline
\end{tabular}

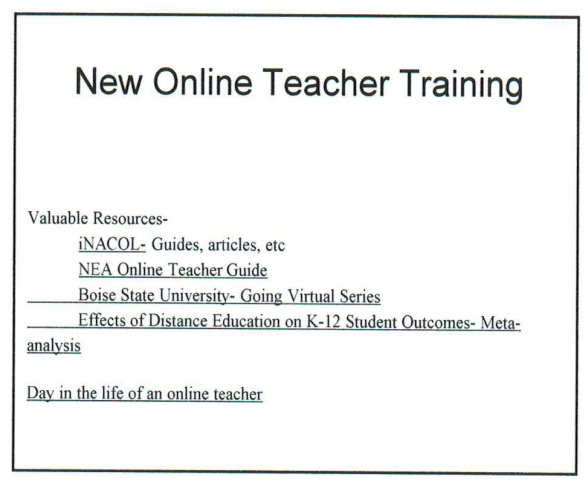

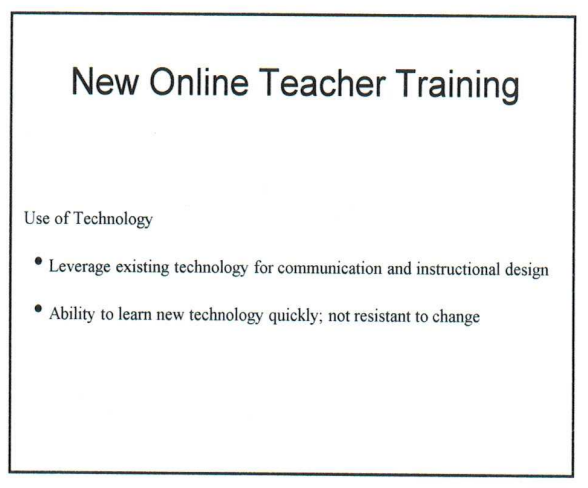

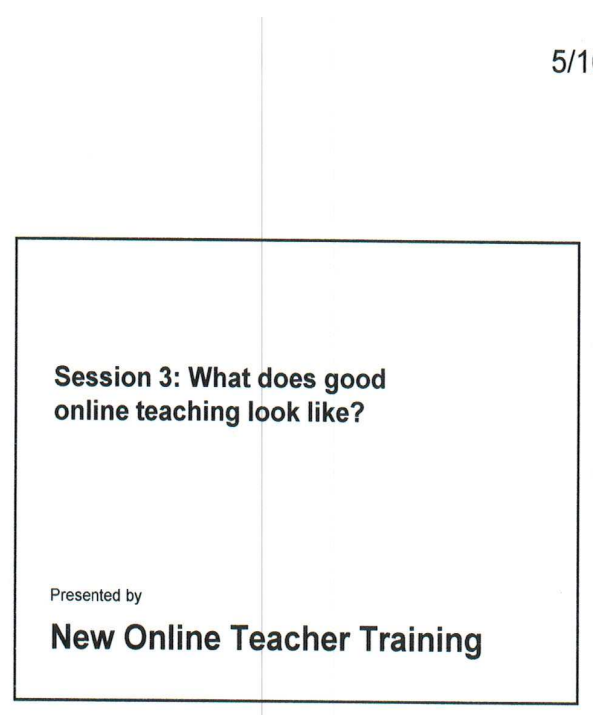

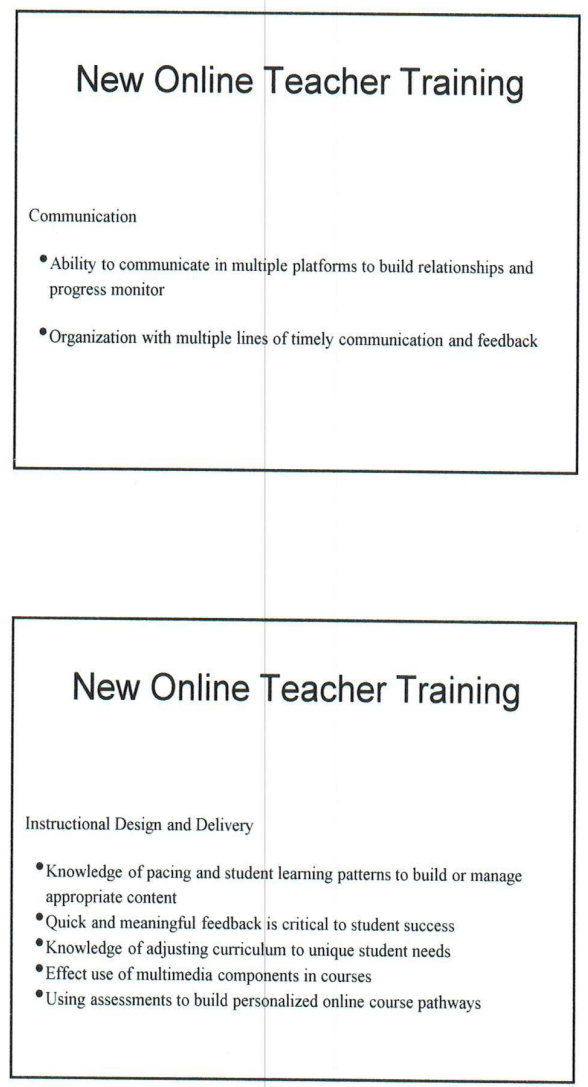




\begin{tabular}{|l|}
\hline New Online Teacher Training \\
Instructional Design and Delivery \\
-Knowledge of pacing and student learning patterns to build or manage \\
appropriate content \\
- Quick and meaningful feedback is critical to student success \\
-Knowledge of adjusting curriculum to unique student needs \\
-Effect use of multimedia components in courses \\
- Using assessments to build personalized online course pathways \\
\hline
\end{tabular}

\begin{tabular}{|l|}
\hline New Online Teacher Training \\
-Every class, every visit, in writing. \\
oProgress towards completion \\
oPerformance \\
oStudy notes/input for support \\
1. Examples
\end{tabular}

New Online Teacher Training

- Section Review

\begin{tabular}{|l|}
\hline New Online Teacher Training \\
- Time with students is the most important thing you do as \\
teachers online or F2F... MAXIMIZE that time \\
1. Suggestion for F2F time: \\
a. Progress monitoring \\
b. Instruction \\
c. Review \\
d. Provide written artifact to parentstudent \\
\hline
\end{tabular}

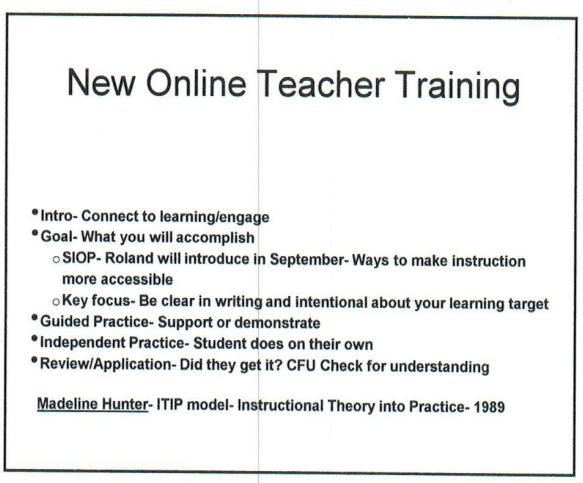

Presented by

New Teacher Training 


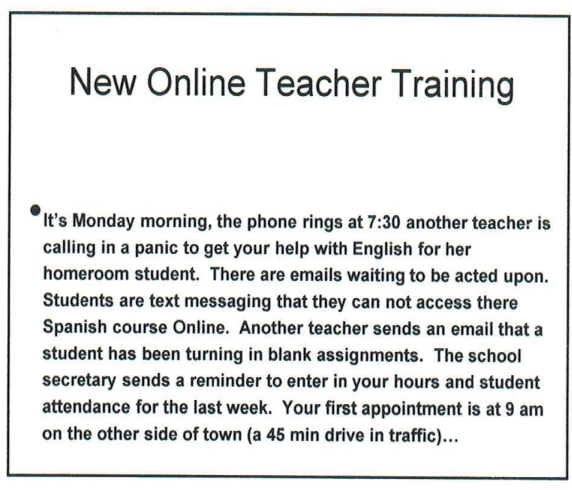

New Online Teacher Training

-You're in the computer lab. A student says I can't get the answer to this math problem can you help me?

Session 5:

Curriculum/Program

Specifics

Presented by

New Teacher Training 
APPENDIX O

MENTORSHIP PROGRAM SAMPLE 


\section{Sample Teacher Mentor Program}

\section{PRIMARY DUTIES:}

By taking on a mentor role you are agreeing to play a significant role in the life of one of our new teachers. This task should be taken seriously as supporting a new teacher in their first year is critical to their long term success. Before committing to the program please carefully read the details of the program.

\section{Weekly:}

- Phone/Skype conversation.

- Text or email once, in addition to voice conversation.

\section{MONTHLY:}

- Attend new teacher trainings.

- Follow up on questions after monthly teacher meetings.

\section{PER SEMESTER:}

- Job shadow-new teacher, in October and February, tag-a-long with veteran teacher (two visits minimum, two hours)

- Meet in person during grading period to assist and share ideas (one on one, brief meeting pre and post grading session)

\section{GENERAL:}

- Report to Teacher mentor coordinator monthly via email and include notes of interactions with mentee.

- Share best practices and teacher preference. Delineate between personal preference and school requirements.

- Keep a journal/record/document of contacts and items discussed.

- Refer new teacher to forms and outlines posted in SCHOOL RESOURCE LOCATION.

\section{COMPENSATION:}

By participating in a full year mentor role you will receive an additional in professional development funds or additional compensation as appropriate. A half year of mentorship will result in half of the compensation. 